Zweiter Beratungsgegenstand:

\title{
Die Zukunft der sozialen Sicherungssysteme
}

1. Bericht von Prof. Dr. Rainer Pitschas, Speyer

Inhalt

Seite

I. Sicherheit durch soziale Sicherung . . . . . . . . . . . 111

1. Soziale Sicherung als Gewährleistung sozialer Sicherheit durch Risikoschutz und Sozialversicherung . . . . . . . . 111

2. Sozialstaatlichkeit als Tragpfeiler solidarischer

Sicherheitsvorsorge . . . . . . . . . . . . . 112

3. Das verfassungsrechtliche Freiheitsprinzip als Grund und Grenze des Sozialstaats . . . . . . . . . . . . . 112

4. Vertrauen in soziale Sicherung:

Das Verfassungsprinzip „Sicherheit“ . . . . . . . . . . . 113

a) „Sicherheit“ als Verfassungsprinzip ... . . . . . . . 113

b) Vertrauensstabilisierung als Schutzauftrag . . . . . . . 114

c) Enttäuschtes Vertrauen als Legitimationsproblem . . . 114

5. Zukunftsentscheidungen über soziale Sicherung im strukturellen Abwägungsspielraum . . . . . . . . . 115

II. Herkunft und Entwicklungslinien der sozialen

Sicherungssysteme . . . . . . . . . . . . 116

1. Der Eintritt des Staates in die Verantwortung für soziale Risiken . . . . . . . . . . . . . . . . 116

2. Institutionelle Ausdifferenzierung und Strukturmerkmale der Sozialversicherung . . . . . . . . . . . . . 117

3. Soziale Sicherung zwischen Reformkontinuität und Veränderungsdynamik . . . . . . . . . . . . . 118

4. Erweiterungstendenzen der Sozialversicherung im ausgehenden 20. Jahrhundert . . . . . . . . . . . . . . . 119

5. Wohlfahrtsstaatliche Beharrungstendenzen ........ 121

6. Aktuelle Modernisierungsansätze im 21. Jahrhundert . . . 122

a) Gesetzliche Rentenversicherung . . . . . . . . . . . . 122

b) Gesetzliche Krankenversicherung . . . . . . . . . 123

c) Arbeitsmarktregulierung und Grundsicherung für Arbeitsuchende .............. 123 
III. Strukturelle Fehlentwicklungen und Veränderungszwänge . . 125

1. Defizite bisheriger Modernisierungsansätze . . . . . . . . 125

2. Strukturelle Fehlentwicklungen . . . . . . . . . . . . 126

3. Vordringliche Modernisierungszwänge . . . . . . . . . . 127

IV. Auf dem Weg zu einer neuen Architektur der sozialen

Sicherung . . . . . . . . . . . . . . . . 128

1. Dominierende Ziele und Konzeptionen . . . . . . . . . 128

2. „Pfadabhängige“ und ,systemverändernde“ Modernisierungsentwürfe . . . . . . . . . . . . . . . 129

3. Soziale Sicherung in Privatrechtsformen . . . . . . . . 130

4. „Bürgerversicherung“ und „Gesundheitsprämie“ . . . . 131

V. Verfassungs- und europarechtlicher Rahmen für

Modernisierungsentscheidungen ............. 133

1. Modernisierung im Gehäuse des Rechts . . . . . . . . . 133

2. Die Verfassung als Leitbild und Rahmenordnung . . . . . 134

3. Verfassungsschutz gegen Systemwechsel? . . . . . . . . 135

4. Vertrauensschutz als „Maßstabsreserve“ . . . . . . . . 136

5. Sozialversicherung als „Volksversicherung“ . . . . . . . 137 


\section{Sicherheit durch soziale Sicherung}

\section{Soziale Sicherung als Gewährleistung sozialer Sicherheit durch Risikoschutz und Sozialversicherung}

Sozialer Schutz gegenüber jenen Wechselfällen des Lebens, die infolge von Krankheit, Unfall und Invalidität, Alter, Tod, Arbeitslosigkeit oder Pflegebedürftigkeit mit dem Verlust des Einkommens bzw. des Unterhalts, aber auch mit besonderen Aufwendungen des Betroffenen oder Hinterbliebenen zu ihrer Abwendung verbunden sind, ist dem Grundgesetz selbstverständlich. Er wird ergänzend zur individuellen Eigenvorsorge der Bürger gesondert dafür geschaffenen öffentlich-rechtlichen Sicherungssystemen anvertraut. Deren Errichtung und solidarische Ausgestaltung hat das BVerfG als Verantwortung, Aufgabe und Pflicht des demokratischen und sozialen Rechtsstaats gekennzeichnet. ${ }^{1}$

Die institutionalisierte soziale Sicherung will den darin einbezogenen Bürgern im „sozialen Bundesstaat“ ein Grundmaß rechtsstaatlich geprägter sowie demokratisch legitimierter ,sozialer Sicherheit“ vermitteln. Ihr Schutz umfasst von Verfassungs wegen den Auftrag, in Gestalt der Sozialversicherung, Entschädigungs- sowie Hilfs- und Förderungssysteme struktur- und funktionsgerechte Institutionen des allgemeinen Gesundheitsschutzes ${ }^{2}$ sowie des Schutzes abhängiger Arbeit unter Beachtung der entsprechenden Arbeitgeberverantwortung zu errichten. ${ }^{3}$ Für die Renten- und Unfallversicherung ist dem Gesetzgeber aufgegeben, das Sozialstaatsgebot des Grundgesetzes zu konkretisieren. ${ }^{4}$ Gleiches gilt für die Pflegeversicherung, auch wenn diese als eine „Volksversicherung“ mit der Einbeziehung der gesamten Bevölkerung sowie unter Verwendung von privatrechtlichen Elementen die vertrauten Pfade der klassischen Sozialversicherung verlassen hat. ${ }^{5}$

1 T. Kingreen Das Sozialstaatsprinzip im europäischen Verfassungsverbund, 2003, 125; R. Pitschas FS 50 Jahre BVerfG, Bd. II, 2001, 828 (831f.); H. F. Zacher HStR II, 3. Aufl. 2004, § 28 Rn. 43, $109 \mathrm{ff} ., 118$.

2 BVerfGE 40, 65 (56); 68, 193 (209); K.-J. Bieback Verfassungsrechtlicher Schutz gegen Abbau und Umstrukturierung von Sozialleistungen, 1997, 34; „offener“ dagegen C. F. Gethmann/W. Gerok/H. Helmchen/K.-D. Henke/J. Mittelstraß/E. Schmidt-Aßmann/G. Stock/ J. Taupitz/F. Thiele Gesundheit nach Maß?, 2004, 170; zum „sozialen Bundesstaat“ s. nur H. F. Zacher FS Schmitt Glaeser, 2003, 199ff.; R. Pitschas Kommunale Sozialpolitik, in: v. Maydell/Ruland (Hrsg.) Sozialrechtshandbuch (SRH), 3. Aufl. 2003, C. 24 Rn. $11 \mathrm{ff.}$., $14 \mathrm{ff}$.

3 BVerfGE 51, 115 (125).

${ }^{4}$ BVerfGE 10, 354 (369); 18, 257 (268, 270 f.); 98, 1 (16); zur Unfallversicherung s. ferner BVerfGE 45, 376 (387).

5 BVerfGE 103, 197 (221). 


\section{Sozialstaatlichkeit als Tragpfeiler solidarischer Sicherheitsvorsorge}

„Sicherheit“ durch soziale Vorsorge zu garantieren, ist eine materielle Kernaufgabe des Verfassungsstaates. ${ }^{6}$ Der tragende Grund hierfür liegt in der zu achtenden und zu schützenden Würde des Menschen, die soziale Gleichheit einfordert und soziale Gerechtigkeit herbeizuführen verlangt. In besonderem Maße gebietet es das soziale Staatsziel, Ungleichheiten zwischen den Menschen auszugleichen. ${ }^{7}$ Der Sozialstaatlichkeit erfließen daher mit den Wertentscheidungen für Solidarität, sozialen Ausgleich und soziale Gerechtigkeit zeitlose Leitlinien des staatlichen Handelns auch für die künftige Ausgestaltung der sozialen Sicherung:8 Weder darf sich der soziale Rechtstaat in Zukunft auf eine radikale Wohlfahrtsdistanzierung zurückziehen („Minimalstaat“), noch bei der Förderung individueller Sozialverantwortung ausschließlich auf das Wirken staatsfreier Marktkräfte vertrauen. ${ }^{9}$

Das Sozialstaatsprinzip übernimmt somit eine wesentliche nationalstaatliche Steuerungsfunktion für die solidarische Sicherheitsvorsorge und insbesondere die mediatisierende Sozialversicherung. Mit dieser Funktion steht es in einem europäischen Verfassungsverbund aus den mitgliedstaatlichen Verfassungen, dem Unionsvertrag und dem Verfassungsentwurf des Europäischen Konvents. Aus der dadurch konstituierten „europäisierten" Sozialordnung schält sich soziale Sicherheit als gemeinsames Zukunftsprojekt des werdenden europäischen Sozialstaats heraus.

\section{Das verfassungsrechtliche Freiheitsprinzip als Grund und Grenze des Sozialstaats}

Das Sozialstaatsgebot trifft auf die grundrechtlichen Freiheitsgarantien dort, wo es für die Bürger verbindliche Sozialformen ihrer sozialen Sicherung konstituiert. So ist die Sozialversicherung weithin eine „Zwangsveranstaltung“, der gegenüber sich der Einzelne auf die Abwehrfunktion der Grundrechte berufen darf.

Das von diesen in Stellung gebrachte Freiheitsversprechen verkörpert im Grundgesetz einen herausragenden Verfassungswert. Es begründet

\footnotetext{
${ }^{6}$ K.-J. Bieback VSSR 2003, 1 (12); M. Burgi Funktionale Privatisierung und Verwaltungshilfe, 1999, $28 \mathrm{ff}$; H. P. Bull Die Staatsaufgaben nach dem Grundgesetz, 2. Aufl. 1977, 152 ff.; T. Kingreen (Fn. 1), 108, 113.

7 BVerfGE 35, 348 (356).

${ }^{8}$ Vgl. nur BVerfGE 18, 257 (273); 29, 221 (235); 59, 231 (263); 69, 272 (314); 82, 60 (80); 103, 197 (221).

${ }^{9} R$. Jaeger Welches System der gesetzlichen Krankenversicherung wird durch das Grundgesetz geschützt?, in: Empter/Sodan (Hrsg.) Markt und Regulierung. Rechtliche Perspektiven für eine Reform der gesetzlichen Krankenversicherung, 2003, 15 (21f.).
} 
die staatliche Ordnung als Freiheitsordnung. ${ }^{10}$ In dieser gewährleistet die Garantie der freien Entfaltung der Persönlichkeit für den Einzelnen dessen Pflicht und Befugnis, eigenständig für sozialen Risikoschutz zu sorgen. ${ }^{11}$ In objektiv-rechtlicher Wendung entspricht dem bis zu einem gewissen Ausmaß die Verpflichtung zu individueller Vorsorge durch Versicherung und Vermögensbildung. ${ }^{12}$ Gegenüber dieser freiheitsrechtlich zugewiesenen Sozialverantwortung tritt Sozialstaatlichkeit zurück. Entsprechend bestimmt sich das Ausmaß sozialer Solidarität neu. ${ }^{13}$

Der in diesem Sinne subsidiäre bzw. "freiheitliche“ Sozialstaat ${ }^{14}$ muss auf Monopolbildung bei der sozialen Sicherung verzichten. Er hat dagegen in jenen Fällen aktiv zu werden, in denen Bürger nicht selbst für ausreichende soziale Sicherheit sorgen können. Dann gebietet das Sozialstaatsprinzip staatliches Eingreifen. Zugleich gibt in diesen Fällen das Freiheitsprinzip selbst das Feld für staatlichen Sozialschutz frei. Denn Freiheit zu behaupten, setzt individuelle Vorsorgefähigkeit und strukturell die Möglichkeit zur eigenständigen Absicherung von sozialen Risiken, z.B. durch berufliche Erwerbstätigkeit, voraus. ${ }^{15}$ Das Freiheitsprinzip ist aus dieser Perspektive sowohl Grund als auch Grenze des Sozialstaats.

\section{Vertrauen in soziale Sicherung: Das Verfassungsprinzip „Sicherheit“}

\section{a) „Sicherheit“ als Verfassungsprinzip}

Der freiheitsdirigierte Sozialstaat bedarf für sein erfolgreiches Wirken einer Reihe ökonomischer und anderer Voraussetzungen, deren Existenz er selbst nicht auf Dauer garantieren kann. Soziale Sicherung unterliegt daher zwangsläufig wiederkehrender Revision. Anspruchsrechtlich geronnene Sozialstaatlichkeit braucht jedoch ebenfalls Gewissheit. Die Antwort auf die Frage, wie sicher ist Sozialversicherung und wie ist sie auch

10 Dazu näher mwN R. Gröschner HStR II, 3. Aufl. 2004, § 23 Rn. 50ff.; K. Hesse Grundzüge des Verfassungsrechts der Bundesrepublik Deutschland, 20. Aufl. 1995, Rn. 72.

${ }^{11}$ H. Braun Selbstverantwortung in der Solidargemeinschaft. Das Recht der sozialen Sicherheit und der Verantwortungswille des Bürger, 1981; vom „Primat der Selbstverantwortung“ spricht H. F. Zacher (Fn. 1), Rn. 33.

12 W. Brugger Gewährleistung von Freiheit und Sicherheit im Lichte unterschiedlicher Staats- und Verfassungsverständnisse, VVDStRL 63 (2004), 101 (126, 131 mit Fn. 170); H. F. Zacher (Fn. 1), Rn. 50 mit Fn. 275; R. Pitschas (Fn. 1), 829f.

${ }^{13}$ F. Hase Versicherungsprinzip und sozialer Ausgleich, 2000, $304 \mathrm{ff} ., 339$; T. Kingreen (Fn. 1), $258 \mathrm{ff}$.

14 Zum „subsidiären“ Sozialstaat siehe bereits R. Pitschas FS Zacher, 1998, 755 (763ff.); mit dem „freiheitliche(n) Sozialstaat“ setzt sich T. Kingreen (Fn. 1), $121 \mathrm{ff}$., auseinander. 15 W. Brugger (Fn. 12), 131; T. Kingreen (Fn. 1), 128 ff.; R. Pitschas (Fn. 14), 762. 
unter diesem Vorzeichen zukünftig zu entwickeln, gibt das Grundgesetz mit dem Verfassungsprinzip Sicherheit. Dieses schützt als verfassungsintegriertes (aber ungeschriebenes) Staatsziel,16 das über „Rechtssicherheit““ als zeitlosen Staatszweck hinausweist, ${ }^{17}$ sowohl das Systemvertrauen in den Fortbestand der Ansprüche auf soziale Sicherheit als auch die individuellen Bestandserwartungen in die soziale Sicherung. ${ }^{18}$

\section{b) Vertrauensstabilisierung als Schutzauftrag}

Sicherheit als Verfassungsprinzip ist allerdings nicht unmittelbar subsumtionsfähig. Die gebotene operative Umsetzung sieht sich einerseits den tatsächlichen und rechtlichen Gegebenheiten der je einschlägigen freiheitsrechtlichen, kompetenziellen und organisationsrechtlichen Komplementärmaßgaben des Grundgesetzes verbunden. Dabei und andererseits impliziert das Verfassungsprinzip im Zusammenwirken mit den Grundrechten die Pflicht des sozialen Rechtsstaats, im Verlauf der „sozialen Realisation“ (E. Forsthoff) die Gewissheit und das Vertrauen gegenüber staatlichen Sicherheitszusagen zu stabilisieren und damit delegitimierende Erwartungsenttäuschungen von Verfassungs wegen zu begrenzen. ${ }^{19}$ Abrupte Systemwechsel haben deshalb in der sozialen Sicherung keinen Platz. ${ }^{20}$

\section{c) Enttäuschtes Vertrauen als Legitimationsproblem}

Die Zukunft der sozialen Sicherungssysteme in den Blick zu nehmen meint, sich über ihre Ausgestaltung und Struktur in der uns vorausliegenden Zeit zu vergewissern. Dafür sind neben den ökonomischen, demografischen und politischen Rahmenbedingungen die jeweils maßgeblichen Grundkonzeptionen und Leitziele sowie deren verfassungs-

\footnotetext{
${ }^{16}$ Näher dazu und mwN W. Brugger (Fn. 12), $129 \mathrm{ff}$; ders. Freiheit und Sicherheit, 2004, $52 \mathrm{ff}$; C . Gusy Gewährleistung von Freiheit und Sicherheit im Lichte unterschiedlicher Staats- und Verfassungsverständnisse, VVDStRL 63 (2004), 151 (156ff., 162ff., 164f.).

17 Anders K.-P. Sommermann Staatsziele und Staatszielbestimmungen, 1997, $3 \mathrm{ff}$. und öfter.

${ }^{18}$ Im Einzelnen findet sich diese Position begründet bei R. Pitschas „Schutzstaat“ oder Sicherheit als gesellschaftlicher Mehr-Wert? Staatliche Integration als nationaler Wertekonflikt, in: Kreyher/Böhret (Hrsg.) Gesellschaft im Übergang, 1995, 57 (61 f., 63 ff.); Bezug genommen wird dabei auf F.-X. Kaufmann Sicherheit als soziologisches und sozialpolitisches Problem, 1970.

${ }^{19} \mathrm{Zu}$ diesem „notwendigen Ergänzungsverhältnis“ s. auch C. Gusy (Fn. 16), 162.

${ }^{20} \mathrm{Zu}$ diesem Ergebnis kommt, von einem anderen Ausgangspunkt her (,Systemgerechtigkeit“), auch H.-J. Papier Der Einfluss des Verfassungsrechts auf das Sozialrecht, in: v. Maydell/Ruland (Hrsg.) Sozialrechtshandbuch (SRH), 3. Aufl. 2003, A. 3 Rn. 94 f. (,Systemwahrungsgebot“).
} 
rechtlicher Rahmen von dirigierender Kraft. ${ }^{21}$ Die weitgehende „Pfadabhängigkeit“ aller Strukturmodernisierung der sozialen Sicherung sowie die Komplexität der Modernisierungsaufgabe mahnen allerdings ebenso zu Bescheidenheit ${ }^{22}$ wie die divergierenden Sicherheitserwartungen, die sich als gesellschaftlicher Wertungskonflikt offenbaren. ${ }^{23}$ Denn in unserer Gesellschaft besteht ein tiefgreifender prinzipieller Gegensatz zwischen denen und insbesondere Familien, die auf „staatliche“ Sicherheit vertrauen (dürfen) und diese Gewissheit an den Staat adressieren (Stichwort: „Montagsdemonstrationen“), sowie jenen, die oftmals - bei beruhigendem eigenen Einkommen - für die soziale Sicherung auf strukturelle Änderungen plädieren und die soziale Eigenvorsorge „fördern und fordern" wollen.

Die Zusammenlegung von Arbeitslosen- und Sozialhilfe („Hartz IV“) hat diesen Konflikt verschärft. ${ }^{24}$ Durch sie entsteht ein Legitimationsproblem für die Zukunft der sozialen Sicherung. Denn deren Akzeptanz gründet auf der Verlässlichkeit ihrer Institutionen und der Gewissheit von Rendite. ${ }^{25}$ Fehlgeschlagene Erwartungen wie hier enttäuschen dagegen, weil gerade die freiheitliche Vorsorgeinvestition verloren geht.

\section{Zukunftsentscheidungen über soziale Sicherung im strukturellen Abwägungsspielraum}

Vor diesem Hintergrund setzt das Verfassungsprinzip „Sicherheit“ einem beliebig flexiblen Sozialschutz durch den Staat Grenzen. Es will die Erwartungsenttäuschung vermeiden - ohne freilich ein „soziales Rückschrittsverbot" in der Verfassung zu verankern. ${ }^{26}$ Vielmehr schlägt sich die

${ }^{21}$ Ebenso C. F. Gethmann/W. Gerok/H. Helmchen/K.-D. Henke/J. Mittelstraß/ E. Schmidt-Aßmann/G. Stock/J. Taupitz/F. Thiele (Fn. 2), 146, 171, für die Gestaltung des Gesundheitssystems; vgl. ferner R. Scholz/R. Pitschas FS 25 Jahre BSG, Bd. II, 1979, 627 (635ff., 642ff.), zu den Strukturprinzipien „verfassungsmäßiger Sozialordnung“ und zur „grundgesetzlichen Sozialverfassung“; s. überdies R. P. Schenke Die Verwaltung 37 (2004), 475 (478ff., $482 \mathrm{ff}$.).

${ }^{22}$ S. Fisch/U. Haerendel Einleitung, in: dies. (Hrsg.) Geschichte und Gegenwart der Rentenversicherung in Deutschland, 2000, 11 (16f., 20).

${ }^{23}$ R. Pitschas (Fn. 18), $63 \mathrm{f}$.

24 Vgl. nur $A$. Brühl info also 2004, $104 \mathrm{ff}$. mwN.

25 So aus ökonomischer Perspektive auch G. Färber Zur Äquivalenz von Beiträgen und Leistungen in der gesetzlichen Rentenversicherung, in: Fisch/Haerendel (Hrsg.) Geschichte und Gegenwart der Rentenversicherung in Deutschland, 2000, 333 (334f., 339f.); juristisch hebt H.-J. Papier (Fn. 20), Rn. 41, die Erstreckung des grundrechtlichen Eigentumsschutzes (Art. 14 GG) auf die „Verzinsung“ der „angesparten Beitragsmittel“ hervor.

${ }^{26}$ Wie es R.-U. Schlenker Soziales Rücktrittsverbot und Grundgesetz, 1986, passim, postuliert. 
staatliche Verpflichtung zur Gewährleistung erworbener sozialer Sicherungsansprüche als relationaler Staatszweck der Vertrauensstabilisierung in einem strukturellen Abwägungsspielraum für den Gesetzgeber nieder. ${ }^{27}$ In dessen Prägung legt das Sicherheitsprinzip - anders als das rechtsstaatlich und grundrechtlich begründete Vertrauensschutzprinzip - gröbere Einstufungen darüber fest, welche Systemänderungen das Grundgesetz für die Zukunftsgestaltung der sozialen Sicherung zulässt. Es ermöglicht zugleich tiefergehende Skalierungen. ${ }^{28}$ So besteht z.B. eine Skala aus der Alternative, künftige Sicherungskonzepte über die Logik der gegebenen Sicherungssysteme hinauszuführen oder aber anzustreben, Lösungen für die zukünftige soziale Sicherung in der bisherigen Logik des Gesamtsystems „Sozialversicherung“ zu belassen. Für das Letztere streitet das Verfassungsprinzip „Sicherheit“. Im Hinblick auf das Vertrauen der Bürger in die Institutionen der sozialen Sicherung sollte daher ein Systemwechsel nur im äußersten Fall in Betracht kommen. ${ }^{29}$

Die zweistufige Skalierung ließe sich durch eine Zwischenstufe der inkrementalen Systemveränderung unter Reaktion auf die Herausforderungen an das jeweilige soziale Sicherungssystem erweitern, wie dies z.B. in der Rentenversicherung mit der Einführung der sogenannten Riester-Rente versucht worden ist..$^{30}$ Darin liegt die Idee einer „weichen“ Modernisierung.

\section{Herkunft und Entwicklungslinien der sozialen Sicherungssysteme}

\section{Der Eintritt des Staates in die Verantwortung für soziale Risiken}

Die prinzipielle und kategoriale Vor-Bestimmtheit der Auseinandersetzung über die Zukunft der sozialen Sicherungssysteme in Deutschland als Mitgliedstaat der Europäischen Union (EU) und namentlich die innere Bindung strukturumwälzender Veränderungsoptionen an das Sicherheitsund Freiheitsprinzip lassen die Schwierigkeiten (verfassungs-)rechtlicher Rahmensetzung für Modernisierungsentscheidungen sowie die Dynamik

\footnotetext{
${ }^{27}$ Hierzu umfassend $R$. Alexy Verfassungsrecht und einfaches Recht - Verfassungsgerichtsbarkeit und Fachgerichtsbarkeit, VVDStRL 61 (2002), 7 (18ff., 22f. mit Fn. 88).

${ }_{28}$ Vgl. R. Alexy (Fn. 27), 20; die gegebene Skala erleichtert rationale Urteile über Eingriffsintensitäten und Wichtigkeitsgrade bei der Abwägung, vgl. ebenda, 20.

${ }^{29}$ Aus wirtschaftswissenschaftlicher Sicht ebenso W. Schmähl Entwicklungstendenzen der deutschen Alterssicherung im internationalen Vergleich. Jüngere Erfahrungen und Perspektiven für die Zukunft, in: Fisch/Haerendel (Hrsg.) Geschichte und Gegenwart der Rentenversicherung in Deutschland, 2000, 351 (361).

${ }^{30}$ Altersvermögensergänzungsgesetz vom 31. März 2001 (BGB1 I 403); Altersvermögensgesetz vom 26. Juni 2001 (BGB1 I 1310); K. Hessert VSSR 2002, 129 (154ff.); F. Ruland NZS 2002, 505 (506ff.).
} 
ahnen, der die Entwicklung sozialer Sicherheit in der Austarierung von sozialer Eigenverantwortung, wohlfahrtsstaatlicher Vorsorge und Vertrauensschutz in staatliche Sicherheitsversprechen unterliegt. Deshalb gibt es kein Zukunftskonzept, das ohne verfassungsrechtliche Risiken wäre. Erkennbar wird zugleich die aller Modernisierung von sozialer Sicherung innewohnende Legitimationsproblematik, die bereits die Herkunft und die frühere Entwicklung der sozialen Sicherung in Deutschland kennzeichnet. ${ }^{31}$ Aus dieser lässt sich denn auch für Zukunftsentscheidungen über soziale Sicherung lernen. ${ }^{32}$

Der insoweit für uns wesentliche Zeitraum mit der Wende zu einem bedarfsstrukturierten modernen Sozialrecht findet sich in der historischen Phase der Bismarckschen Sozialversicherungsgesetzgebung. Mit ihr trat erstmalig ein relativ geschlossenes Prinzip sozialer Sicherung auf den Plan. Der Staat übernahm Verantwortung für soziale Risiken, denen seine Bürger ausgesetzt waren. Damit wurde die Grundrichtung eines neuen „Pfades“ vorgegeben, der sich in der Ausgestaltung der initiierten Sozialversicherung von Anfang an vornehmlich an den spezifischen sozialen Risiken der Industriearbeiterschaft orientierte. ${ }^{33}$

\section{Institutionelle Ausdifferenzierung und Strukturmerkmale der Sozialversicherung}

Die zentralen Strukturmerkmale dieser Grundausrichtung lagen zum einen in der Formenwahl einer Versicherung, die dem Grundsatz nach als Pflichtversicherung öffentlich-rechtlich organisiert war. Sie stand auf der Grundlage einer Selbstverwaltung mit staatlicher Aufsicht. Die vorgesehenen Leistungen wurden durch Beiträge finanziert, die Arbeiter und Arbeitgeber gemeinsam aufbrachten. In der Rentenversicherung war zudem ein Staatszuschuss vorgesehen. Sollte sich das versicherte Risiko verwirklichen, hatte der Berechtigte in einem speziellen Verwaltungsverfahren seinen Leistungsanspruch durchzusetzen. ${ }^{34}$

Alle diese Kriterien prägen die Sozialversicherung noch heute. Dies gilt insbesondere für die Krankenversicherung, die ehedem auf dem Kran-

\footnotetext{
31 Dazu und für die Zeit nach dem zweiten Weltkrieg s. etwa H. G. Hockerts Sozialpolitische Entscheidungen im Nachkriegsdeutschland. Alliierte und deutsche Sozialversicherungspolitik 1945 bis 1957,1980 , insbesondere $413 \mathrm{ff}$.

32 In diesem Sinne äußert sich zu „Langzeitperspektiven der sozialen Sicherung“ differenziert M. Stolleis Geschichte des Sozialrechts in Deutschland, 2003, $321 \mathrm{ff}$.; zur Legitimationsproblematik ebenda, 326, 331.

${ }_{33} \mathrm{Vgl}$. S. Fisch/U. Haerendel (Fn. 22), 16.

${ }^{34}$ Näher hierzu R. Waltermann Sozialrecht, 4. Aufl. 2004, Rn. 46; zur Ausdeutung dieser Verantwortungsübernahme s. M. Stolleis (Fn. 32), $52 \mathrm{ff}$.
} 
kenversicherungsgesetz vom 15. Juni $1883^{35}$ beruhte, für die gesetzliche Unfallversicherung vom 6. Juli $1884^{36}$ sowie für die Invaliditäts- und Altersversicherung vom 22. Juni 188937. Das Gesetz über Arbeitsvermittlung und Arbeitslosenversicherung wurde erst am 16. Juli 1927 vom Reichstag verabschiedet; es trat am 1. Oktober 1927 in Kraft. ${ }^{38}$

Selbstverständlich hat es seitdem partielle Veränderungen in Struktur, Finanzierung, Leistungserbringung und Organisation der Sicherungssysteme gegeben. Vor allem ist auf den Bundeszuschuss als Finanzierungsinstrument in der Sozialversicherung aufmerksam zu machen. ${ }^{39}$ Die Grundstrukturen entsprechen aber auch heute noch denen in den ursprünglichen Modellen; nur die Pflegeversicherung ist anderen Zuschnitts. ${ }^{40}$ Zugleich wird an der Kranken-, Unfall- sowie Alters- und Invaliditätsversicherung jener Tage die Grundstruktur der Sozialversicherung allgemein erkennbar.

\section{Soziale Sicherung zwischen Reformkontinuität und Veränderungsdynamik}

Von einer durchgehenden „Pfadabhängigkeit“ der Entwicklung sozialer Sicherung in Deutschland sollte gleichwohl nicht die Rede sein. Darauf gestützte Annahmen oder auch Analysekonzepte verführen nur dazu, mit den gegenwärtig bestehenden Systemen der sozialen Sicherung vor allem den Eindruck zu verbinden, dass sie immer noch unverändert den Strukturen und Systemimperativen der ehemals geschaffenen Sicherungssysteme treu geblieben wären. Das aber ist gerade nicht der Fall. Im Gegenteil lässt sich der mehr als hundertjährigen Entwicklungsgeschichte der sozialen Sicherungssysteme seit der Kaiserlichen Botschaft vom 17. November 1881 und der anschließenden Ausformung der genannten Sozialversicherungsgesetze eine prozess- und strukturbetonte Veränderungsdyna-

35 RGB1 73; Einzelheiten bei G. Wannagat Lehrbuch des Sozialversicherungsrechts, Bd. I, 1965, $64 \mathrm{ff}$.

${ }^{36}$ RGB1 69; s. wiederum G. Wannagat (Fn. 35), 66ff.

37 RGBl 97; das Gesetz trat am 1. Januar 1891 in Kraft, vgl. R. Waltermann (Fn. 34), Rn. 49.

${ }^{38}$ RGB1 I 187; zur Entstehung des Gesetzes s. V. Hentschel Geschichte der deutschen Sozialpolitik 1880-1980, 1983, 110f.; seine weitere Entwicklung zum Instrument einer pluralen Vielfachsteuerung des Arbeitsmarktes in Gestalt des Arbeitsförderungsgesetzes vom 25. Juni 1969 (BGB1 I 582), zeichnet nach R. Pitschas FS Morsey, 1992, 545 (553ff., $560 \mathrm{ff}$.$) .$

${ }^{39}$ Dazu eingehend H. Butzer Fremdlasten in der Sozialversicherung, 2001, besonders $307 \mathrm{ff}$; die einzelnen Zuwendungen des Bundes an die Sozialversicherungszweige sind besonders gewichtig im Bereich der Rentenversicherung, der Bundesagentur für Arbeit sowie in allen Zweigen der landwirtschaftlichen Sozialversicherung, vgl. ebenda, 308.

40 Vgl. hierzu den Überblick bei B. Schulin/G. Igl Sozialrecht, 7. Aufl. 2002, $162 \mathrm{ff}$. 
mik, mitunter sogar - wie in der gesetzlichen Rentenversicherung - eine „radikale Veränderung des alten Systems“ entnehmen. ${ }^{41}$

In diese Veränderungsdynamik ist die Zukunft unserer sozialen Sicherung eingewoben. Kontinuität und Innovation sind ihre Bausteine; deren Wechselbezüglichkeit verdeutlicht der Gang durch die Sozialgeschichte. Er macht nicht nur ,augenscheinlich, dass auch die nicht zum Tragen gekommenen Alternativen“ - wie etwa der schon von Bismarck bevorzugte Gedanke einer steuerfinanzierten Staatsbürgerversorgung - „eine erhebliche Rolle“ bei Reformschritten spielten. Denn sie standen als Optionen zur Verfügung und wurden „in kritischen Momenten der Entwicklung neu diskutiert" ". ${ }^{42}$ Deutlich wird auch und ferner, das schon immer die Notwendigkeit bestand, aktuell auftretende Sicherungslücken zu schließen und wiederholter Systemerneuerung als Reaktion auf den Druck ökonomischer und/oder sozialer Probleme hinreichend Raum zu geben. ${ }^{43}$

\section{Erweiterungstendenzen der Sozialversicherung im ausgehenden 20. Jahrhundert}

Durchgehend war dies in der Rentenversicherung und in der Arbeitslosenversicherung der Fall, nach dem 2. Weltkrieg dann auch verstärkt in der GKV. In dem Maße, in dem in der Nachkriegszeit mit der sozialen Sicherung neben und jenseits der Garantie individueller Sozialvorsorge vielfältige ökonomische und meta-soziale Ziele bzw. Zwecke verfolgt worden sind, ist es sogar zu „Ausbrüchen“ aus der Eigenlogik einzelner Sicherungssysteme bzw. aus der Gesamtlogik der deutschen Sozialversicherung gekommen. ${ }^{44}$ Diese zielten darauf ab, sich nicht nur durch Beiträge aus der Erwerbsbevölkerung, sondern durch Heranziehung aller Staatsbürger zu finanzieren: Die Pflegeversicherung wurde in diesem

${ }^{41}$ D. Döring Grundlinien der langfristigen Systementwicklung der gesetzlichen Rentenversicherung - Personenkreis, Rentenformel, Finanzierung -, in: Fisch/Haerendel (Hrsg.) Geschichte und Gegenwart der Rentenversicherung in Deutschland, 2000, 169 (187); die Pfadabhängigkeit betont allerdings M. Stolleis (Fn. 32), 324.

42 S. Fisch/U. Haerendel (Fn. 22), 14.

43 Besonders aufschlussreich ist die Spiegelung dieser Erkenntnis in ausländischen Beobachtungen, vgl. etwa M. H. Geyer Von Europa lernen. Die amerikanische Alterssicherung und die Rezeption der europäischen Reformdebatten in den dreißiger Jahren, in: Fisch/Haerendel (Hrsg.) Geschichte und Gegenwart der Rentenversicherung in Deutschland, 2000, $271 \mathrm{ff}$.

${ }^{44}$ Vgl. am Beispiel der Rentenversicherung D. Döring (Fn. 41), 178 ff.: „Schaffung des dynamischen Systems“. 
Sinne zum 1. Januar 1995 als eine „Volksversicherung“ geschaffen. ${ }^{45}$ Deren Verfassungsmäßigkeit ist heute unbestritten. Darüber hinaus hat das BVerfG richtigerweise zum Künstlersozialversicherungsgesetz von 1981 hervorgehoben, die Beschränkung auf Arbeitnehmer und auf eine Notlage gehöre nicht zum Wesen der „Sozialversicherung“. Diese könne auch durch eine Volks- bzw. Staatsbürgerversicherung durchgeführt werden. ${ }^{46}$

Fraglich ist allerdings, ob bei dieser Erweiterung des staatlichen Risikoschutzes - wie überhaupt in der Sozialversicherung - von einer „Versicherung“ gesprochen werden kann. ${ }^{47}$ Jedenfalls will die Beitragsfinanzierung unter paritätischer Beteiligung der Arbeitgeber an den „Versicherungsbeiträgen“ die „gemeinsame Deckung eines möglichen, in seiner Gesamtheit schätzbaren Bedarfs durch Verteilung auf eine organisierte Vielheit““ sicherstellen, wie das BVerfG hervorhebt. ${ }^{48}$ Das Kennzeichen dieser Verknüpfung von Bedarfen und Leistungen ist die Teilhabeäquivalenz, bezogen auf die Versicherungsleistungen. In Abgrenzung gegenüber der Privatversicherung, die der „Individualäquivalenz"verpflichtet ist, ${ }^{49}$ gestaltet also die Sozialversicherung ihre Leistungen unabhängig von dem individuellen Risiko. Ihre Finanzierung ist dabei von der Leistungsfähigkeit der Erwerbstätigen abhängig gestellt sowie auf die solidarische Aufbringung der Mittel verwiesen. Sie kann jedoch - und bleibt auch dann noch im Bild der „Sozialversicherung“ - über diesen Kreis der Beitragszahler hinausgehen.

Zwischenzeitliche Durchbrechungen der historischen Tradition von „Sozialversicherung“ ändern wiederum nichts daran, das diese den spezifischen Charakter des deutschen Sozialstaats nachhaltig geprägt hat. Allerdings beginnen mit dieser Erkenntnis die Zweifel in die Überlebensfähigkeit der heutigen sozialen Sicherungssysteme. Zwar schuf die Gesetzgebung des Kaiserreichs zum Ende des 19. Jahrhunderts in Deutschland ein völlig neues Prinzip sozialer Sicherheit, so dass Deutschland zum „Pionierland in der Entwicklung eines modernen Systems der sozialen

45 Sozialgesetzbuch (SGB) Elftes Buch (XI) - Soziale Pflegeversicherung - vom 26. Mai 1994 (BGB1 I 1014); zum Charakter als „Volksversicherung“ s. BVerfGE 103, 197 (221 ff.); 103, 225 (237); BSG, NZS 2000, 302.

46 BVerfGE 75, 108 (148f.).

47 Zweifelnd K.-J. Bieback (Fn. 6), 20f.; ausführlich und bejahend im Sinne eines sozialrechtlichen Prinzips $F$. Hase (Fn. 13), $149 \mathrm{ff} ., 162 \mathrm{ff}$.

48 BVerfGE 11, 105 (113); 75, 108 (146ff., 157); 78, 249 (267).

49 Zum Versicherungsprinzip und Äquivalenzverhältnis als Elementen von „Sozialversicherung“ und „Privatversicherung“ s. näher K.-J. Bieback (Fn. 6), 28ff.; R. Pitschas VSSR 2002, 187 (194ff.); C. Rolfs Das Versicherungsprinzip im Sozialversicherungsrecht, 2000, 264ff.; minderen Wert messen dem Merkmal der Äquivalenz dagegen F. Hase (Fn. 13), 71 ff., und H. Butzer (Fn. 39), $197 \mathrm{ff} .$, zu. 
Sicherheit" wurde. ${ }^{50}$ Doch stellt sich die Frage, ob im Anschluss an die Erweiterungstendenzen der Sozialversicherung im ausgehenden 20. Jahrhundert diese Auszeichnung am Beginn des 21. Jahrhunderts der Bundesrepublik Deutschland noch immer gebührt.

\section{Wohlfahrtsstaatliche Beharrungstendenzen}

Die späten Entwicklungsphasen der Sicherungssysteme im 20. Jahrhundert lassen die Frage verneinen. Denn sie sind durch komplexe Verschmelzungsprozesse der Sozialleistungen sowie durch eine Tendenz gekennzeichnet, das Ausmaß sozialen Risikoschutzes noch zu erhöhen und die Systeme selbst durch vielfachen „Anbau“ neuer Regelungskomplexe, wie z.B. der Qualitätssicherung in der GKV, zu verfeinern. Insgesamt hat dies in den letzten zwei Jahrzehnten zu einer anhaltenden Juridifizierung, zu wachsender institutioneller Ausdifferenzierung aus Gründen der Spezialisierung, zum Ausbau solidarischer Fremdhilfe und zur Kollektivierung statt individuellen Eigenvorsorge geführt. ${ }^{51}$ Zugleich kommt es gegenwärtig zu einer ausgreifenden Betonung der Prävention in der sozialen Sicherung, namentlich in der GKV.52 Alles das bedeutet in der Summe den weiteren Ausbau des fürsorglichen Sozialstaates zum kostspieligen Wohlfahrtsstaat, mit dem ein entsprechendes Wachstum der Sozialbürokratie einhergeht.

Dem entgegen ist die Ausgliederung von Ergänzungssystemen der betrieblichen Altersversorgung, landwirtschaftlicher sozialer Sicherung, berufständischer Alterssicherung, der Zusatzversorgung für Arbeiter und Angestellte im öffentlichen Dienst sowie privilegierter Zusatzsysteme wie etwa der Altersversorgung für Abgeordnete, nicht länger hinnehmbar. Die Sondersysteme sind aus Gründen der Effektivität und Effizienz sozialer Sicherung zu reduzieren und transparent in die Struktursystematik der Grundsysteme rückzugliedern. Veränderungen erfordert angesichts des Strukturwandels der Alterssicherung auch die systembedingte Trennung der betrieblichen Altersvorsorge von der gesetzlichen Rente. ${ }^{53} \mathrm{Im}$

50 G. A. Ritter Soziale Frage und Sozialpolitik in Deutschland seit Beginn des 19. Jahrhunderts, 1998, 28.

51 Zutreffende Beobachtung bei $H$. Bley/R. Kreikebohm/A. Marschner Sozialrecht, 8. Aufl. 2001, Rn. 23.

52 O. Seewald FS 50 Jahre BSG, 2004, 289 (290f., 291 ff.); U. Walter Gesundheitswesen 66 (2004), $69 \mathrm{ff} . \mathrm{mwN}$.

${ }^{53}$ Der deutsche Gesetzgeber geht dagegen von der fortzuführenden „Zweigleisigkeit“ der Alterssicherung aus, nämlich in der gesetzlichen Rentenversicherung einerseits, der betrieblichen Altersvorsorge als freiwilliger ergänzender Vorsorge andererseits, vgl. Art. 8 Gesetz zur Neuordnung der einkommensteuerrechtlichen Behandlung von Altersvorsorgeaufwendungen und Altersbezügen (Alterseinkünftegesetz - AltEinkG) vom 5. Juli 
Übrigen rufen die „Verschiebebahnhöfe“ in der Finanzierung der sozialen Sicherung mit der jeweiligen Quersubvention einzelner Sicherungssysteme durch andere - wie z.B. der Rentenversicherung durch die GKV nach Abhilfe. Auch in Bezug hierauf steht eine Grundsatzrevision des geltenden Sozialgesetzbuchs an.

\section{6. $\quad$ Aktuelle Modernisierungsansätze im 21. Jahrhundert}

Abhilfe ist freilich unterwegs. Zunehmend wird erkannt, dass die sozialen Sicherungssysteme der Entbürokratisierung, Deregulierung und Privatisierung bedürfen. Die Aufgabe, der sich der Gesetzgeber zukünftig vor allem gegenübersieht, ist freilich ungleich größer noch: Die gesamte Architektur der sozialen Sicherung verlangt angesichts der an sie gewendeten Herausforderungen am Beginn des 21. Jahrhunderts nach umfassender Erneuerung. ${ }^{54}$

Einen ersten Eindruck von den ins Haus stehenden unerlässlichen Systemänderungen gibt die sogenannte Agenda 2010 der Bundesregierung. ${ }^{55}$ Sie markiert den Beginn des programmatischen Umbaus der sozialen Sicherungssysteme in Deutschland. Ihre Ziele liegen u.a. im Rückschnitt des Wohlfahrtsstaates sowie in der Stärkung individueller Eigenverantwortung für die soziale Sicherung; sie will ferner die Wirtschaft von zu hohen Arbeitskosten entlasten und zugleich die Haushaltssanierung fördern. Ausfluss ihrer Konzeption sind gegenwärtig erste gesetzesförmige Modernisierungsschritte.

\section{a) Gesetzliche Rentenversicherung}

In der gesetzlichen Rentenversicherung ist hierzu an erster Stelle auf den Aufbau einer staatlich geförderten, freiwilligen und kapitalgedeckten pri-

2004 (BGBl I 1427). Zu Recht wird aber darauf aufmerksam gemacht, dass sich dieses „besonders komplexe System ... auch europarechtlich bisweilen als hinderlich erweist“, und zwar für den Zugang zur Alterssicherung, vgl. H.-D. Steinmeyer Private und betriebliche Altersvorsorge zwischen Sicherheit und Selbstverantwortung, in: Ständige Deputation des Deutschten Juristentages (Hrsg.) Verhandlungen des 65. Deutschen Juristentages, Bd. I, 2004, F 81; der Verfasser widerrät indes einer grundsätzlichen Umgestaltung sie würde „zusätzliche Verunsicherung der Bürger mit sich bringen“, ebenda, F 86.

${ }_{54}$ Dazu aus sozialwissenschaftlicher und ökonomischer Perspektive die Beiträge in Evers (Hrsg.) Eine neue Architektur der Sozialen Sicherung in Deutschland?, ZSR 2004, Heft 1-2; aus rechtlicher Sicht M. Wallerath JZ 2004, 949 ff.

55 Agenda 2010 - Innovation und Wachstum. Regierungserklärung von Bundeskanzler Schröder am 14. März 2003 vor dem Deutschen Bundestag, abrufbar unter: http:// www.bundesregierung.de/Politikthemen/Agenda-2010-,9768/Regierungserklaerung.htm (Stand: 9. November 2004). 
vaten oder betrieblichen Altersvorsorge hinzuweisen. ${ }^{56}$ Dem schließt sich das „Alterseinkünftegesetz“ zur Neuordnung der einkommensteuerrechtlichen Behandlung von privaten Altersvorsorgeaufwendungen und Altersbezügen ${ }^{57}$ in der Folge der Rechtsprechung des BVerfG zur Besteuerung von Altersrenten an. ${ }^{58}$ Das Gesetz sieht zugleich die Ausdehnung der Einkommensanrechnung in der Rentnerkrankenversicherung vor, ${ }^{59}$ was beträchtliche Vertrauensschutzprobleme aufwirft und verfassungswidrig sein dürfte. $\mathrm{Zu}$ nennen sind ferner das „Rentenversicherungs-Nachhaltigkeitsgesetz“ zur Sicherung der Finanzierungsgrundlagen ${ }^{60}$ und die föderale Reorganisation der Rentenversicherung. ${ }^{61}$

\section{b) Gesetzliche Krankenversicherung}

In der Gesetzlichen Krankenversicherung ( $G K V)$ bleibt das Gesetz zu deren Modernisierung (Gesundheits-Modernisierungsgesetz - GMG) vom 14. November 2003 hervorzuheben. ${ }^{62}$ Es sucht die vor einer Reihe von Jahren begonnene und immer wieder fortgeschriebene „Gesundheitsreform“ nunmehr mit einer tiefgreifenden Strukturmodernisierung in Bezug auf die Finanzierung des Systems, die Leistungserbringung, deren Qualitätssicherung und die künftige Organisation des Gesundheitswesens abzuschließen.

\section{c) Arbeitsmarktregulierung und Grundsicherung für Arbeitsuchende}

Mit den ersten zwei Gesetzen für moderne Dienstleistungen am Arbeitsmarkt ${ }^{63}$ sollen schließlich neue Beschäftigungsmöglichkeiten für Arbeitslose erschlossen sowie die durchgreifende Verbesserung von Qualität und

\footnotetext{
56 S. dazu bereits oben in Fn. 30; vgl. ferner W. Binne VSSR 2002, $161 \mathrm{ff}$; B. JährlingRahnefeld SGb 2003, 82 ff., R. Pitschas (Fn. 49), 189ff.; F. Ruland FS Schmähl, 2002, 189 ff., zur Reaktion der Rentenversicherung auf Veränderungen der Arbeitswelt.

57 Vgl. die Nachweise in Fn. 53 sowie F. Ruland FS Selmer, 2004, 889 (894ff., 896f.); kritisch R. Pitschas (Fn. 49), $204 \mathrm{f}$.

58 BVerfGE 105, 73 (110ff.).

59 Art. 9 Nr. 1 AltEinkG.

${ }^{60}$ Gesetz zur Sicherung der nachhaltigen Finanzierungsgrundlagen der gesetzlichen Rentenversicherung (RV-Nachhaltigkeitsgesetz) vom 21. Juli 2004 (BGB1 I 1791); dazu der Überblick von H.-J. Kramer DAngVers 2004, $404 \mathrm{ff}$.

$61 \mathrm{Vgl}$. Gesetz zur Organisationsreform in der gesetzlichen Rentenversicherung (RVOrgG) vom 9. Dezember 2004 (BGB1 I 3242); C. Waibel VSSR 2003, $115 \mathrm{ff}$.

62 BGB1 I 2190; dazu eingehend aus verfassungsrechtlicher Sicht H. Butzer MedR 2004, 177 ff.; vgl. ferner T.-C. Hiddemann/S. Muckel NJW 2004, 7 ff.; Pitschas (Hrsg.) Umsetzung des GKV-Modernisierungsgesetzes, Speyerer Arbeitshefte Nr. 164, 2004.

${ }^{63}$ Erstes Gesetz für moderne Dienstleistungen am Arbeitsmarkt vom 23. Dezember 2002 (BGB1 I 4607); Zweites Gesetz für moderne Dienstleistungen am Arbeitsmarkt vom 23. Dezember 2002 (BGB1 I 4621); dazu im Überblick M. Neumann NZS 2003, $113 \mathrm{ff}$.
} 
Schnelligkeit der Arbeitsvermittlung erreicht werden. Herzstück dieses Modernisierungsansatzes ist die Einrichtung sogenannter PersonalServiceAgenturen (PSA) als neuer Form einer integrationsorientierten Vermittlung in Zeitarbeit. Darüber hinaus werden der Eintritt Arbeitsuchender in die Selbständigkeit durch Existenzgründungszuschüsse sowie die Entgeltabsicherung für ältere Arbeitnehmer gefördert. Das Dritte Gesetz für moderne Dienstleistungen am Arbeitsmarkt ${ }^{64}$ steuert ergänzend die Transformation der ehemaligen Bundesanstalt für Arbeit von einer Behörde für Arbeitsförderung und Arbeitslosenversicherung in eine moderne Dienstleistungsagentur. ${ }^{65}$ Diese soll ihre Vermittlungshilfen und alle weiteren Serviceleistungen effizient, bürgerfreundlich und transparent anbieten, um auf diese Weise die Regulierung des Arbeitsmarktes durch Selbstregulierung zu ermöglichen. Damit sieht sich der Schulterschluss mit der an anderer Stelle im Sozialsektor stattfindenden Verwaltungsmodernisierung erreicht. ${ }^{66}$

Hieran knüpft auch das umstrittene vierte Gesetz dieser Art („Hartz IV“) an. Es hebt das bisherige Nebeneinander der Arbeitslosen- und Sozialhilfe für Erwerbstätige zum 1. Januar 2005 durch Verschmelzung beider Leistungsarten auf. ${ }^{67}$ Hierdurch entsteht für Erwerbstätige eine neue Grundsicherung mit dem Ziel, die Eigeninitiative erwerbsfähiger Hilfebedürftiger durch schnelle Einführung in Arbeit und Anreize dazu zu unterstützen („Grundsatz des Förderns“). Die Eigenverantwortung dieses Kreises und von Personen, die in einer Bedarfsgemeinschaft leben, soll hierdurch gestärkt werden. In der Suchzeit gewährleistet die als Sozialgesetzbuch II neu eingerichtete „Grundsicherung für Arbeitsuchende“68 den Lebensunterhalt erwerbsfähiger Hilfebedürftiger und ihrer Angehörigen durch pauschalierte bedarfsdeckende Leistungen und die Einbeziehung in die Sozialversicherung. Mit Hilfe von Sanktionsdrohungen wird darüber hinaus die Aufnahme einer Arbeit gefordert („Grundsatz des

64 Vom 23. Dezember 2003 (BGBl I 2848); zur Neuregelung vgl. B. Gaul/A. Bonanni/B. Otto DB 2003, $2386 \mathrm{ff}$.

65 D. Schimanke FS König, 2004, 151 (162ff.).

${ }^{66} \mathrm{Vgl}$. R. Pitschas Organisationsrecht als Steuerungsressource in der Sozialverwaltung, in: Schmidt-Aßmann/Hoffmann-Riem (Hrsg.) Verwaltungsorganisationsrecht als Steuerungsressource, 1997, 151 (160ff., 202ff.); ders. Strukturen und Verfahrensweisen des Jugendamtes im kooperativen Rechts- und Sozialstaat, in: Sachverständigenkommission 11. Kinder- und Jugendbericht (Hrsg.) Strukturen der Kinder- und Jugendhilfe. Eine Bestandsaufnahme, 2002, 163 (169f., $237 \mathrm{ff}$.).

67 Viertes Gesetz für moderne Dienstleistungen am Arbeitsmarkt vom 24. Dezember 2003 (BGB1 I 2954).

${ }^{68}$ Art. 1 des Vierten Gesetzes für moderne Dienstleistungen am Arbeitsmarkt (Fn. 67): Sozialgesetzbuch (SGB) Zweites Buch (II) - Grundsicherung für Arbeitsuchende. 
Forderns"): Ein Erwerbstätiger muss sich vorrangig und eigeninitiativ um die Beendigung seiner Erwerbslosigkeit bemühen und seine Arbeitskraft sowie sein Vermögen einsetzen, um seinen Lebensunterhalt und den seiner Angehörigen zu bestreiten. ${ }^{69}$

\section{Strukturelle Fehlentwicklungen und Veränderungszwänge}

Die Zukunft hat also schon begonnen: Der Gesetzgeber reagiert auf den übermächtigen Veränderungsdruck, der auf den sozialen Sicherungssystemen lastet. Die Erfahrung ist zwar, dass Krisen nicht in jedem Fall geeignet sind, großzügige Systemänderungen in Gang zu setzen; der Problemdruck muss, wie das Beispiel der Entwicklung von Renten- und Arbeitslosenversicherung zeigt, erst so intensiv werden, dass die gesamten Grundlagen der sozialen Sicherung in Frage stehen. Doch gehen die Modernisierungsschritte in die richtige Richtung. Sie sind freilich mit dem Begriff der „Reform“ kaum noch erfassbar. Bewusst wird deshalb hier der Begriff der „Modernisierung“ verwendet. ${ }^{70}$

\section{Defizite bisheriger Modernisierungsansätze}

Die skizzierten Modernisierungsansätze vermitteln allerdings das Bild einer noch sehr zögerlichen Reaktion auf die Herausforderungen an die Sicherungssysteme. Denn sie fördern vor allem die Abhängigkeit von der öffentlichen Sicherung und weniger die soziale Eigenvorsorge.

Verfehlt wird auch das Ziel, die finanzielle Krise der deutschen Sicherungssysteme zu beenden, weil die bisherigen Fehlanreize für den Umgang mit Sozialleistungen teilweise fortbestehen. Die soziale Absicherung gegen Arbeitslosigkeit, Krankheit, Armut und für eine sichere Rente oder eine gerechte Familienförderung gehorcht nun einmal eigenen ökonomischen Gesetzmäßigkeiten. Deren Vernachlässigung führt zu strukturellen Fehlentwicklungen. So ist in der Rentenversicherung unterblieben, die Rentenaltersgrenze anzuheben. Unbezweifelbar ist jedoch, dass sich die wachsende Lebenserwartung der Bürger nicht in immer

$69 \S \S 2$, 14 SGB II; umfassend dazu die Kommentierung von Münder (Hrsg.) Sozialgesetzbuch II, 2005; A. Brühl (Fn. 24), 105; I. Ebsen FS 50 Jahre BSG, 2004, 725 (729ff., $732 \mathrm{ff}$.); zu verfassungsrechtlichen Bedenken gegenüber dem SGB II siehe nur $U$. Berlit info also 2003, 195 (203f.); kritisch gegenüber § 23 Abs. 1 SGB II P. Mrozynski ZfSH/SGB 2004, 198 (217f.).

70 Zur Abgrenzung der „Modernisierung“ von der „Reform“ s. noch immer wegweisend J. J. Hesse/A. Benz Die Modernisierung der Staatsorganisation, 1990, $13 \mathrm{ff}$. 
längerer Bezugsdauer der Renten niederschlagen darf, sondern zwingend eine längere Lebensarbeitszeit verlangt. Würde diese realisiert, könnte auch die Beitragslast gesenkt werden. Diese verhindert ihrerseits, dass sich neue wirtschaftliche Dynamik als Binnen-Nachfrage auf den Märkten entfaltet. Sie nimmt andererseits vielen gesetzlich Versicherten den finanziellen Atem für eine ergänzende Privatvorsorge, die angesichts der Senkung des allgemeinen Rentenniveaus künftig unerlässlich sein wird.

\section{Strukturelle Fehlentwicklungen}

Wirkliche Modernisierungspolitik kommt dagegen nicht umhin, künftig den strukturellen Fehlentwicklungen in der sozialen Sicherung effektiv gegenzusteuern.

Zu ihnen zählt an erster Stelle die unablässige Anspruchsausweitung, weil staatliche Sozialpolitik als ein „ständiges Umlaufverfahren mit partikularer Erfüllung von Teilerwartungen“ immer wieder die Erträge aus dem Wirtschaftswachstum auf andere Erwartungsträger verteilen will. ${ }^{11}$ So ist aus der ehedem vorgesehenen Grundsicherung schon längst eine „Komfortsicherung“"gegen soziale Risiken geworden. Die Erfordernisse der sozialen Sicherung haben sich in hohem Maß von den ursprünglichen Prämissen, auf denen die Sicherungssysteme beruhen, entfernt.

Gleiches gilt für den bisher nicht wirklich gelungenen Versuch, die Wohlfahrtsausgaben zu begrenzen. Ihr Anstieg lässt einerseits erkennen, dass sozialstaatliche Solidarverantwortung und in deren Gefolge soziale Ansprüche des Einzelnen gegen den Staat nicht, wie es geboten gewesen wäre, zugunsten sozialer Selbstverantwortung und Eigenvorsorge nachhaltig begrenzt worden sind. Es überrascht daher nicht, dass andererseits mit dem fortgesetzten Ausgaben- bzw. Leistungsanstieg die übermäßige Belastung der Beitragszahler anhält. Diese verschlechtert nicht allein die wirtschaftlichen Standortbedingungen, sondern auch - wie schon erwähnt - die Chancen individueller Vorsorge.

Schließlich verweist der nicht wirklich realisierte marktwirtschaftliche Wechselbezug von Sozial- und Wirtschaftspolitik auf ein ernsthaftes Strukturproblem. Denn die Erstere muss auf den Erfolg der Letzteren und damit auf die Funktionskraft der sozialen Marktwirtschaft vertrauen: Deren Ziel ist unter dem Grundgesetz die Mehrung des Wohlstandes durch die Erträge von Markt und Wettbewerb bei gleichzeitiger Verwirklichung des sozialstaatlichen Auftrags zur sozialen Umverteilung. Die hier skizzierten Modernisierungsansätze arbeiten zwar mit Wettbewerbselementen, sie bleiben aber in der Tendenz den Monopolansprüchen der staatlichen Si-

${ }^{71}$ H. F. Zacher Wirtschaft und Wissenschaft 1978, 17 (19ff., 23f.). 
cherungsinstitutionen verhaftet. Wettbewerb ist diesen fremd. Schon unter dem maßgeblichen Gesichtspunkt der Entwicklung eines werdenden europäischen Sozialstaats ${ }^{72}$, der Monopole verhindern will, die soziale Eigenverantwortung der Gemeinschaftsbürger für soziale Sicherung betont und im Übrigen diesen den Zugang zu den nationalen Sicherungssystemen sukzessive öffnet ${ }^{73}$, erweist sich die wettbewerbsskeptische Position der Sozialversicherung als strukturell verfehlt. Daran ändert nichts, dass im Gemeinschaftsrecht die Verantwortung der Mitgliedstaaten für die Systeme der sozialen Sicherung festgeschrieben ist.

\section{Vordringliche Modernisierungszwänge}

Derartige strukturelle Fehlentwicklungen erschweren in den nächsten Jahren die weitere dringliche Anpassung der sozialen Sicherungssysteme an externe Rationalitätsbindungen des Modernisierungsprozesses. Dazu rechnen in erster Linie die „Globalisierung“ der Wirtschaft mit den daraus resultierenden Arbeitsmarktfolgen ${ }^{74}$ sowie der Strukturwandel des Alters in Deutschland. ${ }^{75}$ Daneben bleibt, wie schon angedeutet, die interne Rationalisierung des öffentlichen Sozialsektors eine anhaltende Herausforderung. ${ }^{76}$

72 Dazu die Beiträge in Merten/Pitschas (Hrsg.) Der Europäische Sozialstaat und seine Institutionen, 1993; B. Schulte ZIAS 17 (2003), 391 ff.; vgl. ferner U. Becker Die soziale Dimension des Binnenmarkts, in: Schwarze (Hrsg.) Der Verfassungsentwurf des Europäischen Konvents, 2004, $201 \mathrm{ff}$.

73 U. Becker NJW 2003, 2272ff.; E. Eichenhofer Sozialrecht der Europäischen Union, 2. Aufl. 2003, Rn. 33, 35 ff., 395 ff., 399 ff., 420 ff., 432 ff.; ders. FS 50 Jahre BSG, 2004, 835 (838ff.); R. Pitschas Das Territorialitäts-Prinzip im Sachleistungssystem der gesetzlichen Krankenversicherung zwischen sozialpolitischer Souveränität und Gemeinschaftsrecht, in: Ebsen (Hrsg.) Europarechtliche Gestaltungsvorgaben für das deutsche Sozialrecht, 2000, 83 (97ff., 100f.); ders. VSSR 2002, 75 (86f., $88 \mathrm{ff}$.).

${ }^{74}$ Dazu u.a. A. Heise/H. Küchle WSI-Mitteilungen 1996, 237 (240); W. Schäfer Globalisierung: Entmonopolisierung des Nationalen?, in: Berg (Hrsg.) Globalisierung der Wirtschaft: Ursachen - Formen - Konsequenzen, 1999, $9 \mathrm{ff}$.; wN zur wirtschafts- und sozialwissenschaftlichen Diskussion bei $C$. Engel Arbeitsmarkt und staatliche Lenkung, VVDStRL 59 (2000), 56 (60ff.); R. Scholz FS Steinberger, 2002, 611 (612ff.); aus öffentlich-rechtlicher Perspektive M. Ruffert Die Globalisierung als Herausforderung an das öffentliche Recht, 2004, 23 ff., 55 ff.; R. Schmidt FS Vogel, 2002, 21 (42f.).

75 Dazu Einzelheiten im Schlussbericht der Enquête-Kommission des Deutschen Bundestages „Demografischer Wandel - Herausforderung unserer älter werdenden Gesellschaft an den Einzelnen und die Politik“, BT-Drucks. 14/8800. 31 ff. Nach einer Prognose des Statistischen Bundesamtes werden im Jahr 2035 nicht weniger als 68,5\% der Wohnbevölkerung über 60 Jahre alt sein, vgl. C. Engel (Fn. 74), 61 mit Fn. 26.

76 Vgl. statt vieler B. Jährling-Rahnefeld VSSR 2003, $293 \mathrm{ff}$.; R. Pitschas Die Modernisierung der sozialen Sicherung im Zeichen von Effektivität und Effizienz - zum Grund- 
Als Konsequenz dieser Modernisierungszwänge wird in der $G K V$ die Bedarfsplanung für Vertragsärzte obsolet. In der Rentenversicherung hat der „Generationenvertrag“ zur Begründung künftiger sozialstaatlicher Politik ausgedient. Denn er war (politisch) stets so gedacht, dass wesentlich mehr Arbeitnehmer im Verhältnis zu Rentnern vorhanden sein würden, um das Prinzip der lebensstandardsichernden Rente, bei der ein Durchschnittsverdiener etwa 70\% seines Einkommens erhalten soll, zu garantieren. Die gegenwärtige Entwicklung geht indessen in die entgegengesetzte Richtung. Die in den letzten Jahren eingetretene Senkung des Rentenniveaus, die sich fortsetzen wird, ist deshalb unvermeidlich. ${ }^{77} \mathrm{Die}$ Kombination einer immer älter werdenden Gesellschaft, in der immer mehr Rentner durch immer weniger Beitragszahler gesichert werden können, führt wegen der anhaltenden Arbeitslosigkeit zum Verfall des derzeitigen Alterssicherungssystems wie überhaupt aller auf Beitragszahlungen aus Erwerbseinkommen gestützten Sicherungssysteme.

\section{Auf dem Weg zu einer neuen Architektur der sozialen Sicherung}

\section{Dominierende Ziele und Konzeptionen}

Wenn aber die Gesellschaft immer älter wird und der Konkurrenzdruck in der globalisierten Wirtschaft ständig steigt, bedarf es neuer Konzepte, damit die sozialen Sicherungssysteme in der Zukunft noch finanziert werden können.

Die lange im Dunkeln verbliebenen Konturen einschlägiger Überlegungen werden in den letzten Jahren sichtbarer. Wesentliche Elemente einer neuen Architektur der sozialen Sicherung schälen sich heraus. ${ }^{78}$ Sie betonen den Gedanken der individuellen Eigenvorsorge. Ihn begleitet das Bestreben, künftighin den engen Zusammenhang zwischen Sozialversicherungsbeiträgen und Erwerbseinkommen zugunsten einer anderen Finanzierungsweise der Sozialversicherung aufzulösen. Zugleich soll deren

satz der Wirtschaftlichkeit im Sozialrecht, in: Butzer (Hrsg.) Wirtschaftlichkeit durch Organisations- und Verfahrensrecht, 2004, 31 (44ff.).

77 K. Hessert (Fn. 30), 154; H.-J. Kramer (Fn. 60), 406f.; zur verfassungsrechtlichen Problematik s. U. Wenner FS 50 Jahre BSG, 2004, 625 (628ff.); vgl. auch die Niveausicherungsklausel in $\S 154$ Abs. 3 SGB VI idF des RV-Nachhaltigkeitsgesetzes (Fn. 60), wonach das „Nettorentenniveau vor Steuern“ im Jahr 2020 nicht unter 46\% des Durchschnittsentgelts fallen soll.

78 Zur Forderung nach einer „neuen Architektur des Wohlfahrtsstaats“ in „ganz Europa“ s. G. Esping-Andersen Die gute Gesellschaft und der neue Wohlfahrtsstaat, in: Evers (Hrsg.) Eine neue Architektur der Sozialen Sicherung in Deutschland?, ZSR 2004, Heft 1-2, 191 (193); vgl. ferner U. Steiner FS 50 Jahre BSG, 2004, 61 (75f.). 
Einnahmeseite gestärkt werden..$^{79}$ Doch reicht dies für die Gewährleistung zukunftssicherer Sozialsysteme noch nicht aus. Im Dilemma ihrer Zielorientierung an Beitragssatzstabilität, Demografie, Beschäftigungswirkungen und politischen Präferenzen gefangen, bleibt für Modernisierungskonzepte zur sozialen Sicherung auch die Verringerung der Leistungsausgaben bedeutsam. 80

Zwischen den unterschiedlichen Zielen gilt es, eine Wahlentscheidung zu treffen. Zudem wird immer häufiger die Forderung nach höherer Effizienz der Leistungserbringung und Qualitätssicherung der Dienstleistungen im Rahmen des Risikoschutzes erhoben. ${ }^{81}$ Der Wirtschaftlichkeitsanspruch aller Modernisierung setzt sich eben auch im Sozialsektor als „Ökonomisierung der sozialen Sicherung“ durch. Da selbst unter diesem Vorzeichen die Modernisierung im Sozialstaat weiterhin sozialer Gerechtigkeit und sozialer Gleichheit verpflichtet bleibt, wird die Wahlentscheidung nicht gerade leichter.

\section{2. „Pfadabhängige“ und „systemverändernde“ Modernisierungsentwürfe}

Die Auseinandersetzung mit den gesamten und verfassungsrechtlich begründeten Modernisierungszielen hat zu einer Reihe von Vorschlägen geführt, die entweder die herkömmlichen Sicherungssysteme weiterentwickeln oder aber an deren Stelle neue Gebäude der sozialen Sicherung setzen wollen. ${ }^{82}$ Für die „Systemveränderung“ stehen dabei die noch nicht endgültig ausgereiften Konzepte der „Bürgerversicherung“ einerseits, der „Pauschalprämie“ andererseits mit mancherlei Variationen. Auf einen Systemwechsel verzichten dagegen jene Modernisierungsentwürfe, die den Veränderungszwängen vor allem mit einem Wandel des Finanzierungssystems der sozialen Sicherung unter gleichzeitig stärkerer Hervorhebung der Individualverantwortung hierfür entsprechen wollen.

79 J. Wasem Finanzierungsprobleme und -rahmen der zukünftigen sozialen Krankenversicherung in Deutschland, in: Pitschas (Hrsg.) Finanzierungsprobleme der Gesundheitsreform und GKV-Modernisierungsgesetz, Speyerer Arbeitshefte Nr. 162, 2004, 5 (23ff., $28 \mathrm{f}$.).

${ }^{80} \mathrm{~S}$. wiederum am Beispiel der GKV C. F. Gethmann/W. Gerok/H. Helmchen/ K.-D. Henke/J. Mittelstraß/E. Schmidt-Aßmann/G. Stock/J. Taupitz/F. Thiele (Fn. 2), $190 \mathrm{ff} ., 199 \mathrm{ff}$.

81 C. F. Gethmann/W. Gerok/H. Helmchen/K.-D. Henke/J. Mittelstraß/E. Schmidt-Aßmann/G. Stock/J. Taupitz/F. Thiele (Fn. 2), $196 \mathrm{f}$.

${ }^{82} \mathrm{Zu}$ der Vielzahl unterschiedlicher Reformmodelle in der GKV und der gesetzlichen Rentenversicherung s. für die erstere S. Huster JZ 2002, $371 \mathrm{ff}$.; R. P. Schenke (Fn. 21), $478 \mathrm{ff}$; J. Wasem (Fn. 79), $22 \mathrm{ff}$.; für die letztere vgl. nur S. Heidel/B. Loose DAngVers 2004, 221 ff.; K. Hessert (Fn. 30), $144 \mathrm{ff} ., 150 \mathrm{ff} ., 154 \mathrm{ff}$. 
Dazu rechnen Vorschläge, in der GKV die Versicherungspflicht und/oder Beitragsbemessungsgrenze anzuheben bzw. die Beitragsbemessungsgrundlagen $\mathrm{zu}$ verbreitern. ${ }^{83}$ Insgesamt konkurrieren auf diese Weise pfadabhängige und „systemimmanente“ mit „systemsprengenden“ Modernisierungskonzepten.

\section{Soziale Sicherung in Privatrechtsformen}

Bei alledem wird die Rolle des Staates prekär: Die Veränderung vom konsumtiven Wohlfahrtsstaat zum aktivierenden Sozialstaat kann im Rahmen der Finanzierung und Leistungsbereitstellung durch öffentliche Systeme gestaltet werden; es kann jedoch auch zu einer Trennung dieser beiden Aufgabenbereiche und deren Aufteilung auf Staat und Privatsektor kommen. So führt z.B. ein Vertrag mit der Arbeitsverwaltung die Individualisierung der dem Arbeitsuchenden auferlegten Handlungspflichten herbei; er legt die Grundlage für dessen individuelle Handlungsverantwortung. Risikoprävention ist das Ziel dieser Vorgehensweise. ${ }^{84}$ Aus verwaltungsrechtlicher und -wissenschaftlicher Perspektive mutiert Arbeitsförderung dadurch zum Risikomanagement.

Entlässt aber der Neuzuschnitt des Sozialstaats die soziale Sicherung in ein (öffentlich-rechtliches) Vertragsprivatrecht, wie dies zu geringen Anteilen - dann aber durch zivilrechtliche Vertragsgestaltung - auch in der Rentenversicherung der Fall ist („Riester-Rente“), dann wandelt sich zugleich der Deutungsgehalt vertrauter sozialrechtlicher Institutionen. Rechtstaatlich-gleichheitsrechtlich relevante Grundtatbestände sozialer Sicherheit unterliegen nunmehr individual-privatrechtlicher Dispositionsfreiheit.85 Dementsprechend muss staatliche „Gewährleistungsaufsicht" um ihrer Funktion willen nunmehr selbst und aktiv die Renten- und Krankenversicherung bzw. die Arbeitsförderung lenkend regulieren - es sei denn, der Gesetzgeber greift ein und setzt, wie z.B. mit der Verpflichtung privater Versicherungsträger auf Unisex-Tarife, zwingendes Recht. ${ }^{86}$

\footnotetext{
${ }^{83}$ Dazu besonders S. Huster (Fn. 82), $372 \mathrm{f}$., $377 \mathrm{f}$.

84 So z.B. die Eingliederungsvereinbarung gemäß $§ 35$ Abs. 4 SGB III; vgl. näher noch B. Mutschler in: Wissing/ders./Bartz/Schmidt-De Caluwe (Hrsg.) Sozialgesetzbuch III Arbeitsförderung, 2. Aufl. 2004, § 35 Rn. 44f.; R. Pitschas FS 50 Jahre BSG, 2004, 765 (780).

85 So z. B. E. Eichenhofer VSSR 2004, 93 (110); undeutlich B. Mutschler(Fn. 84), Rn. 44: die Eingliederungsvereinbarung sei ein „vertragsähnliches Konstrukt“.

86 Vgl. E. Eichenhofer (Fn. 85), 112 f.
} 


\section{4. „Bürgerversicherung“ und „Gesundheitsprämie“}

Im Zentrum der aktuellen Entwürfe für die Neugestaltung der sozialen Sicherung stehen die alternativen Vorschläge einer „Bürgerversicherung“ und „Gesundheitsprämie“ im Bereich des Krankenversicherungsschutzes. ${ }^{87}$

Das Modell einer Gesundheits- bzw. Kopfprämie, auch „Pauschalprämie“ genannt, nimmt den Modernisierungsdruck auf und versucht, die beitragspflichtigen Einnahmen von der wirtschaftlichen Entwicklung abzukoppeln. Doch sieht es nicht den gegenteiligen Schritt vor, nämlich die Verbreiterung der Bemessungsgrundlagen. Statt dessen wird der Beitrag einkommensunabhängig pauschaliert. Er soll für alle (erwachsenen) Versicherten in gleicher Höhe erhoben werden. Die Versicherten müssten die Prämie aus ihren gesamten Einkünften finanzieren. Nach den Vorstellungen der sogenannten Rürup-Kommission soll die Pauschalprämie 190 Euro je Erwachsenen betragen. Von Arbeitgeberseite wird ergänzend eine Modellvariante ins Spiel gebracht, die bei reduziertem Leistungsumfang der gesetzlichen Krankenkassen mit einer monatlichen Pauschale von 163 Euro je Versicherten zu finanzieren wäre; Kinder würden beitragsfrei mitversichert. Die GKV soll für Erwachsene, die den Pauschalbetrag nicht zahlen können, einen Sozialausgleich aus Steuern erhalten. Das erinnert an das schweizerische Krankenversicherungs-Modell. ${ }^{88}$

Über den impliziten Wegfall des Arbeitgeberbeitrags führt der Vorschlag mittelfristig zu einer Senkung der Lohnnebenkosten, unterstellt, die Beitragssätze würden bei einkommensabhängigen Beiträgen steigen. Allerdings müssten bei Tarifverhandlungen die Tarifpartner „mitspielen“. Das Konzept ist jedoch unabhängig davon problematisch, weil für Geringverdiener steuerliche Transfers benötigt werden. ${ }^{89}$ Da ferner die Ausgabendynamik im Gesundheitswesen keine konstanten Prämien zulässt, müsste

87 S. zu beiden Konzepten Bundesministerium für Gesundheit und Soziale Sicherung (Hrsg.) Nachhaltigkeit in der Finanzierung der sozialen Sicherungssysteme. Bericht der Kommission, Typoskript, 2003; Bericht der Kommission „Soziale Sicherheit“ zur Reform der sozialen Sicherungssysteme („Herzog-Kommission“) Typoskript, 2004; aus der Literatur vgl. C. F. Gethmann/W. Gerok/H. Helmchen/K.-D. Henke/J. Mittelstraß/E. SchmidtAßmann/G. Stock/J. Taupitz/F. Thiele (Fn. 2), 207 ff.; K. Jacobs Gesundheit und Gesellschaft 2003, 42ff.; A. Mihm FAZ vom 14. Juli 2004, 10, A. Neubacher/M. Sauga DER SPIEGEL Nr. 30 vom 19. Juli 2004; C. C. v. Weizsäcker FAZ vom 29. Mai 2004, 13; PKV Publik 2004, 68ff.; das Bürgerversicherungs-Modell der sogenannten Nahles-Kommission ist in Auszügen abgedruckt in: Deutsches Ärzteblatt 2004, B $1983 \mathrm{f}$.

88 S. Spycher GGW 4 (2004), 19 (20ff.); zum Modell der Arbeitgeber s. FAZ vom 15. September 2004, 13.

${ }^{89} \mathrm{Vgl}$. C. F. Gethmann/W. Gerok/H. Helmchen/K.-D. Henke/J. Mittelstraß/E. SchmidtAßmann/G. Stock/J. Taupitz/F. Thiele (Fn. 2), 208; J. Wasem (Fn. 79), 26. 
häufig die Höhe der sozialen Ausgleichszahlungen verändert werden und das Parlament jeweils von Neuem darüber entscheiden. Insofern zeigt sich sehr eindrucksvoll, wie die Abgrenzung von Sozial- und Steuerstaat durch die Verschmelzung ihrer je unterschiedlichen Verselbständigung im Grundgesetz gefährdet wird. ${ }^{90}$ Darüber hinaus müssen Beiträge zur GKV an der wirtschaftlichen Leistungsfähigkeit der Versicherten orientiert sein. ${ }^{91}$ Besser Verdienende und damit leistungsfähigere Versicherte sind deshalb durch höhere Beiträge für den Versicherungsschutz der weniger gut verdienenden Erwerbspersonen und damit weniger Leistungsfähigen heranzuziehen. ${ }^{92}$ Es scheint demgegenüber, als ob das Modell der Gesundheitsprämie das Prinzip der Beitragsbemessung nach der wirtschaftlichen Leistungsfähigkeit vernachlässigen würde. Um dieser Gefahr zu entgehen, wird zu Recht unter Modifizierung des Modells über eine Staffelung der Gesundheitsprämie nach Leistungsfähigkeit („StufenprämienModell“") nachgedacht. ${ }^{93}$

Anders ist dagegen die „Bürgerversicherung“ konstruiert. Sie strebt nach Ausbau der GKV zu einer „Volksversicherung“ mit Verbreiterung der Beitragsbemessungsgrundlagen, was auch auf andere Sozialversicherungszweige „abfärben“ könnte, z.B. auf die Rentenversicherung. Tendenziell werden die Beiträge vom Erwerbseinkommen abgekoppelt. ${ }^{94}$ Nach dem „Modell einer solidarischen Bürgerversicherung“, dass inzwischen vorgelegt wurde, ${ }^{95}$ kann sich jeder entweder bei einer gesetzlichen Krankenkasse oder einem privaten Krankenversicherungsunternehmen für den sogenannten Bürgerversicherungstarif entscheiden. Dieser muss folgende Mindestanforderungen erfüllen: Einkommensbezogene Beiträge, Kontrahierungszwang, einheitlicher Leistungskatalog, Sachleistungsprinzip, Einbezug der Versicherten in einen morbiditätsorientierten Risikostrukturausgleich. Wer bislang privat versichert ist, kann seinen Vertrag behalten oder in einen Bürgerversicherungstarif seiner Wahl wechseln. Wer gesetzlich krankenversichert ist, kann zwischen privaten und gesetzlichen Anbietern wählen. Wer sich neu krankenversichern muss, kann sich nun auch für einen Bürgerversicherungstarif entschei-

\footnotetext{
90 Dazu aus grundsätzlicher Perspektive W. Heun FS Selmer, 2004, 657 (668, 670); F. Kirchhof NZS 1999, $161 \mathrm{ff}$.

91 BVerfGE 44, 70 (90); 92, 53 (69ff., 79); 102, 68 (89).

92 So auch $J$. Wieland VSSR 2003, 259 (274f.); aA F. Kirchhof (Fn. 90), 166f.

${ }_{93}$ Dazu der Bericht von A. Mihm (Fn. 87), 10.

94 Vgl. A. Mihm (Fn. 87), 10.

95 Modell einer solidarischen Bürgerversicherung. Bericht der Projektgruppe Bürgerversicherung des SPD-Parteivorstandes, vvM., 2004, auszugsweise abgedruckt in: Deutsches Ärzteblatt 2004, B 1983 f.
} 
den. Familienmitglieder ohne eigenes Einkommen und Kinder werden beitragsfrei mitversichert. ${ }^{96}$

Auf Dauer führen beide Modelle den Krankenversicherungsschutz auf eine Grundsicherung zurück. Verändert wird auch das bisherige Verhältnis von GKV und privater Krankenversicherung (PKV) im Sinne eines Unternehmenswettbewerbs. ${ }^{97}$ Für alle Versicherten soll es aber das gleiche gesetzlich normierte Leistungspaket zu gleichen Bedingungen und gleichen Preisen geben. Im Übrigen ermöglicht die Bürgerversicherung mehr Gerechtigkeit bei der Beitragsgestaltung, aber jedenfalls keine Entlastung bei den Lohnkosten. Sie verfehlt somit ein wesentliches Modernisierungsziel. Überdies kommt es zur Kollision mit der Berufsfreiheit der Privatversicherer und der besonderen Rechtfertigungslast des Bürgerversicherungstarifs im Steuerstaat. Unklar ist ferner der Rechtsstatus von Alt-Anwartschaften der Versicherten. Dagegen führt die Gesundheitsprämie zwar zur Abkoppelung der Lohnkosten von den Sozialversicherungsbeiträgen, vermag aber kaum größere Beitragsgerechtigkeit zu bewirken. So oder so tragen beide Modelle zum Übergang in eine rechtlich zulässige, umlagegesteuerte und beitragsfinanzierte Grund- sowie kapitalgedeckte und durch Risikoprämien finanzierte Ergänzungssicherung bei. Die Rentenversicherung dürfte sich im „europäisierten“ Sozialstaat dem anschließen. ${ }^{98}$

\section{Verfassungs- und europarechtlicher Rahmen für Modernisierungsentscheidungen}

\section{Modernisierung im Gehäuse des Rechts}

Dem (Verfassungs-)Recht kommt in diesem Zusammenhang die Funktion zu, die Ziele künftiger Modernisierung sozialer Sicherungssysteme zu präzisieren und der Entwicklung von Konzeptionen einen verbindlichen Rahmen zu setzen. Es hält zu diesem Zweck ebenso rechtliche Strukturvorgaben bereit („Bereitstellungsfunktion des Rechts“), wie es auch die Modernisierungsgehalte und -prozesse selbst zu steuern vermag (,Steue-

\footnotetext{
96 Modell einer solidarischen Bürgerversicherung (Fn. 95).

97 Anders allerdings die Stellungnahme der PKV in PKV Publik 2004, 76: Das Modell der Bürgerversicherung versuche, „die private Krankenversicherung formal beizubehalten, sie aber inhaltlich abzuschaffen".

${ }^{98}$ Ich beziehe mich hierbei auf W. Schmähl (Fn. 29), 358, 360, 366; zur Entwicklung der GKV im Sinne einer „Grundsicherung für alle mit individuellen Wahl- und Wechselmöglichkeiten“" s. nur C. F. Gethmann/W. Gerok/H. Helmchen/K.-D. Henke/J. Mittelstraß/E. Schmidt-Aßmann/G. Stock/J. Taupitz/F. Thiele (Fn. 2), 208f.; zuvor bereits R. Pitschas (Fn. 73), 91.
} 
rungsfunktion des Rechts"). ${ }^{99}$ Zugleich wird Grundrechtsschutz unter den Bedingungen komplexer Strukturen ${ }^{100}$ ausgeprägt. Das Gemeinschaftsrecht überformt diese Gestaltungskraft nationalen Freiheits- und Gleichheitsschutzes. ${ }^{101}$

\section{Die Verfassung als Leitbild und Rahmenordnung}

Der Modernisierungsgesetzgeber verfügt bei der Modellauswahl über einen weiten Experimentierspielraum, um das magische Vieleck aus Eigenverantwortung und Solidarität, individueller Wahlfreiheit und Gemeinwohlbindung, Wettbewerb und sozialer Gerechtigkeit in ein zukunftsoffenes Arrangement sozialer Sicherheit zu übertragen. Freilich fällt die rechtliche Verortung der sozialen Sicherungssysteme nicht eben leicht. Das Grundgesetz schützt die Sicherungssysteme nicht gesondert und spezifisch. ${ }^{102}$ Es legt die Gesetzgebungskompetenzen in speziellen Titeln und Hinweisen im Organisationsrecht fest, doch fehlen „einfache Regelungen für einfache Antworten“. Es gilt sonach, verfassungsrechtliche Verbürgungen aufzuspüren, die im Geflecht der Kranken- und Rentenversicherung sowie bei der Grundsicherung für Arbeitsuchende bzw. in der Arbeitsförderung wirksam werden. Dabei kommen als Grundrechte neben dem Gleichheitssatz vor allem die Art. 2 Abs. 1 und 2, 6 Abs. 1 und 2, 12 Abs. 1 und 14 GG in Betracht. Daneben treten verfassungsrechtliche Systemaussagen. ${ }^{103}$ In jedem Fall erweist sich der Modernisierungsprozess als eine Bewährungsprobe für das dem Gesetzgeber verfassungsrechtlich eingeräumte Optionenermessen.104

${ }^{99} \mathrm{Zu}$ diesen Funktionen des Rechts s. statt anderer G. F. Schuppert Verwaltungswissenschaft, 2000, $480 \mathrm{ff}$, $507 \mathrm{ff}$., $976 \mathrm{f}$.

100 Vgl. C. F. Gethmann/W. Gerok/H. Helmchen/K.-D. Henke/J. Mittelstraß/E. SchmidtAßmann/G. Stock/J. Taupitz/F. Thiele (Fn. 2), 151, mit Blick auf das Gesundheitssystem.

101 R. Pitschas Gesundheitswesen zwischen Staat und Markt. Rechtliche Maßgaben und Grenzen einer Verantwortungsteilung für Gesundheitsversorgung zwischen Bürger, Markt und Staat, in: Häfner (Hrsg.) Gesundheit - unser höchstes Gut?, 1999, 169 (171 ff., 182f., 189, 194).

102 Am Beispiel der GKV s. R. Jaeger (Fn. 9), 15f.; E. Schmidt-Aßmann NJW 2004, $1689 \mathrm{ff}$; zur „Sozialversicherung“ allgemein zutreffend H. Reiter FS Klein, 1994, 1101 (1103).

${ }^{103}$ H.-J. Papier (Fn. 20), Rn. 62, 93 ff.; R. Scholz/R. Pitschas (Fn. 21), 639ff. („Sozialverfassung“).

${ }^{104} \mathrm{Zu}$ dieser ursprünglich für den Verwaltungsvollzug im Umweltrecht eingeführten Ermessensform s. W. Hoffmann-Riem DVB1. 1994, 605 ff.; sie trifft für den Bereich des Sozialverfassungsrechts die Wahlsituation des Gesetzgebers ebenso punktgenau. 


\section{Verfassungsschutz gegen Systemwechsel?}

Soweit Modellüberlegungen den bisherigen Entwicklungspfad eines Sicherungssystems verlassen und einen Systemwechsel intendieren, stellt sich die Frage nach der Möglichkeit, hiergegen vorzugehen. Das Grundgesetz gibt dazu keine klare Antwort. Berufs- und Eigentumsschutz durch Grundrechte helfen wegen der Dignität der eingriffslegitimierenden Gemeinwohlgüter nicht. ${ }^{105}$ Immerhin hält das BVerfG ausdrücklich fest, dass z.B. die Rentenversicherung „als das Grundsystem sozialer Sicherung“106 keinen verfassungsrechtlichen Systemschutz genieße, sondern vom Gesetzgeber auf andere Grundlagen gestellt werden könnte. ${ }^{107}$ In der $G K V$ lässt das Gericht den Übergang zu einer Einheitsversicherung durch gesetzgeberische Regelung zu. ${ }^{108}$

Die parlamentarische Neuordnung der sozialen Sicherung wird mit anderen Worten als solche nicht an die Kette gelegt; der Gesetzgeber darf unter anders nicht behebbaren Modernisierungszwängen ein einzelnes Sicherungssystem umgestalten. ${ }^{109}$ Er muss dafür allerdings zureichende Gründe angeben und die gewählten Gestaltungsoptionen müssen grundrechtsfest sowie erforderlich und geeignet sein; ferner darf die Umstellung nicht mit unverhältnismäßigen Einbußen für Versicherte und Dritte, wie z.B. die PKV, einhergehen.110

Im Übrigen legt die Verfassungsrechtsprechung der Optionenwahl keinen eigenständigen Prüfungsmaßstab der „Systemgerechtigkeit“ zugrunde. ${ }^{111}$ Sofern Rechtsänderungen zu Lasten der Versicherten gehen, verweist das BVerfG einerseits auf den Grundrechtsschutz und in Ansehung des Rechtstaatsprinzips in Verbindung mit der „Maßstabsreserve“

105 Vgl. etwa BVerfGE 82, 209 (229ff.), zum überragenden Gemeinwohlbelang der Krankenhauspflege. Gleichwohl wird für die GKV ein „schleichender Freiheitsverlust“ beklagt, der nicht zum Thema gemacht werde, vgl. E. Schmidt-Aßmann (Fn. 102), 1690. Daran ist manches richtig, s. nur F. Hufen NJW 2004, $14 \mathrm{ff}$.

106 BVerfGE 98, 1 (16).

107 BVerfGE 100, 1 (39).

108 BVerfGE 39, 302 (377); 77, 340 (344); 89, 365 (377); kritisch zu diesem Prinzip der verfassungsrechtlich eingeräumten Freiheit der Organisationswahl s. R. Pitschas Gesundheitsstrukturreform - Einheitsversicherung oder Trägervielfalt?, Bitburger Gespräche 31 (1996), 15 (26ff.).

109 BVerfGE 85, 238 (347); zutreffend stellt daher H.-J. Papier(Fn. 20), Rn. 94, fest, dass jegliches „Systemwahrungsgebot“ an Stringenz verloren habe. In diese Richtung auch R. Jaeger NZS 2003, 225 (227).

110 BVerfGE 100, 1 (37).

111 BVerfGE 62, 354 (360ff.); U. Becker FS 50 Jahre BSG, 2004, 77 (86ff., $90 \mathrm{ff}$.$) ;$ H.-J. Papier (Fn. 20), Rn. 93; R. Prokisch FS Vogel, 2000, 293 (294), unter Hinweis auf BVerfGE 60, 16 (43). 
des Art. 2 Abs. $1 \mathrm{GG}^{112}$ auf den Gesichtspunkt des Vertrauensschutzes. ${ }^{113}$ Darüber hinaus setzt das Sozialstaatsprinzip, dass der ausschließlichen Marktgängigkeit sozialer Sicherung trotz seiner Distanzierung gegenüber dem Wohlfahrtsstaat widerstrebt, der umfänglichen Überführung sozialer Sicherung in die Privatautonomie Grenzen. ${ }^{114}$ Hinzu tritt andererseits die dem grundrechtlichen Schutz der sozialen Gleichheit innewohnende Verpflichtung des Gesetzgebers zur Systemgerechtigkeit seiner rechtlichen Steuerung im Sinne einer Rechtsetzungsgleichheit. ${ }^{115}$ Insoweit geht es um die Sachgerechtigkeit von Grenzziehungen auch bei Systemwechsel. ${ }^{116}$

\section{Vertrauensschutz als „Maßstabsreserve“}

Die dem sozialversicherten Bürger auferlegten Lasten von Modernisierungsentscheidungen sind schließlich mit Blick auf das Verfassungsprinzip der (sozialen) Sicherheit und den daraus mit erfließenden grundgesetzlichen Schutz des Vertrauens in den Fortbestand der in Gesetzesform zugesagten Sozialleistungen zu würdigen. Denn die Versicherten haben üblicherweise Dispositionen mit langfristigen Festlegungen getroffen und dabei in besonderem Maße auf den Fortbestand der Rechtslage vertraut.

Für den Schutz dieser Ansprüche besteht ein System des abgestuften Vertrauensschutzes. Vor allem dem Verfassungsprinzip „Sicherheit“ ersprießt ein strukturwirksames Vertrauensschutzgebot, dass die allgemeine Verpflichtung des Gesetzgebers zur vorrangigen Wahrung von Systemkontinuität bei Modernisierungsentscheidungen enthält. Es handelt sich insoweit um einen verfassungsspezifischen Systemvertrauensschutz: Der Gesetzgeber unterliegt dem Verbot, gewachsene soziale Sicherungssysteme schlagartig zu ändern (,Verbot des überraschenden Systemwechsels“). Darüber hinaus trifft ihn eine verfassungsrechtliche Kontinuitätsverpflichtung bei der Modernisierung der Sozialversicherung. ${ }^{117}$

112 Begriff bei $U$. Steiner Vertrauensschutz als Verfassungsgrundsatz, in: Henke (Hrsg.) Vertrauensschutz in der Europäischen Union, 1997, 31 (33).

${ }_{113}$ Zum rechtsstaatlichen Vertrauensschutz s. zuletzt BVerfGE 102, 68 (96ff.).

114 R. Jaeger (Fn. 9), $21 \mathrm{f}$.

115 Dazu näher M. Sachs VSSR 1994, 33 ff.; P. M. Huber VSSR 2000, 369 (394); den möglichen Übergang zu einer „neuen Systemgerechtigkeit“ diskutiert am Beispiel der Pflegeversicherung J. Haas KJ 2002, $104 \mathrm{ff}$.

116 U. Becker (Fn. 111), 88, 89.

117 Ähnlich BVerfGE 102, 68 (97): Der Bürger darf „auf die Kontinuität einer Regelung“ vertrauen, ,auf Grund deren altes Recht noch für eine bestimmte Zeit ... aufrechterhalten wird“, s. ferner mwN F. Ruland GS Heinze, 2005, 731 (738ff.). Im hiesigen Kontext meint „Kontinuität“ darüber hinaus die möglichst weitreichende Anknüpfung an bisherige Systemstrukturen im Fall des Systemwechsels. 
Im Übrigen gilt: Vertrauensschutz gibt es nur innerhalb des Systems. ${ }^{118}$ Versicherte oder Dritte sind insofern auf den allgemeinen rechtsstaatlichen Vertrauensschutz verwiesen, der sich aus Art. 2 Abs. 1 GG in Verbindung mit dem Rechtstaatsprinzip herleitet.

Schließlich hat der Grundsatz des Vertrauensschutzes zunehmend in den thematisch betroffenen Grundrechten und vor allem in denen aus Art. 14 und 12 GG eine eigene und spezielle Ausprägung erfahren. In diesem Sinne ist auch der Sozialversicherungsbeitrag kein grundrechtsfreier Raum. ${ }^{119}$

\section{Sozialversicherung als „Volksversicherung“}

Der von Verfassungs wegen im Sozialstaat gegebene Vorrang individueller Vorsorge durch Versicherung und Vermögensbildung, z.B. im Wege der Privatversicherung oder auf andere Weise stellt die Grenzen der Solidarität zur Diskussion. Nicht ohne Weiteres scheint der weitere Ausbau der sozialen Sicherung in Gestalt einer „Bürgerversicherung“ zulässig. Allerdings ermöglichen der Kompetenztitel der „Sozialversicherung“ (Art. 74 Abs. 1 Nr. 12 GG) und diese als ein weitgefasster verfassungsrechtlicher Gattungsbegriff die Einrichtung einer „Volksversicherung“ auch unter Zwangsmitgliedschaft. Dem Kompetenztitel können neue Lebenssachverhalte unterfallen, die den traditionellen Rahmen der Sozialversicherung sprengen. ${ }^{120}$ Es muss sich allerdings um einen ,schutzfähigen Bedarf" handeln. Dieser wäre sowohl mit der angestrebten Stabilisierung der GKV als überragender Gemeinwohlbelang ${ }^{121}$ als auch mit der Grundsicherung für Arbeitsuchende als Schutzgut zu bejahen. Zudem muss sich „Sozialversicherung“ nicht auf Arbeitnehmer und auf die Sicherung gegen Notlagen begrenzen. Dann aber erscheint es vertretbar, gerade um der individuellen Freiheit aller willen neue Solidaritätszusammenhänge zu stiften bzw. gegebene umzuformen. ${ }^{122}$

118 Ähnlich E. Schmidt-Aßmann (Fn. 102), 1689: „Die verfassungsrechtliche Prüfung bewegt sich innerhalb des Systems“; ebenso R. Jaeger (Fn. 9), 29, zum Vertrauensschutz.

119 So zutreffend H. Butzer (Fn. 39), 320ff.; C. F. Gethmann/W. Gerok/H. Helmchen/ K.-D. Henke/J. Mittelstraß/E. Schmidt-Aßmann/G. Stock/J. Taupitz/F. Thiele (Fn. 2), 162 mwN.

120 Ebenso R. Jaeger (Fn. 109), 232; H.-J. Papier (Fn. 20), Rn. 12.

121 BVerfGE 103, 172 (184f.); U. Steiner MedR 2003, 1 (6).

122 K.-J. Bieback (Fn. 6), 41; U. Steiner SchlHA 2004, 85 (86 mit Fn. 6), sieht die verfassungsrechtliche Beurteilung als nicht präjudiziert an; strikt dagegen N. Brall/H.-J. Voges Modell Bürgerversicherung - Verfassungsrechtliche und europarechtliche Fragen, 2005, passim; F. Kirchhof NZS 2004, 1ff.; J. Isensee NZS 2004, 393 (396); R. Scholz 
Die gesetzgeberische Kompetenzinanspruchnahme vermag allerdings nicht die Freiheitsordnung des Grundgesetzes außer Kraft zu setzen: Verteilungsgerechtigkeit bleibt selbst in der Sozialversicherung ein Problem des Grundrechtschutzes. ${ }^{123}$ Dieser tritt ebenso Dritten zur Seite, die außerhalb eines Sozialrechtsverhältnisses stehen. So würde die Ausdehnung der gesetzlichen Krankenversicherungspflicht auf alle Staatsbürger ein Verwaltungsmonopol errichten, das in seinen tatsächlichen Folgen einem Eingriff in die Berufswahl der PKV-Unternehmen gleichkäme.124 Dennoch ließen sich Modernisierungszwänge vorstellen, die eine solche Entwicklung und damit eine „Bürgerversicherung“ legitimieren könnten. Dessen ungeachtet bleibt das Verhältnis der GKV zur PKV sowohl unter verfassungsrechtlichen wie unter gemeinschaftsrechtlichen Gesichtspunkten der Angelpunkt einer künftigen Lösung. Diese liegt im Übergang zu einer Grundversorgung mit zusätzlicher Eigenvorsorge - wie in der Alterssicherung. ${ }^{125}$ Zukunftsentscheidungen über die soziale Sicherung in diesem Sinne berücksichtigen die freiheitsstiftende Kraft der $\mathrm{ko}$ operativen Versicherungsverfassung unter dem Grundgesetz und in europäischer Perspektive. ${ }^{126}$

Deutschland - in guter Verfassung?, 2004, $198 \mathrm{ff}$; H. Sodan ZRP 2004, 217 ff. - jeweils mit zahlreichen Nachworten.

123 Denn die Sozialversicherung ist kein Instrument der Verteilungspolitik, vgl. S. Huster (Fn. 82), 377.

124 Vgl. auch J. Isensee (Fn. 122), 400 f.; E. Schmidt-Aßmann (Fn. 102), 1694, jeweils mwN.

125 S. dazu die Nachweise in Fn. 98 sowie R. Pitschas VSSR 1998, 253 (256ff., 259f.); E. Schmidt-Aßmann (Fn. 102), $1694 \mathrm{f}$.

126 Zur „kooperativen Versicherungsverfassung“ s. besonders $R$. Scholz FS Sieg, 1976, 507 (523ff.); vgl. zum europäischen Einfluss insoweit nur B. v. Maydell VSSR 1999, $1 \mathrm{ff}$;; F. Ruland (Fn. 117), $743 \mathrm{ff}$. 
Leitsätze des 1. Berichterstatters über:

\section{Die Zukunft der sozialen Sicherungssysteme}

\section{Sicherheit durch soziale Sicherung}

(1) Dem Grundgesetz ist der soziale Risikoschutz durch institutionalisierte soziale Vorsorge in Gestalt der Sozialversicherung, von Entschädigungs- sowie Hilfs- und Förderungssystemen selbstverständlich. Sie alle gewährleisten in typisierten Bedarfssituationen durch die subjektiv berechtigende normative $\mathrm{Zu}$ sage von Sozialleistungen soziale Sicherheit. Hierdurch wird zugleich Solidarität organisiert.

(2) Das Sozialstaatsprinzip übernimmt eine wesentliche nationalstaatliche Steuerungsfunktion für die solidarische Sicherheitsvorsorge und insbesondere die mediatisierende Sozialversicherung. Mit dieser Funktion steht es in einem europäischen Verfassungsverbund aus den mitgliedstaatlichen Verfassungen, dem Unionsvertrag und dem Verfassungsentwurf des Europäischen Konvents. Aus der dadurch konstituierten „europäisierten “ Sozialordnung schält sich soziale Sicherheit als gemeinsames Zukunftsprojekt des werdenden europäischen Sozialstaats heraus.

(3) Grund und Grenze des Sozialstaats europäischer und nationaler Dimension setzt das Freiheitsprinzip. Auch in Zukunft gewährleistet daher unter dem Grundgesetz die Garantie der freien Entfaltung der Persönlichkeit die Pflicht und Befugnis des Bürgers, eigenständig für soziale Sicherheit zu sorgen. In objektiv-rechtlicher Wendung entspricht dem bis zu einem gewissen Ausmaß die Verpflichtung zu individueller Vorsorge durch Versicherung und Vermögensbildung.

Der in diesem Sinne subsidiäre bzw. "freiheitliche“ Sozialstaat unterliegt der Absage an öffentlich-rechtliche Monopolbildung in der sozialen Sicherung zugunsten ihrer Aufgliederung in staatliche Grund- und private Ergänzungssicherung. Anderes gilt jedoch in den Fällen, in denen Bürgern die Eigenvorsorge unmöglich ist. Dann gebietet Sozialstaatlichkeit im Verbund mit dem Freiheitsprinzip staatlichen Mindestschutz.

(4) In der sozialen Sicherung wird der Staat als kordiales Gemeinwesen angesehen, auf das der Sozialbürger für den Bestand und Schutz seiner Ansprüche auf soziale Sicherung vertraut und vertrauen darf. Das Verfassungsprinzip „Sicherheit“ schützt sowohl dieses Systemvertrauen als auch die indi- 
viduellen Erwartungen in die Sicherheit der sozialen Sicherung. Das Grundgesetz erteilt in der Folge dessen dem Gesetzgeber einen Auftrag zur Vertrauensstabilisierung: Abrupte Systemwechsel scheiden aus dem Instrumentarium der Zukunftssicherung gegenüber sozialen Risiken aus. Wird dieser Auftrag verfehlt, offenbart sich enttäuschtes Sozialvertrauen als Legitimationsproblem.

(5) Das Verfassungsprinzip „Sicherheit“ setzt einem beliebig flexiblen Sozialschutz durch den Staat Grenzen, ohne ein „soziales Rückschrittsverbot “ in der Verfassung zu verankern. Innerhalb der Grenzen schlägt sich die staatliche Verpflichtung zur Gewährleistung erworbener sozialer Sicherungsansprüche als relationaler Staatszweck der Vertrauensstabilisierung in einem strukturellen Abwägungsspielraum für den Gesetzgeber nieder. In jedem Fall erzwingt das Verfassungsprinzip „Sicherheit“ die „weiche“ Systemmodernisierung.

\section{Herkunft und Entwicklungslinien der sozialen Sicherungssysteme}

(6) Erkennbar ist damit einerseits die Dynamik, der die Entwicklung sozialer Sicherung in der Austarierung von sozialer Eigenverantwortung, wohlfahrtsstaatlicher Vorsorge und Vertrauensschutz unterliegt. Zugleich und andererseits wohnt aller Modernisierung sozialer Sicherung eine erhebliche Legitimationsproblematik inne. Deshalb gibt es keine Zukunftsgestaltung der sozialen Sicherungssysteme ohne verfassungsrechtliches Risiko.

Beides lässt sich aus der Herkunft und den Entwicklungslinien der sozialen Sicherung seit dem Eintritt des Staates in die Verantwortung für sozialen Risikoschutz mit der Bismarck'schen Sozialversicherungsgesetzgebung lernen. Mit ihr trat erstmals ein relativ geschlossenes Prinzip sozialer Sicherung auf den Plan. Dadurch wurde die Grundrichtung eines neuen „Pfades“ vorgegeben, der sich in der Sozialversicherung von Anfang an vornehmlich an den spezifischen sozialen Risiken der Industriearbeiterschaft orientierte.

(7) Diese Grundausrichtung fußte auf den zentralen Strukturmerkmalen der Sozialversicherung als öffentlich-rechtlicher Pflichtversicherung auf der Grundlage von Selbstverwaltung mit staatlicher Aufsicht, die durch paritätische Beiträge von Arbeitern und Arbeitgebern gemeinsam finanziert und - in der Rentenversicherung - durch einen Staatszuschuss gestützt wurde. Ein spezifisches Verwaltungsverfahren diente der Anspruchsdurchsetzung. Alle diese Kriterien prägen die Sozialversicherung noch heute; nur die Pflegeversicherung ist anderen Zuschnitts. Gleichwohl lässt sich der mehr als hundertjährigen Entwicklungsgeschichte der sozialen Sicherungssysteme eine prozess- und strukturbetonte Veränderungsdynamik, mitunter sogar - wie in der gesetzlichen Rentenversicherung - eine radikale Systemveränderung entnehmen. 
Soziale Sicherung entwickelte sich somit zwischen Reformkontinuität und systemischen Veränderungsschritten. Nicht zum Tragen gekommene Alternativen standen immer wieder zur Verfügung und sie werden heute, wie der Gedanke einer teilweise steuerfinanzierten Staatsbürgervorsorge erweist, neu diskutiert.

(8) Erweiterungstendenzen der Sozialversicherung im ausgehenden 20.Jahrhundert verweisen auf die Aktualität und Verfassungsverträglichkeit einer Volks- bzw. Staatsbürgerversicherung. Zugleich zeigt sich, dass deren Finanzierung nicht allein am Erwerbseinkommen anknüpfen muss. Auch dann noch liegt eine „Sozialversicherung“ vor.

(9) Die späten Entwicklungsphasen der Sicherungssysteme im 20. Jahrhundert sind ungeachtet aller Kritik am Wohlfahrtsstaat und trotz der Beschwörung staatlicher Distanzierung davon tendenziell durch fortgesetzte Ausweitung des sozialen Risikoschutzes gekennzeichnet. Das eingeführte Ziel der Effizienzsteigerung wurde durch vielfachen „Anbau“ weiterer Regelungskomplexe an jeweils bestehende Sicherungssysteme konterkariert.

(10) Erst die aktuellen Modernisierungsansätze sozialer Sicherung im 21. Jahrhundert legen in Verfolg der sogenannten Agenda 2010 den Grundstein für eine neue Architektur der sozialen Sicherung im Sinne der Stärkung individueller Eigenverantwortung hierfür. Namentlich der Grundsatz des „Förderns und Forderns“ setzt sich auf dem Arbeitsmarkt als Prinzip des freiheitlichen Sozialstaats durch.

\section{Strukturelle Fehlentwicklungen und Veränderungszwänge}

(11) Die Modernisierungsansätze reagieren programmatisch auf die krisenhafte Entwicklung in der Sozialversicherung. Doch steuern sie noch nicht hinreichend den strukturellen Fehlentwicklungen der sozialen Sicherung in Deutschland entgegen. Vor allem wird dem gemeinschaftsrechtlich fundierten Wechselbezug von Sozial- und Marktwirtschaftspolitik nicht genügend Rechnung getragen: Die Sozialversicherungsmonopole werden aufrecht erhalten, obwohl zumindest für den Gesundheitsmarkt die wettbewerbliche Verfassung der Europäischen Union sowohl ambulant wie stationär eine Deregulierung fordert. Noch stärker zu öffnen ist auch der ungehinderte Zugang des Unionsbürgers zu den mitgliedstaatlichen Gesundheitsangeboten.

(12) Die strukturellen Fehlentwicklungen machen es schwierig, die sozialen Sicherungssysteme an die „Globalisierung“ der Wirtschaft sowie an den Strukturwandel des Alters anzupassen. Mit der Ersteren ist anhaltende strukturelle Arbeitslosigkeit verbunden, so dass die Beiträge zur Sozialversicherung künftig von den Erwerbseinkommen abgekoppelt und an der unternehmerischen Wertschöpfung orientiert werden müssen. Die Letztere lässt in der Ren- 
tenversicherung den „Generationenvertrag“ und in der Krankenversicherung die Bedarfsplanung für Vertragsärzte obsolet werden. Auch die weitere Senkung des Rentenniveaus ist unvermeidlich. Auf dem Arbeitsmarkt ist eine Politik der Verlängerung der Lebensarbeitszeit erforderlich.

\section{Auf dem Weg zu einer neuen Architektur der sozialen Sicherung}

(13) Inzwischen vorgelegte „neue“ Konzepte zur Zukunft der sozialen Sicherung nehmen die voraufgehend skizzierten Rationalitätsbindungen auf. Dabei unterscheiden sich „pfadabhängige“ von „systemverändernden“ Modernisierungsentwürfen. Darüber hinaus wird die Rolle des Staates prekär: Im Neuzuschnitt der sozialen Sicherung unterliegen rechtsstaatlich-gleichheitsrechtlich verankerte Sicherungskomplexe als öffentliche Güter immer stärker individual-privatrechtlicher Disposition. Tendenziell lässt diese Entwicklung eine Renaissance der Privatautonomie in der sozialen Sicherung erkennen.

(14) Im Vordergrund aller Zukunftsüberlegungen stehen derzeit die Modelle einer „Gesundheitsprämie“ („Kopf“- bzw. „Pauschalprämie“) und der „Bürgerversicherung“. Beide nehmen Anleihen bei dem Schweizerischen Krankenversicherungsgesetz auf. Doch verfehlt die „Pauschalprämie“ ihre Finanzierbarkeit und den sozialstaatlichen Grundsatz der Beitragsgerechtigkeit. Die „Bürgerversicherung “ erreicht ihrerseits keine Entlastung der Lohnkosten; sie kollidiert zudem mit der Berufsfreiheit der privaten Versicherer und der besonderen Rechtfertigungslast des Bürgerversicherungstarifs im Steuerstaat. In Zweifel zu ziehen ist auch die Validität erworbener Anwartschaften Versicherter mit Blick auf Art. 14 GG. Verfassungsrechtlich gesehen, sind beide Modelle teilweise ungeeignet, die Sozialversicherung der Zukunft zu begründen.

(15) Auf Dauer bewirken sie im Übrigen die Aufspaltung der sozialen Sicherung in eine umlagegesteuerte und beitragsfinanzierte Grund-sowie kapitalgedeckte und prämien- bzw. risikofinanzierte Ergänzungssicherung. Die gesetzliche Rentenversicherung hat diesen Weg bereits eingeschlagen.

\section{Verfassungs- und europarechtlicher Rahmen für Modernisierungsentscheidungen}

(16) Die Modernisierung der sozialen Sicherungssysteme ist nicht zuletzt eine Frage des (Verfassungs-)Rechts. Es hält entsprechende Strukturvorgaben als Rahmenordnung bereit, steuert die Modernisierungsprozesse und gewährt Grundrechtsschutz in komplexen Strukturen. Das Gemeinschaftsrecht überformt diese nationalen Einflüsse des Rechts. Es erzwingt die weitere Öffnung 
des Zugangs der Unionsbürger zu den nationalen Sicherungssystemen. Die notwendige Systemkonvergenz wird durch „offene Koordination “ erreicht.

(17) Im Vieleck der Modernisierungsziele von Eigenverantwortung und Solidarität, Wettbewerb und Gemeinwohlbindung, individueller Wahlfreiheit und sozialer bzw. Generationengerechtigkeit verfügt der Sozialgesetzgeber über einen erheblichen Experimentierspielraum und ein weites Optionenermessen. Grenzen zieht der gestufte verfassungsrechtliche Vertrauensschutz aller privaten Verantwortungsinvestitionen.

(18) Kein soziales Sicherungssystem genießt freilich absoluten verfassungsrechtlichen Systemschutz. Soweit Rechtsänderungen zu Lasten einzelner Versicherter oder Dritter gehen, verweist deshalb das BVerfG zu Recht auf den Grundrechtsschutz, namentlich durch Art. 14 GG, sowie in Ansehung des Rechtsstaatsprinzips und der „Maßstabsreserve“ (Steiner) des Art. 2 Abs. 1 GG auf den Gesichtspunkt des Vertrauensschutzes. Dieser ist allerdings auch aus Art. 12 Abs. 1 GG ableitbar. Strukturell setzt das Sozialstaatsprinzip einer ausschließlichen Marktorganisation sozialer Sicherung ebenso Grenzen wie die soziale Gleichheit für die Sachgerechtigkeit von Systemänderungen streitet.

Vor allem aber erfließt dem Verfassungsprinzip „Sicherheit“ das an den Gesetzgeber gewendete Gebot, den Vorrang der Systemkontinuität zu beachten. Es handelt sich um einen spezifischen Systemvertrauensschutz. Die soziale Sicherung der Zukunft wird sich deshalb vornehmlich in der Logik der bisherigen Sozialversicherung entwickeln.

(19) Im Übrigen gilt: Vertrauensschutz gibt es vor allem im System. Versicherte oder Dritte sind insofern auf den allgemeinen rechtsstaatlichen Vertrauensschutz verwiesen, der solche Systemänderungen betrifft, bei denen insbesondere rechtliche Anwartschaften gekürzt oder aufgehoben werden sollen. Auch die Ausweitung des Sozialversicherungsbeitrags steht nicht in einem grundrechtsfreien Raum.

(20) Der Kompetenztitel der „Sozialversicherung“ (Art. 74 Abs. 1 Nr. 12 $G G)$ ermöglicht als ein weitgefasster verfassungsrechtlicher Gattungsbegriff die Errichtung einer „Volksversicherung“ mit Zwangsmitgliedschaft. Doch vermag die gesetzgeberische Kompetenzinanspruchnahme nicht die Freiheitsordnung des Grundgesetzes zu überwinden: Verteilungsgerechtigkeit, die der freiheitliche Sozialstaat anstrebt, ist in den komplexen Sicherungsstrukturen immer auch ein Grundrechtsproblem. Die „Bürgerversicherung“ in ihrer gegenwärtigen Konzeption begegnet daher erheblichen verfassungsrechtlichen Bedenken. 
Zweiter Beratungsgegenstand:

\section{Die Zukunft der sozialen Sicherungssysteme}

2. Bericht von Prof. Dr. Helge Sodan, Berlin

Inhalt

I. Entwicklung sozialer Sicherungssysteme . . . . . . . . . . . . 145

II. Personeller Umfang der Sozialversicherung . . . . . . . . . . . . . 147

1. Sozialrechtliche Grundlagen . . . . . . . . . . . . . . . 147

2. Zur Einführung einer „Bürgerversicherung“ . . . . . . . . 149

3. System pauschaler Gesundheitsprämien . . . . . . . . 154

4. Reduzierung des Versichertenkreises auf sozial

Schutzbedürftige . . . . . . . . . . . . . 155

5. Finanzierung des Familienlastenausgleichs . . . . . . . . . . 157

III. Sachlicher Umfang der Sozialversicherung . . . . . . . . . . . 159

IV. Leistungserbringung für die Sozialversicherung . . . . . . . . . 164

V. Resümee ..................... 168 


\section{Entwicklung sozialer Sicherungssysteme}

Im bereits liberal geprägten 19. Jahrhundert fragte ein Abgeordneter in der französischen Kammer den Rechtsprofessor und Minister Royer-Collard: „Muss denn nicht jedermann leben können?“ Die kühle Antwort lautete: „Ich sehe keine Notwendigkeit."1 In Deutschland sah diese soziale Notwendigkeit wenig später Otto von Bismarck. Er hielt die wesentlich von ihm kreierte Sozialpolitik für „praktisches Christentum“; ihre Zielsetzung galt dem „Wohl der staatlich geeinten Gemeinschaft“.2 So heißt es etwa in der Begründung zu dem schon Anfang 1881 dem Reichstag vorgelegten Entwurf eines Gesetzes betreffend die Unfallversicherung der Arbeiter: „Daß der Staat sich in höherem Maße als bisher seiner hilfsbedürftigen Mitglieder annehme, ist nicht blos eine Pflicht der Humanität und des Christentums, von welchem die staatlichen Einrichtungen durchdrungen sein sollen, sondern auch eine Aufgabe staatserhaltender Politik ..."3 Dieser Gesetzentwurf blieb zwar noch in den parlamentarischen Debatten stecken. ${ }^{4}$ Seine Zielrichtung führte jedoch in den folgenden Jahren zu einer wegweisenden Sozialgesetzgebung: zu dem Gesetz betreffend die Krankenversicherung der Arbeiter ${ }^{5}$, dem Unfallversicherungsgesetz ${ }^{6}$ sowie dem Gesetz betreffend die Invaliditäts- und Altersversicherung7. Diesen bedeutenden Gesetzgebungswerken liegen Prinzipien zugrunde, die noch heute die Sozialversicherung prägen: die Errichtung einer grundsätzlichen Pflichtversicherung mit öffentlich-rechtlicher Organisation und auf der Grundlage einer Selbstverwaltung mit staatlicher Aufsicht; die Finanzierung durch gemeinsam von Arbeitern und deren Arbeitgebern aufgebrachte Beiträge, wobei für die Rentenversicherung ein Staatszuschuss vorgesehen war; die Regelung eines für den Eintritt des Versicherungsfalls gegebenen öffentlich-rechtlichen Leistungsanspruchs. ${ }^{8}$

Seit dem ersten „Bismarckschen“ Sozialgesetz - dem bereits genannten Gesetz betreffend die Krankenversicherung der Arbeiter aus dem

1 S. W. Leisner Grundgesetz und gesetzliche Krankenversicherung, in: Empter/Sodan (Hrsg.) Markt und Regulierung - Rechtliche Perspektiven für eine Reform der gesetzlichen Krankenversicherung, 2003, 43.

${ }^{2}$ H. Rothfels Bismarck, der Osten und das Reich, 2. Aufl. 1960, 169; s. ferner W. Vogel Bismarcks Arbeiterversicherung, 1951, 154; W. Mommsen Otto von Bismarck, 1966, $131 \mathrm{ff}$.

3 Sammlung sämtlicher Drucks. des Reichstags, 1881, Nr. 41, S. 17 (Anlage 2).

4 S. dazu W. Mommsen (Fn. 2), 131.

5 Vom 15. Juni 1883 (RGB1 73).

6 Vom 6. Juli 1884 (RGB1 69).

7 Vom 22. Juni 1889 (RGB1 97).

8 R. Waltermann Sozialrecht, 4. Aufl. 2004, Rn. 46. 
Jahre 1883 - sind mehr als 120 Jahre vergangen. In dieser Zeit ist es in Deutschland zu einer gewaltigen Expansion der sozialen Sicherungssysteme gekommen. Herkömmlich wird zwischen Sozialversicherung, Sozialversorgung und Sozialfürsorge unterschieden. ${ }^{9}$ Diese traditionelle Einteilung orientiert sich an den wichtigsten Gesetzgebungskompetenzen auf dem Gebiet des Sozialrechts (vgl. Art. 74 Abs. 1 Nr. 7, 10 und 12 GG). In diese klassische Dreiteilung lassen sich allerdings einige neuere Bereiche wie das Wohngeldrecht oder die Ausbildungsförderung nicht einordnen. Daher wird teilweise eine Differenzierung zwischen Vorsorge, Entschädigung sowie Hilfe und Förderung vorgeschlagen. ${ }^{10}$ Angesichts der strikten Begrenzung dieses Berichts werden sich die nachfolgenden Ausführungen auf die deutsche Sozialversicherung konzentrieren. Diese ruht derzeit auf insgesamt fünf Säulen: der gesetzlichen Krankenversicherung, der sozialen Pflegeversicherung, der gesetzlichen Unfallversicherung und der gesetzlichen Rentenversicherung einschließlich der Alterssicherung der Landwirte sowie der Arbeitslosenversicherung. ${ }^{11}$ Der letztgenannte Versicherungszweig ist zwar im Arbeitsförderungsrecht geregelt; in Art. 74 Abs. 1 Nr. 12 GG ist jedoch von der „Sozialversicherung einschließlich der Arbeitslosenversicherung“ die Rede.

Die bereits angesprochene Expansion der sozialen Sicherungssysteme hat zugleich zu einer Explosion der Kosten geführt. Im Jahre 2002 umfasste das Sozialbudget, in dem sämtliche Ausgaben für Zwecke der sozialen Sicherung enthalten sind, rund 685 Milliarden Euro - knapp ein Drittel des Bruttoinlandsprodukts in Deutschland; noch 1960 betrug das Verhältnis des Sozialbudgets zum Bruttoinlandsprodukt desselben Jahres nur etwas über 20 Prozent, 197025 Prozent. ${ }^{12}$ Weder die Berichte noch die Diskussionen auf der Tagung der Vereinigung der Deutschen Staatsrechtslehrer 1969 zum Thema „Die Rechtsformen der sozialen Sicherung und das Allgemeine Verwaltungsrecht"13 haben die spätere Krise sozialer Sicherungssysteme vorausgesehen. Fast genau 35 Jahre später ist Sozialstaatlichkeit in Deutschland vor allem zu einem Finanzierungsproblem

\footnotetext{
${ }^{9}$ S. etwa G. Wannagat Lehrbuch des Sozialversicherungsrechts, Bd. I, 1965, $31 \mathrm{ff}$; W. Gitter/J. Schmitt Sozialrecht, 5. Aufl. 2001, § 1 Rn. $9 \mathrm{ff}$.

$10 \mathrm{~S}$. dazu H. F. Zacher Zur Rechtsdogmatik sozialer Umverteilung, DÖV 1970, 3 (6 Fn. 41); ders. Einführung in das Sozialrecht der Bundesrepublik Deutschland, 1983, $20 \mathrm{f}$; R. Waltermann (Fn. 8), Rn. $64 \mathrm{f}$.

11 Ein Bild von dem auf fünf Säulen ruhenden Gebäude der Sozialversicherung mit einer Übersicht über die entsprechenden Rechtsgrundlagen zeichnet $R$. Waltermann (Fn. 8), Rn. 95.

12 Vgl. die Angaben im Sozialbudget 2002, www.bmgs.bund.de/downloads/ A230-2002.pdf (Stand: 26. November 2004).

13 S. die Berichte von W. Henke und W. Rüfner VVDStRL 28 (1970), $149 \mathrm{ff}$. bzw. $187 \mathrm{ff}$.
} 
geworden. Dieses betrifft sowohl die Einnahmen- als auch die Ausgabenseite. Wer also zur Bewältigung der Zukunft durch Lösungsvorschläge für die unvermeidlichen Reformen sozialer Sicherungssysteme beitragen will, muss zunächst Defizite in den Grundstrukturen herausarbeiten. Ohne sich in der Fülle der Detailregelungen zu verlieren, werden sich die nachfolgenden Überlegungen auf drei Schwerpunktbereiche konzentrieren: 1. den personellen Umfang der Sozialversicherung, 2. den sachlichen Umfang der Sozialversicherung und 3. die Leistungserbringung für die Sozialversicherung. Insbesondere ist der verfassungsrechtliche Rahmen für Reformen abzustecken. Zu erörtern wird die Frage sein, ob derzeit stark differierende soziale Sicherungssysteme durch Stärkung gemeinsamer Strukturen zu einem weitgehend einheitlichen Sozialversicherungssystem ausgestaltet werden können.

\section{Personeller Umfang der Sozialversicherung}

\section{Sozialrechtliche Grundlagen}

Die Basis jeder Versicherung bildet der Versichertenkreis. Grundlage einer sozialen Versicherung ist das Prinzip der Pflichtversicherung. Wie sehr der Kreis insbesondere der Pflichtversicherten in den letzten rund 120 Jahren erweitert wurde, lässt sich am Beispiel der gesetzlichen Krankenversicherung veranschaulichen: Dieser gehörten nach Errichtung der Krankenversicherung der Arbeiter 1883 zunächst nur etwa 10 Prozent der Bevölkerung als sozial Schutzbedürftige an, nämlich die Arbeiter mit den niedrigsten Löhnen. ${ }^{14} 1931$ waren im Deutschen Reich bereits 32 Prozent der Bevölkerung in der gesetzlichen Krankenversicherung direkt versichert; in der Bundesrepublik Deutschland wurden unter Hinzurechnung der mitversicherten Familienangehörigen 1960 rund 80 Prozent der Bevölkerung in den Schutz der gesetzlichen Krankenversicherung einbezogen. ${ }^{15}$ Mittlerweile sind es etwa 90 Prozent. ${ }^{16}$ Damit befindet sich diese Versicherung schon seit längerem deutlich auf dem Weg in eine „Einheits-“ bzw. „Volksversicherung“. Arbeiter und Angestellte sind grund-

\footnotetext{
14 Vgl. W. Albers Plädoyer für mehr Markt im Gesundheitswesen, Staatswissenschaften und Staatspraxis 4 (1993), 431 (438).

15 BVerfGE 11, 30 (43f.).

$16 \mathrm{~S}$. die vom Bundesministerium für Gesundheit und Soziale Sicherung veröffentlichte Monatsstatistik der gesetzlichen Krankenversicherung über Mitglieder, mitversicherte Angehörige, Beitragssätze und Krankenstand für September 2004, www.bmgs.bund.de/ downloads/km1jul_sep_04.pdf (Stand: 26. November 2004).
} 
sätzlich versicherungspflichtig und nur insoweit versicherungsfrei, als ihr regelmäßiges Jahresarbeitsentgelt eine bestimmte Grenze übersteigt; diese liegt derzeit bei 46350 Euro. ${ }^{17}$

In den Schutz der sozialen Pflegeversicherung sind kraft Gesetzes alle einbezogen, die in der gesetzlichen Krankenversicherung versichert sind. ${ }^{18}$ In der gesetzlichen Rentenversicherung sind grundsätzlich alle Personen versicherungspflichtig, die gegen Arbeitsentgelt oder zu ihrer Berufsausbildung beschäftigt sind;19 eine Versicherungspflichtgrenze, bei deren Überschreiten Versicherungsfreiheit eintritt, ist für diesen Sozialversicherungszweig nicht geregelt. Versicherungsfrei sind allerdings insbesondere Beamte, Richter und Soldaten. ${ }^{20}$

Die aktuell beitragszahlenden Mitglieder einer Sozialversicherung sind für deren Funktionsfähigkeit von besonderer Bedeutung, weil die deutsche Sozialversicherung auf dem so genannten Umlageverfahren beruht: In dem die private Versicherung prägenden Kapitaldeckungsverfahren wird aus den Beiträgen Vermögen gebildet, das die Grundlage späterer Versicherungsleistungen darstellt; das Umlageverfahren, welches auch als „Generationenvertrag“ bezeichnet wird, kommt hingegen ohne Kapitalakkumulation aus. ${ }^{21}$ Deutschland erlebte während des Aufbaus sozialer Sicherungssysteme eine demographische Explosion. Auf einer solchen Grundlage konnten umlagefinanzierte Sozialversicherungssysteme funktionieren. Heute allerdings müssen immer weniger junge Erwerbstätige die Sozialleistungen für immer mehr ältere Menschen finanzieren. Die von der Bundesministerin für Gesundheit und Soziale Sicherung eingesetzte „Kommission für die Nachhaltigkeit in der Finanzierung der Sozialen Sicherungssysteme“, die nach dem Namen ihres Vorsitzenden als „Rürup-Kommission“ bezeichnet wird, geht in ihrem Bericht aus dem Jahre 2003 von einer Fortsetzung des Trends steigender Lebenserwartung aus: Danach wird die fernere Lebenserwartung von 65-Jährigen bis zum Jahr 2030 bei Männern um 2,6 Jahre und bei Frauen um 3,1 Jahre steigen. Damit werden 65-jährige Männer 2030 im Durchschnitt 83,4 Jahre alt, Frauen sogar 87,6 Jahre. Zugleich wird die Anzahl der 15- bis 64-Jährigen kontinuierlich zurückgehen. ${ }^{22}$

\footnotetext{
${ }^{17}$ S. $\S 5$ Abs. 1 Nr. $1, \S 6$ Abs. 1 Nr. 1 iVm $\S 6$ Abs. 6 SGB V sowie $\S 4$ Abs. 1 der Verordnung über maßgebende Rechengrößen der Sozialversicherung für 2004 vom 9. Dezember 2003 (BGB1 I 2497).

$18 \S 1$ Abs. 2 SGB XI. S. im Einzelnen die Regelungen in den $\S \S 20 \mathrm{ff}$. SGB XI.

19 S. $§ 1$ S. 1 Nr. 1 SGB VI.

${ }^{20}$ S. $\S 5$ Abs. 1 S. 1 Nr. 1 SGB VI.

${ }^{21}$ R. Waltermann (Fn. 8), Rn. $323 \mathrm{f}$.

${ }^{22}$ Nachhaltigkeit in der Finanzierung der Sozialen Sicherungssysteme, Bericht der Kommission, 2003, 6, 53, 55, www.soziale-sicherungssysteme.de/download/PDFs/Bericht.pdf (Stand: 26. November 2004).
} 
Das sich daraus bei einem Umlageverfahren ergebende Finanzierungsproblem wird aufgrund der einkommensorientierten Beiträge zur Sozialversicherung durch Massenarbeitslosigkeit noch erheblich verschärft.

\section{Zur Einführung einer „Bürgerversicherung“}

Dennoch empfiehlt die „Rürup-Kommission“ speziell für die gesetzliche Rentenversicherung keine Ausweitung des versicherungspflichtigen Personenkreises auf Beamte und Selbständige: Diese Erweiterung könne „nur vorübergehend eine Entlastung für den Beitragssatz bewirken“; neben „der verfassungsrechtlichen Verankerung der Beamtenversorgung“ sei „zu beachten, dass Pensionen bereits im Umlageverfahren finanziert“ würden. ${ }^{23}$ Eine Erweiterung des personellen Umfangs der gesetzlichen Rentenversicherung ist derzeit kein zentrales Thema.

In Bezug auf die gesetzliche Krankenversicherung sieht die „RürupKommission“ hingegen eine mögliche Alternative in der Einführung einer „Bürgerversicherung“. Das vorgeschlagene Modell hebt die bisherige Versicherungspflichtgrenze auf und schafft eine umfassende „Einwohnerversicherung“, bezieht also auch Selbständige und Beamte ein; die private Krankenversicherung soll auf das Angebot von Zusatzversicherungen beschränkt werden. ${ }^{24}$ Dieses Konzept stößt jedoch auf schwerwiegende verfassungsrechtliche Einwände, von denen sich einige wie folgt skizzieren lassen:

Nach ständiger Rechtsprechung des Bundesverfassungsgerichts greifen Pflichtmitgliedschaften in öffentlich-rechtlichen Körperschaften wie den gesetzlichen Krankenkassen in das durch Art. 2 Abs. 1 GG geschützte Grundrecht auf freie Entfaltung der Persönlichkeit ein ${ }^{25}$ und sind damit rechtfertigungsbedürftig. Diesbezügliche Regelungen müssen in formeller und materieller Hinsicht verfassungsgemäß sein, um zur verfassungsmäßigen Ordnung zu gehören. ${ }^{26}$ Sehr zweifelhaft ist jedoch, ob der Bund für gesetzliche Festlegungen einer als umfassende Zwangsversicherung ausgestalteten gesetzlichen Krankenversicherung den Kompetenztitel

\footnotetext{
${ }^{23}$ Kommission (Fn. 22), 12; s. näher ebenda, 122 ff.

24 Kommission (Fn. 22), 14, 149.

25 S. BVerfGE 10, 89 (102); 15, 235 (239); 32, 54 (63f.); 38, 281 (297f.); 44, 70 (89); 48, 227 (234); 53, 313 (326); 78, 320 (329f.); 89, 365 (376); 92, 53 (69); BVerfG, NVwZ 2002, 335 (336); BVerfG, NVwZ 2004, 463 (464). S. zur Abgrenzung von der „negativen“ Vereinigungsfreiheit des Art. 9 Abs. 1 GG H. Sodan Berufsständische Zwangsvereinigung auf dem Prüfstand des Grundgesetzes, 1991, 22 ff.; ders./J. Ziekow Grundkurs Öffentliches Recht, 2005, § 37 Rn. 6.

26 Vgl. etwa BVerfGE 6, 32 (37f.); 20, 150 (154); 50, 256 (262); 80, 137 (153); 96, 375 (397f.); 104, 337 (346).
} 
„Sozialversicherung“(Art. 74 Abs. 1 Nr. 12 GG) für sich in Anspruch nehmen könnte. Nach der Judikatur des Bundesverfassungsgerichts können neue Lebenssachverhalte in das Gesamtsystem "Sozialversicherung“ einbezogen werden, wenn zumindest eine Orientierung am klassischen Bild der Sozialversicherung erfolgt. ${ }^{27}$ Von diesem Bild würde sich jedoch eine „Bürgerversicherung“ genannte „Einwohnerversicherung“ - gerade durch die künftige Einbeziehung von Selbständigen und Beamten - vollends lösen. ${ }^{28}$ Dem Bundesverfassungsgericht zufolge gehört zur Sozialversicherung ,jedenfalls die gemeinsame Deckung eines möglichen, in seiner Gesamtheit schätzbaren Bedarfs durch Verteilung auf eine organisierte Vielheit"“. ${ }^{29}$ Nimmt man das Bundesverfassungsgericht insoweit beim Worte, so ließe sich im Falle einer die gesamte Bevölkerung umfassenden Sozialversicherung schwerlich von einer "organisierten Vielheit" sprechen. ${ }^{30}$ „Bedarfsdeckung durch eine organisierte Vielheit setzt einen Ausschnitt aus der Bevölkerung voraus, der zur Deckung des Bedarfs herangezogen wird." 31

Das Bundesverfassungsgericht stellte schon früh fest, die Sozialversicherung gehe „nicht vom Risikobegriff der Privatversicherung“ aus, sondern enthalte „von jeher auch ein Stück staatlicher Fürsorge“.32 Das Prinzip der Äquivalenz von Beiträgen und Leistungen der Versicherung ist für die Sozialversicherung demnach zwar durch den Grundsatz des sozialen Ausgleichs im Sinne einer „Globaläquivalenz“ modifiziert. ${ }^{33}$ Es darf aber keinesfalls in seiner Maßgeblichkeit beseitigt werden, ohne dass zugleich

27 S. BVerfGE 11, 105 (111ff.); 62, 354 (366); 63, 1 (35); 75, 108 (146). Vgl. dazu H. Sodan Der „Beitrag“ des Arbeitgebers zur Sozialversicherung für geringfügige Beschäftigungsverhältnisse, NZS 1999, 105 (110f.); ders. Verfassungsrechtliche Anforderungen an Regelungen gemeinschaftlicher Berufsausübung von Vertragsärzten - Zum Spannungsverhältnis von Berufs- und Sozialversicherungsrecht, NZS 2001, 169 (170ff.).

${ }^{28}$ H. Sodan Die „Bürgerversicherung“ als Bürgerzwangsversicherung, ZRP 2004, 217 (219). So im Ergebnis auch H. Egger Verfassungsrechtliche Grenzen einer Gesundheitsreform, SGb 2003, 76 (78); J. Isensee „Bürgerversicherung“ im Koordinatensystem der Verfassung, NZS 2004, 393 (396); vgl. auch bereits D. Merten Die Ausweitung der Sozialversicherungspflicht und die Grenzen der Verfassung, NZS 1998, 545 (547). Dagegen wird das Problem übersehen von D. Beer/D. Klahn Rechtliche und ökonomische Eckpunkte einer Bürgerversicherung, SGb 2004, 13 (17).

${ }^{29}$ So BVerfGE 11, 105 (112); 75, 108 (146), jeweils im Anschluss an BSGE 6, 213 (228).

${ }^{30}$ H. Sodan (Fn. 28), 218.

31 T. Maunz in: ders./Dürig, GG, Art. 74 Rn. 172 (Stand: Oktober 1984).

32 BVerfGE 11, 105 (114); vgl. ferner bereits BVerfGE 9, 124 (133); 10, 141 (165f.).

33 S. dazu F. E. Schnapp Organisation der gesetzlichen Krankenversicherung, in: Schulin (Hrsg.) Handbuch des Sozialversicherungsrechts, Bd. I, 1994, § 49 Rn. 48; H. Sodan/O. Gast Die Relativität des Grundsatzes der Beitragssatzstabilität nach SGB V, Verfassungs- und Europarecht, NZS 1998, 497 (498). 
das Versicherungsprinzip ${ }^{34}$ erheblich eingeschränkt wäre. ${ }^{35}$ Im Falle einer umfassenden „Bürgerversicherung“ dürften jedoch den hohen Beiträgen der zusätzlich in die gesetzliche Krankenversicherung einbezogenen Personen keine auch nur annähernd adäquaten Versicherungsleistungen entsprechen.

Zusätzlich zu den Einwänden gegen die Gesetzgebungskompetenz des Bundes bestehen in materieller Hinsicht Bedenken gegen eine als „Volksversicherung“ ausgestaltete Sozialversicherung. Zwar ist eine soziale Pflichtversicherung prinzipiell zulässig. ${ }^{36}$ Eine die gesamte Bevölkerung einbeziehende Bürgerzwangsversicherung würde aber eben für viele Pflichtmitglieder, die eindeutig nicht sozial schutzbedürftig sind, in keinem vernünftigen Verhältnis zu den diesen Personen aus der Pflichtzugehörigkeit erwachsenden Vorteilen stehen. ${ }^{37}$ Sie wäre daher wegen Verstoßes gegen das Recht auf freie Entfaltung der Persönlichkeit verfassungswidrig. ${ }^{38}$ Ebenso wenig ließe sich der zumindest mittelbare Eingriff in das den privaten Krankenversicherungsunternehmen durch Art. 12 Abs. 1 GG gewährleistete Grundrecht der Berufsfreiheit rechtfertigen. ${ }^{39}$ Ein Kam-

\footnotetext{
${ }^{34}$ S. dazu näher $F$. Hase Versicherungsprinzip und sozialer Ausgleich, 2000, $71 \mathrm{ff}$., 145 ff.; B. Schulin Rechtliche Grundprinzipien der gesetzlichen Krankenversicherung und ihre Probleme, in: ders. (Hrsg.) Handbuch des Sozialversicherungsrechts, Bd. I, 1994, § 6 Rn. $45 \mathrm{ff}$.

35 In Verkennung der inhaltlichen Strukturelemente der „Sozialversicherung“ iSv Art. 74 Abs. 1 Nr. 12 GG, wie sie das Bundesverfassungsgericht für diesen Kompetenztitel fordert, ist in BSGE 81, 276 (282) die nicht mehr nachvollziehbare These vertreten, der Begriff der Sozialversicherung sei rein formal und offen, nicht aber ,inhaltlich nach einem Versicherungsprinzip" bestimmt - Hervorhebung vom Verfasser.

${ }^{36} \mathrm{~S}$. dazu näher $H$. Sodan Das Beitragssatzsicherungsgesetz auf dem Prüfstand des Grundgesetzes, NJW 2003, 1761 (1765).

37 Vgl. zu dem damit angewandten Maßstab BVerfGE 38, 281 (302).

${ }^{38}$ H. Sodan (Fn. 28), 220; so im Ergebnis auch H. Egger (Fn. 28); F. Kirchhof Verfassungsrechtliche Probleme einer umfassenden Kranken- und Renten-,Bürgerversicherung“, NZS 2004, 1 (2f.); vgl. ferner C. Uleer Die „richtige“ Abgrenzung von PKV und GKV, in: Boecken/Ruland/Steinmeyer (Hrsg.) Sozialrecht und Sozialpolitik in Deutschland und Europa, FS Baron von Maydell, 2002, 767 (773f.), sowie die diesbezügliche Rezension von H. Sodan VSSR 2003, 141 (143f.); aA D. Beer/D. Klahn (Fn. 28), 17 f.; differenzierend S. Muckel Verfassungsrechtliche Grenzen der Reformvorschläge zur Krankenversicherung, SGb 2004, 583 (590ff.).

${ }^{39}$ S. dazu näher W. Leisner Sozialversicherung und Privatversicherung - Dargestellt am Beispiel der Krankenversicherung, 1974, 35 ff.; J. Isensee (Fn. 28), 400f.; F. Hufen Grundrechte der Leistungserbringer in der gesetzlichen Krankenversicherung und Gestaltungsspielraum des Gesetzgebers, in: Sodan (Hrsg.) Finanzielle Stabilität der gesetzlichen Krankenversicherung und Grundrechte der Leistungserbringer - Vorträge im Rahmen der 1. Berliner Gespräche zum Gesundheitsrecht am 16. und 17. Juni 2003, 2004, 27 (36f.); F. Kirchhof (Fn. 38), 3f. Anders hingegen S. Storr „Neuorganisa-
} 
merbeschluss des Bundesverfassungsgerichts vom 4. Februar $2004^{40}$ weist darauf hin, dass die im so genannten Beitragssatzsicherungsgesetz ${ }^{41}$ geregelte und als verfassungsgemäß angesehene deutliche Erhöhung der Versicherungspflichtgrenze „das duale Krankenversicherungssystem nicht grundsätzlich“ verändere und „der Geschäftsbereich der privaten Krankenversicherung der Beamten und Selbständigen“" unangetastet bleibe. Der Gesetzgeber hat die „bipolare Versicherungsverfassung “42 zu beachten.

Eine abgeschwächte Variante einer „Bürgerversicherung“ sieht das Ende August 2004 vorgelegte „Modell einer solidarischen Bürgerversicherung " 43 vor. Danach bleiben die bestehenden Altverträge in der privaten Krankenversicherung unangetastet. Für Neuverträge soll jedoch ausschließlich ein so genannter „Tarif Bürgerversicherung“ zur Verfügung stehen. Zum Angebot dieses Tarifs könnten sowohl die gesetzlichen Krankenkassen als auch die privaten Krankenversicherungsunternehmen zu gleichen Wettbewerbsbedingungen zugelassen werden; Beitragssatzunterschiede sind möglich. Der „Tarif Bürgerversicherung“ ist u.a. durch einen einheitlichen gesetzlichen Leistungskatalog und einen Kontrahierungszwang auch für private Krankenversicherungsunternehmen gekennzeichnet. Alle Bürgerversicherungstarife sollen in den bislang nur für die gesetzliche Krankenversicherung geltenden „Risikostrukturausgleich“44 einbezogen werden.

tion der Sozialen Sicherungssysteme“ - zu den verfassungsrechtlichen Grenzen von Reformen in der Sozialversicherung am Beispiel der Krankenversicherung, SGb 2004, 279 (287).

40 BVerfG, VersR 2004, 898 (899).

41 Vom 23. Dezember 2002 (BGB1 I 4637); s. Art. 1 Nr. 1 dieses Gesetzes.

42 S. zu diesem Begriff W. Leisner (Fn. 39), 167, 170; H. Sodan Freie Berufe als Leistungserbringer im Recht der gesetzlichen Krankenversicherung - Ein verfassungsund verwaltungsrechtlicher Beitrag zum Umbau des Sozialstaates, 1997, 332; vgl. ferner M. Fuchs Privatversicherung und Sozialversicherung, VSSR 1991, 281 (294); G. Hennies Zum Monopol der gesetzlichen Krankenversicherung, ArztR 1994, 95 (96).

${ }^{43} \mathrm{~S}$. den mit diesem Titel erstatteten Bericht der Projektgruppe Bürgerversicherung des SPD-Parteivorstandes vom 26. August 2004, www.spd.de/servlet/PB/show/1038852/ buergerversicherungsmodell.pdf (Stand: 26. November 2004), und die auf der Grundlage dieses Berichts vom SPD-Parteivorstand auf seiner Klausur am 28./29. August 2004 beschlossenen „Eckpunkte für eine solidarische Bürgerversicherung“, www.spd.de/servlet/ PB/show/1038909/2004_08_29_WBHM_buergerversicherung.pdf (Stand: 26. November 2004).

44 S. zu den damit verbundenen Rechtsproblemen BSGE 90, $231 \mathrm{ff}$.; H. Sodan/O. Gast Der Risikostrukturausgleich in der GKV als Quadratur des Kreises, VSSR 2001, $311 \mathrm{ff}$; dies. Umverteilung durch „Risikostrukturausgleich“ - Verfassungs- und europarechtliche Grenzen des Finanztransfers in der Gesetzlichen Krankenversicherung, 2002, passim. 
Erhebliche verfassungsrechtliche Bedenken gegen dieses Modell bestehen bereits im Hinblick auf die erforderliche Gesetzgebungskompetenz des Bundes. Diese könnte sich, soweit die private Krankenversicherung betroffen ist, aus dem in Art. 74 Abs. 1 Nr. 11 GG genannten Kompetenztitel „privatrechtliches Versicherungswesen“ ergeben. Legt man ein Urteil des Bundesverfassungsgerichts aus dem Jahre 2001 zur Verfassungsmäßigkeit der Vorschriften des Pflege-Versicherungsgesetzes ${ }^{45}$ zugrunde, so stehen zwar der Inanspruchnahme dieses Kompetenztitels nicht entgegen: eine Versicherungspflicht, ein Kontrahierungszwang und Einschränkungen privatautonomer Gestaltungsfreiheit. Die Entscheidung gibt jedoch zu erkennen, dass bei einer „Nivellierung der Prämien “ 46 die Grenze zu einem nicht mehr privatrechtlichen Versicherungswesen überschritten wird. $\mathrm{Zu}$ einer solchen Nivellierung würde aber die gesetzliche Regelung eines von jedem individuellen Risiko gelösten, versicherungsintern einheitlichen „Tarifs Bürgerversicherung“ führen. Der auch in einer privatrechtlichen Versicherung grundsätzlich zulässige soziale Ausgleich könnte jedoch durch eine Begrenzung der Beiträge auf einen zumutbaren Höchstsatz erreicht werden. Im Übrigen müsste der Gesetzgeber allerdings zur Wahrung der Kompetenz des privatrechtlichen Versicherungswesens Raum für eine Differenzierung der Beiträge lassen. ${ }^{47}$ Die private Krankenversicherung wäre anderenfalls der Sache nach zur Sozialversicherung mutiert. Für die Versicherten würde sich angesichts der Tatsache, dass ihre Wahlmöglichkeit nur auf die Organisationsform der gesetzlichen Krankenkasse bzw. des privaten Krankenversicherungsunternehmens beschränkt wäre, faktisch keine nennenswert geringere Belastung ergeben als im Falle der zwangsweisen Einbeziehung in eine Sozialversicherung. Insofern gelten die aus dem Grundrecht auf freie Entfaltung der Persönlichkeit diesbezüglich entwickelten Überlegungen hier entsprechend. Die privaten Krankenversicherungsunternehmen könnten dem genannten Modell ihr Grundrecht der Berufsfreiheit entgegenhalten, welches die Wettbewerbsfreiheit einschließt ${ }^{48}$. In diese würde jedoch eine Verpflichtung zum Kontrahierungszwang ohne Risikoprüfung und zum Angebot eines einheitlichen Leistungskataloges sowie von Pauschalprämien intensiv und in nicht zu rechtfertigender Weise eingreifen.

\footnotetext{
45 BVerfGE 103, 197 (218f.).

46 BVerfGE 103, 197 (220) - Hervorhebung vom Verfasser.

47 Vgl. H. Sodan Zur Verfassungsmäßigkeit der Ausgliederung von Leistungsbereichen aus der gesetzlichen Krankenversicherung - Dargestellt am Beispiel der Versorgung mit Zahnersatz, NZS 2003, 393 (399f.).

48 S. zur Herleitung der Wettbewerbsfreiheit aus Art. 12 Abs. 1 GG etwa BVerfGE 32, 311 (317); 46, 120 (137); BVerwGE 71, 183 (189); H. Sodan Vorrang der Privatheit als Prinzip der Wirtschaftsverfassung, DÖV 2000, 361 (364).
} 


\section{System pauschaler Gesundheitsprämien}

Halten sich demnach die beiden vorgeschlagenen Varianten einer künftigen „Bürgerversicherung“ nicht in dem vorgegebenen verfassungsrechtlichen Rahmen, rückt umso mehr ein Systemwechsel zur Sicherung der Überlebensfähigkeit der gesetzlichen Krankenversicherung ins Blickfeld. Das von der „Rürup-Kommission“ als zweite Alternative vorgeschlagene „System pauschaler Gesundheitsprämien orientiert sich am Äquivalenzprinzip und zielt auf eine völlige Entkoppelung der Beiträge zur Gesetzlichen Krankenversicherung von den Arbeitskosten“.49 Die bisherigen Arbeitgeberbeiträge ${ }^{50}$ sollen als Bruttolohnbestandteile ausgezahlt werden. ${ }^{51}$ Beitrags- bzw. Prämienerhöhungen zögen künftig keine Verteuerung des Faktors Arbeit mehr nach sich. Diesem Modell zufolge ergäbe sich auf der Grundlage eines prinzipiell unveränderten Versichertenkreises und auf dem Stand des Jahres 2003 im Durchschnitt eine monatliche Prämie von rund 210 Euro je erwachsenem Versicherten.52 Um den erforderlichen sozialen Ausgleich zu gewährleisten, sollen Versicherte mit geringen Haushaltseinkommen steuerfinanzierte Prämienzuschüsse erhalten. ${ }^{53}$ Den damit für die öffentlichen Haushalte verbundenen Belastun-

\footnotetext{
${ }^{49}$ Kommission (Fn. 22), 15. Der Bericht der vom Bundesvorstand der CDU Deutschlands eingesetzten Kommission „Soziale Sicherheit“ zur Reform der sozialen Sicherungssysteme, die als „Herzog-Kommission“ bezeichnet wird, vom 29. September 2003 schlägt zwar auch den Übergang zu einem Prämienmodell vor (22f.), empfiehlt aber, die Kosten der gesetzlichen Krankenversicherung, soweit sie Lohnnebenkosten sind, nur teilweise von den Arbeitskosten zu entkoppeln: „Dazu ist es erforderlich, die paritätische Finanzierung teilweise aufzugeben. Um den Arbeitgebern eine langfristig stabile Kalkulation der Arbeitskosten zu ermöglichen und die Lohnnebenkosten dauerhaft begrenzt zu halten, soll der Arbeitgeberanteil zur Finanzierung der Gesundheitskosten abgesenkt und bei 6,5 Prozent festgeschrieben werden“ (20); www.cdu.de/tagesthema/30_09_03_soziale sicherheit.pdf (Stand: 26. November 2004).

50 Die Arbeitgeber tragen gemäß $§ 249$ Abs. 1 SGB V die nach dem Arbeitsentgelt zu bemessenden Krankenkassenbeiträge ihrer nach $\S 5$ Abs. 1 Nr. 1 SGB V versicherungspflichtig Beschäftigten jeweils zur Hälfte und haben nach $§ 257$ Abs. 1 SGB V ihren freiwillig in der gesetzlichen Krankenversicherung versicherten Beschäftigten Beitragszuschüsse zu zahlen.

${ }^{51}$ Kommission (Fn. 22), 162.

52 Kommission (Fn. 22), 15, 171.

${ }^{53}$ Kommission (Fn. 22), 15, 162. S. zur Verteilung der Belastungen folgende Ausführungen der Kommission, ebenda, 173: „Zusammenfassend lässt sich festhalten, dass sich durch eine Umstellung der Finanzierung auf Gesundheitsprämien keine großen Änderungen gegenüber der heutigen Belastungsverteilung ergäben. Die durchschnittliche maximale Belastung betrüge - je nach gewähltem Tarif des zumutbaren Eigenbeitrags $0,6 \%$ bzw. 2,4\% des verfügbaren Haushaltseinkommens oder rund 0,3\% bzw. 1,2\% des Bruttoeinkommens. Dies entspricht im heutigen System etwa den Belastungen eines Beitragssatzanstiegs um etwa 0,6 bzw. 2,4 Beitragssatzpunkte. Keine soziale Gruppe - abge-
} 
gen stünden Entlastungseffekte infolge höheren Wirtschaftswachstums und steigender Beschäftigung gegenüber.

Durchgreifende verfassungsrechtliche Bedenken gegen ein einkommensunabhängiges Prämienmodell sind nicht ersichtlich. Für die angestrebten Neuregelungen hätte der Bund die Gesetzgebungszuständigkeit aus dem Kompetenztitel „Sozialversicherung“. Zwar baut das klassische Bild der Sozialversicherung auf dem Prinzip der versicherungsinternen Umverteilung und nicht auf einer Finanzierung über das Steuersystem auf. Das vom Bundesverfassungsgericht genannte Kriterium, wonach zur Sozialversicherung, ,jedenfalls die gemeinsame Deckung eines möglichen, in seiner Gesamtheit schätzbaren Bedarfs durch Verteilung auf eine organisierte Vielheit" gehört, ${ }^{54}$ wäre aber erfüllt. Nach Art. 120 Abs. 1 S. 4 GG trägt der Bund ohnehin die Zuschüsse zu den Lasten der Sozialversicherung einschließlich der Arbeitslosenversicherung und der Arbeitslosenhilfe. ${ }^{55}$

\section{Reduzierung des Versichertenkreises auf sozial Schutzbedürftige}

Zusätzlich zur Einführung eines Prämienmodells sollte auch der Versichertenkreis durch eine deutliche Senkung der Versicherungspflichtgrenze und eine Beseitigung der Möglichkeit zur freiwilligen Versicherung 56 erheblich reduziert werden, und zwar auf die wirklich sozial Schutzbedürftigen ${ }^{57}$. Damit ist nicht eine - praktisch für jeden Menschen

sehen von Haushalten der Beamten und Pensionäre - würde systematisch durch die Reform belastet. Dagegen würden durch die Reform insbesondere Haushalte von Alleinstehenden im mittleren Einkommensbereich entlastet. Nach geltendem Recht tragen diese überproportional zur Finanzierung der Gesetzlichen Krankenversicherung bei und sind auch sonst im Steuer-Transfer-System hohen Grenzbelastungen ausgesetzt. Im Einzelnen ergäben sich jedoch sehr unterschiedliche Wirkungen in Abhängigkeit von Haushaltstyp und Haushaltsgröße. Durch die Gestaltung des Zuschusssystems und die Art der Gegenfinanzierung können politisch unerwünschte Verteilungseffekte vermieden werden."

${ }^{54}$ S. die Nachweise in Fn. 29.

${ }^{55}$ Vgl. dazu BVerfG, NVwZ 2004, 463 (464); H. Sodan/O. Gast Umverteilung (Fn. 44), 133.

${ }^{56}$ Die freiwillige Versicherung ist derzeit geregelt in $\S 9$ SGB V.

${ }^{57}$ S. dazu bereits W. Leisner (Fn. 39), 55 ff.; ders. Finanzielle Stabilität der gesetzlichen Krankenversicherung - ein grundgesetzliches Gebot?, in: Sodan (Hrsg.) Finanzielle Stabilität der gesetzlichen Krankenversicherung und Grundrechte der Leistungserbringer Vorträge im Rahmen der 1. Berliner Gespräche zum Gesundheitsrecht am 16. und 17. Juni 2003, 2004, 15 (20ff.); H. Sodan (Fn. 42), 332f.; F. Reuther Verfassungsrechtliche Determinanten für die Beitragsbemessung in der sozialen Kranken- und Pflegeversicherung, in: Depenheuer/Heintzen/Jestaedt/Axer (Hrsg.) Nomos und Ethos, Hommage an 
zutreffende - Schutzbedürftigkeit gegen allgemeine Lebensrisiken gemeint. So heißt es etwa in dem von Alfred Manes herausgegebenen Versicherungslexikon noch im Jahre 1930, die Sozialversicherung sei begrifflich beschränkt „auf notleidende Bevölkerungsschichten“58. Zwar vertritt das Bundesverfassungsgericht die Ansicht, die Beschränkung auf eine Notlage gehöre nicht zum „Wesen der Sozialversicherung“.59 Der Gesetzgeber könnte aber die Sozialversicherung den von ihm als sozial schutzbedürftig angesehenen Personen vorbehalten; für entsprechende Regelungen hätte er einen erheblichen Gestaltungsspielraum. ${ }^{60}$ Mit einer Kombination von Prämiensystem und Beschränkung des Versichertenkreises auf sozial Schutzbedürftige ließe sich auch dem Einwand „sozialer Ungerechtigkeit" begegnen, der auf die gleiche Höhe der Beitragsleistungen von Menschen mit hohem und solchen mit niedrigem Einkommen gestützt wird. Die Unterschiede der in die gesetzliche Krankenversicherung Einbezogenen wären in materieller Hinsicht nämlich deutlich geringer; der Versichertenkreis erwiese sich insgesamt als homogener. ${ }^{61}$ Über ein Steuer-Transfer-System würden auch die finanziell Leistungsstärksten zur Unterstützung der sozial Schutzbedürftigen herangezogen, ohne - wie beim Modell einer umfassenden „Bürgerversicherung“ - zugleich selbst in eine Sozialversicherung gezwungen zu werden. Wer nicht sozial schutzbedürftig ist, vermag sein Krankheitsrisiko eigenverantwortlich abzusichern. Mit der damit verbundenen Eröffnung eines zusätzlichen erheblichen Marktes für die private Krankenversicherung würden neue Marktteilnehmer in einem dann auch im Bereich der Krankenversicherung verwirklichten europäischen Binnenmarkt hinzukommen. Diese könnten mit differenzierten Versicherungsangeboten für eine - gemeinschaftsrechtlich ohnehin intendierte ${ }^{62}$ - Intensivierung des Wettbewerbs unter den privaten Krankenversicherungsunternehmen sorgen.

J. Isensee zum 65. Geburtstag von seinen Schülern, 2002, 435 (447ff.). Vgl. auch H. Butzer Fremdlasten in der Sozialversicherung - Zugleich ein Beitrag zu den verfassungsrechtlichen Vorgaben für die Sozialversicherung, 2001, $431 \mathrm{ff}$.

58 O. Stein Sozialversicherung, in: Manes (Hrsg.) Versicherungslexikon, 3. Aufl. 1930, Sp. 1446.

59 So BVerfGE 11, 105 (113); 63, 1 (35); 75, 108 (146).

$60 \mathrm{H}$. Sodan Die gesetzliche Krankenversicherung nach dem GKV-Modernisierungsgesetz - Zehn Thesen zur Gesundheitsreform, GesR 2004, 305 (309).

$61 \mathrm{Vgl}$. zum Gesichtspunkt der Homogenität des Versichertenkreises W. Leisner (Fn. 39), 88.

62 S. etwa Art. 4 Abs. 1 EG: Danach umfasst die Tätigkeit der Mitgliedstaaten und der Gemeinschaft die Einführung einer Wirtschaftspolitik, die „dem Grundsatz einer offenen Marktwirtschaft mit freiem Wettbewerb verpflichtet ist". 
Das Modell einkommensunabhängiger Prämien bei gleichzeitiger Reduzierung des Versichertenkreises auf sozial Schutzbedürftige ließe sich auch auf andere Zweige der Sozialversicherung übertragen. Es könnte zu einem verbindenden Strukturelement eines einheitlichen Systems sozialer Sicherung werden.

\section{Finanzierung des Familienlastenausgleichs}

Konsequent wäre es, den notwendigen Familienlastenausgleich künftig nicht innerhalb einer begrenzten Solidar-Versichertengemeinschaft, sondern als gesamtgesellschaftliche Aufgabe durch Steuern zu finanzieren. Bereits im so genannten Trümmerfrauen-Urteil aus dem Jahre 1992 forderte das Bundesverfassungsgericht speziell in Bezug auf die gesetzliche Rentenversicherung den Gesetzgeber zu Maßnahmen mit dem Ziel auf, „daß sich mit jedem Reformschritt die Benachteiligung der Familie tatsächlich verringert".63 In einem Urteil zum Familienlastenausgleich in der sozialen Pflegeversicherung aus dem Jahre 2001 stellte das Bundesverfassungsgericht fest, dass wesentliche Regelungen im Elften Buch Sozialgesetzbuch ${ }^{64}$ mit Art. 3 Abs. 1 iVm Art. 6 Abs. 1 GG nicht vereinbar sind, soweit Mitglieder der sozialen Pflegeversicherung, die Kinder betreuen und erziehen, mit einem gleich hohen Pflegeversicherungsbeitrag wie Mitglieder ohne Kinder belastet werden. ${ }^{65}$ Hintergrund ist die dramatische demographische Entwicklung: ${ }^{66}$ „In Deutschland ist seit Mitte der sechziger Jahre die Zahl der Lebendgeborenen je Frau von 2,49 in rascher Folge auf mittlerweile 1,3 gesunken.“67 In den Worten von Paul Kirchhof: „Deutschland ist bei all seinem Kapitalreichtum - eines der ärmsten Länder der Welt. Es fehlt am wichtigsten Gut einer lebendigen Gesellschaft: den Kindern“.68

\footnotetext{
${ }^{63}$ BVerfGE 87, 1 (41).

64 S. $\S 54$ Abs. 1 und 2, $\S 55$ Abs. 1 S. 1 und Abs. 2 sowie $\S 57$ SGB XI vom 26. Mai 1994 (BGB1 I 1014).

65 BVerfGE 103, 242. S. zu einer „Klarstellung“, die von einem der an dem Urteil beteiligten Richter in einem Vortrag vorgenommen wurde, U. Steiner Generationenfolge und Grundgesetz, NZS 2004, 505 (507). Kritisch zu dieser Entscheidung etwa F. Ruland Das BVerfG und der Familienlastenausgleich in der Pflegeversicherung, NJW 2001, $1673 \mathrm{ff}$; I. Ebsen Familienlastenausgleich und die Finanzierung der Sozialversicherung aus verfassungs- und sozialrechtlicher Sicht, VSSR 2004, 3 (9ff.); F. Hase Familienlastenausgleich und die Finanzierung der Gesetzlichen Kranken- und Pflegeversicherung, VSSR 2004, $55 \mathrm{ff}$.

${ }^{66} \mathrm{~S}$. dazu jüngst $U$. Becker Die alternde Gesellschaft - Recht im Wandel, JZ 2004, $929 \mathrm{ff}$; T. Kingreen Familie als Kategorie des Sozialrechts, JZ 2004, $938 \mathrm{ff}$.

${ }^{67}$ BVerfGE 103, 242 (267).

68 P. Kirchhof Ist unsere Gesellschaft hinreichend zukunftsfähig?, in: Walter-RaymondStiftung der BDA (Hrsg.) Demographie und gesellschaftlicher Wandel, 2004, 11.
} 
Das Bundesverfassungsgericht verpflichtete den Gesetzgeber dazu, spätestens bis zum 31. Dezember 2004 eine verfassungsgemäße Neuregelung zur relativen Entlastung beitragspflichtiger Versicherter mit einem oder mehreren Kindern zu treffen; es gab ihm ferner auf, innerhalb dieses Zeitraums auch die Bedeutung des Urteils für andere Sozialversicherungszweige zu prüfen. ${ }^{69}$ Letzteres ist offenbar bis heute nicht geschehen, obwohl Konsequenzen jedenfalls für die gesetzliche Krankenversicherung auf der Hand liegen. Bezüglich der sozialen Pflegeversicherung beschloss der Deutsche Bundestag erst nach etwa dreieinhalb Jahren am 1. Oktober 2004 das Gesetz zur Berücksichtigung von Kindererziehung im Beitragsrecht der sozialen Pflegeversicherung (Kinder-Berücksichtigungsgesetz $\mathrm{KiBG})^{70}$. Dieses Gesetz wird jedoch dem vom Bundesverfassungsgericht konkretisierten Verbot nicht gerecht, Ungleiches im Beitragsrecht der sozialen Pflegeversicherung verfassungswidrig gleichzubehandeln ${ }^{71}$. Denn es stellt einen beitragspflichtigen Versicherten mit einem Kind genauso wie etwa einen beitragspflichtigen Versicherten mit zehn Kindern ${ }^{72}$; letzterer erbringt jedoch im Vergleich zu einem beitragspflichtigen Versicherten mit nur einem Kind einen erheblich größeren generativen Beitrag und fördert damit in wesentlich stärkerem Maße den Systemerhalt. ${ }^{73}$

${ }^{69}$ BVerfGE 103, 242 (270f.).

70 S. KiBG vom 15. Dezember 2004 (BGB1 I 3448). Das Gesetz fügt dem $\S 55$ SGB XI einen Abs. 3 an, dessen S. 1 lautet: „Der Beitragssatz nach Absatz 1 Satz 1 und 2 erhöht sich für Mitglieder nach Ablauf des Monats, in dem sie das 23. Lebensjahr vollendet haben, um einen Beitragszuschlag in Höhe von 0,25 Beitragssatzpunkten (Beitragszuschlag für Kinderlose).“

${ }^{71}$ S. zu diesem Verbot BVerfGE 103, 242 (271); s. zu den sich aus dem Kinder-Berücksichtigungsgesetz ergebenden Verfassungsproblemen näher H. Sodan Schriftliche Stellungnahme zum Entwurf eines Kinder-Berücksichtigungsgesetzes (BT-Drucks. 15/3671), Drucks. des BT-Ausschusses für Gesundheit und Soziale Sicherung 0688 vom 23. September 2004, 15. Wahlperiode.

72 Dieser Hinweis beruht darauf, dass das Urteil des Bundesverfassungsgerichts vom 3. April 2001 auf die Verfassungsbeschwerde eines Vaters mit zehn Kindern erging; vgl. BVerfGE 103, 242 (246).

${ }^{73}$ S. dazu BVerfGE 103, 242 (269): „Gleich bleibend hohe, wenn nicht gar steigende Leistungsausgaben müssen von immer weniger Personen finanziert werden. Dies führt auch dazu, dass immer weniger jüngere Versicherte neben ihrer Beitragslast zur Sicherung der Funktionsfähigkeit der sozialen Pflegeversicherung die Kostenlast der Kindererziehung tragen. Die gleiche Belastung mit Versicherungsbeiträgen führt zu einem erkennbaren Ungleichgewicht zwischen dem Gesamtbeitrag, den Kindererziehende in die Versicherung einbringen, und dem Geldbeitrag von Kinderlosen. ... Ein gewisser Ausgleich besteht zwar darin, dass die kinderbetreuenden und -erziehenden Versicherten bei gleichen Beiträgen, wie sie Kinderlose zahlen, Leistungen auch für die anderen Familienangehörigen erhalten. Diese Begünstigung wiegt aber den mit der Erziehungsleistung zusätzlich erbrachten generativen Beitrag und den damit verbundenen Nachteil der Erzie- 


\section{Sachlicher Umfang der Sozialversicherung}

Die derzeit erheblichen Finanzierungsprobleme stellen auch den Umfang der Sozialleistungen auf den Prüfstand. Dies gilt zunächst für die gesetzliche Rentenversicherung. Auf deren Finanzierbarkeit wirken sich die bereits angesprochene demographische Entwicklung, die Massenarbeitslosigkeit und der anhaltende Trend zur Frühverrentung in besonderem $\mathrm{Maße}$ aus. Der Gesetzgeber versucht seit längerem, den veränderten Rahmenbedingungen durch Maßnahmen zu begegnen, die letztlich zu Rentenkürzungen führen. Jüngstes Beispiel dafür ist das Gesetz zur Sicherung der nachhaltigen Finanzierungsgrundlagen der gesetzlichen Rentenversicherung vom 21. Juli 200474. Dieses Gesetz sieht insbesondere eine erneute Änderung der Rentenanpassungsformel durch Ergänzung um einen „Nachhaltigkeitsfaktor“ vor: Danach wird die Anpassung künftig umso geringer ausfallen, je weniger Beitragszahler für einen Rentner aufkommen. ${ }^{75}$

Das Bundesverfassungsgericht erstreckt seit seiner Entscheidung zum Versorgungsausgleich aus dem Jahre $1980^{76}$ den Grundrechtsschutz der Eigentumsgarantie auch auf Ansprüche und Anwartschaften auf Versichertenrenten aus der gesetzlichen Rentenversicherung. Denn eine sozialversicherungsrechtliche Rechtsposition ist nach der bundesverfassungsgerichtlichen Judikatur von der Eigentumsgarantie umfasst, wenn sie einen Vermögenswert aufweist, dem Inhaber im Sinne eines Ausschließlichkeitsrechts als privatnützig zugeordnet ist, auf einer nicht unerheblichen Eigenleistung des Inhabers beruht und zur Sicherung seiner Existenz bestimmt ist. ${ }^{77}$ Mit der Entrichtung von Beiträgen zur gesetz-

henden angesichts des Vorteils, der den Kinderlosen durch die Erziehungsleistung zuwächst, nicht vollständig auf. Dementsprechend fordert der Ausgleich der Benachteiligung mehr als nur den beitragsfreien Erwerb des Rechts auf Inanspruchnahme von Pflegeleistungen durch Familienangehörige.“

${ }^{74}$ BGB1 I 1791.

75 S. dazu näher F. Ruland Der neue Nachhaltigkeitsfaktor in der Rentenanpassungsformel und seine Auswirkungen, SGb 2004, 327 (330ff.).

76 BVerfGE 53, 257 (289ff.); seitdem ständige Rechtsprechung, s. etwa BVerfGE 58, 81 (109); 64, 87 (97); 100, 1 (32).

77 S. BVerfGE 69, 272 (300); 72, 9 (18f.); 76, 220 (235). Vgl. aus dem Schrifttum etwa R. Stober Eigentumsschutz im Sozialrecht, SGb 1989, 53 (54ff.); A. v. Brünneck Eigentumsschutz der Renten - Eine Bilanz nach zehn Jahren, JZ 1990, 992ff.; W. Leisner Eigentum, HStR VI, 2. Aufl. 2001, § 149 Rn. $119 \mathrm{ff}$; H. Sodan (Fn. 42), 256ff.; ders./J. Ziekow (Fn. 25), § 42 Rn. 11; M. Herdegen Garantie von Eigentum und Erbrecht, in: Badura/Dreier (Hrsg.) FS 50 Jahre Bundesverfassungsgericht, Bd. II, 2001, 273 (276f.). Kritisch hingegen H. v. Ditfurth Die Einbeziehung subjektiv-öffentlicher Berechtigungen, insbesondere sozialversicherungsrechtlicher Positionen, in den Schutz der Eigentumsga- 
lichen Rentenversicherung erbringt der Versicherte eine wesentliche eigene Leistung zur Entstehung seines Versicherungsanspruchs. Dass ein Teil der Versicherten im Rentenalter aufgrund einer ausreichenden Vermögensanhäufung zur Erhaltung der Lebensgrundlage auf die Leistungen aus der gesetzlichen Rentenversicherung verzichten könnte, ändert nichts am Zweck der Existenzsicherung. Denn nach der Rechtsprechung des Bundesverfassungsgerichts ist nicht die individuelle Bedürftigkeit, sondern die objektive Zielsetzung der Existenzsicherung maßgeblich. ${ }^{78}$ Die Versichertenrente ist, soweit sie nicht im Ermessen des Versicherungsträgers steht, dem Anspruchsinhaber als privatnützig zugeordnet. Sie unterliegt nämlich seiner grundsätzlichen - wenn auch eingeschränkten ${ }^{79}$ Verfügungsbefugnis und wird wesentlich durch eine eigene Beitragsleistung mitbestimmt. 80

Die Kürzung sowohl von Rentenansprüchen als auch von Rentenanwartschaften wird allgemein als Inhalts- und Schrankenbestimmung eingeordnet, die am Grundsatz der Verhältnismäßigkeit zu messen ist. ${ }^{81}$ Nach der Rechtsprechung des Bundesverfassungsgerichts verengt sich die Gestaltungsfreiheit des Gesetzgebers ,in dem Maße, in dem Rentenansprüche oder Rentenanwartschaften durch den personalen Bezug des Anteils eigener Leistung des Versicherten geprägt sind“.82 Daher steht dem Gesetzgeber bei der Regelung beitragsunabhängiger Rentenberechnungsfaktoren, wie etwa der Anrechnung von Ausbildungsausfallzeiten, ein weiter Gestaltungsspielraum zu. ${ }^{83}$ Die Änderung beitragsabhängiger Faktoren, insbesondere der Entgeltpunkte in der gegenwärtigen Rentenformel, unterliegt hingegen engen verfassungsrechtlichen Beschränkungen. ${ }^{84}$ Die sowohl von der „Rürup-Kommission“85 als auch von

rantie, 1994, insbesondere $185 \mathrm{ff}$; $O$. Depenheuer Wie sicher ist verfassungsrechtlich die Rente?, AöR 120 (1995), 417 (423ff.); H.-J. Papier in: Maunz/Dürig, GG, Art. 14 Rn. 6 f. (Stand: Juni 2002); W.-R. Schenke Sozialversicherungsrechtliche Ansprüche und das Eigentumsgrundrecht, in: Wandt/Reiff/Looschelders/Bayer (Hrsg.) Kontinuität und Wandel des Versicherungsrechts, FS Lorenz, 2004, $715 \mathrm{ff}$.

78 S. BVerfGE 69, 272 (303f.).

$79 \mathrm{~S}$. nur $\S 53$ SGB I.

80 BVerfGE 53, 257 (290f.).

81 S. etwa $H$. D. Jarass Sicherung der Rentenfinanzierung und Verfassungsrecht, NZS 1997, 545 (547); T. Wiechmann Verfassungsmäßigkeit der Rentenanpassung 2003, DAngVers 2003, 307 (308).

82 So BVerfGE 53, 257 (293); vgl. auch BVerfGE 58, 81 (112ff.); 64, 87 (101).

83 BVerfGE 58, 81 (112ff.).

${ }^{84}$ Vgl. H.-J. Papier Alterssicherung und Eigentumsschutz, in: Isensee/Lecheler (Hrsg.)

Freiheit und Eigentum, FS Leisner, 1999, 721 (723f.).

85 Kommission (Fn. 22), 7 f., 82 ff. 
der „Herzog-Kommission“ 86 vorgeschlagene Anhebung der Regelaltersgrenze von 65 auf 67 Jahre wird in der Literatur als beitragsunabhängiger Rentenfaktor qualifiziert. Nicht zu übersehen ist allerdings, dass die Altersgrenze unmittelbar den Barwert der Rentenleistungen beeinflusst. Dem insoweit im Hinblick auf die Lebensplanungen der Betroffenen jedenfalls gebotenen verfassungsrechtlichen Vertrauensschutz ${ }^{87}$ tragen beide Sachverständigengremien dadurch Rechnung, dass sie eine stufenweise Anhebung dieser Altersgrenze ab 2011 in einem Zeitkorridor von 12 Jahren („Herzog-Kommission“) 88 bzw. 24 Jahren („Rürup-Kommission“) ${ }^{89}$ vorschlagen. Das Verhältnismäßigkeitsprinzip gebietet auch, dem Rentenbezieher auf jeden Fall eine Basissicherung zu gewähren, die deutlich über dem Sozialhilfeniveau liegt. Denn der Altersrentner soll - wie es bereits in einer Gesetzesbegründung aus dem Jahre 1956 heißt - ,aus der Nähe des Fürsorgeempfängers in die Nachbarschaft des Lohnempfängers" ${ }^{* 90}$ gerückt werden.

Die Gestaltungsfreiheit des Gesetzgebers im Hinblick auf die Änderung von Sozialleistungen wird nicht nur bei der gesetzlichen Rentenversicherung, sondern auch bei den anderen Sozialversicherungszweigen wesentlich durch das bereits genannte ${ }^{91}$ Umlageverfahren beeinflusst. Dieses beruht nicht auf der Bildung von Vermögen, sondern auf der Kontinuität der Versicherung. Danach können die Sozialleistungen von heute „nur durch den Transfer von heute und die Sozialleistungen von morgen nur durch den Transfer von morgen aufgebracht werden. Es gibt kein kollektives, sondern nur ein individuelles Sparen ... Das Umlageverfahren bedeutet ein unsicheres Wirtschaften, von der Hand in den Mund‘.... Ein auf dem Umlageverfahren beruhendes Sozialleistungssystem kann keine Sicherheit garantieren, weil sein Fortbestand von Leistungsbereitschaft und Leistungsvermögen künftiger Generationen abhängt“.92 Den Übergang auf ein Kapitaldeckungsverfahren, wie es für die gesetzliche Rentenversicherung vor der Rentenreform von 1957 galt, ${ }^{93}$ schlagen für diesen

\footnotetext{
${ }^{86}$ Herzog-Kommission (Fn. 49), 42. Wer allerdings 45 Versicherungsjahre nachweist und das 63. Lebensjahr vollendet hat, soll bereits abschlagsfrei Rente beziehen können.

87 S. dazu etwa BVerfGE 58, 81 (120f.); 64, 87 (104); 69, 272 (310); 76, 220 (244f.); T. Hebeler Verfassungsrechtliche Probleme der gesetzlichen Alterssicherung und deren Reform, ZfSH/SGB 2001, 528 (535f.); H. Sodan/J. Ziekow (Fn. 25), § 7 Rn. $44 \mathrm{ff.}$

${ }^{88}$ Herzog-Kommission (Fn. 49), 42.

${ }^{89}$ Kommission (Fn. 22), 7, 84.

90 BT-Drucks. 2/2437, 57f. (vom 5. Juni 1956); ebenso BSGE 90, 11 (16).

91 S. oben bei Fn. 8.

92 E. Eichenhofer Sozialrecht, 5. Aufl. 2004, Rn. $61 \mathrm{f}$.

93 S. dazu R. Waltermann (Fn. 8), Rn. $323 \mathrm{f}$.
} 
Sozialversicherungszweig jedoch weder die „Rürup-“94 noch die „Herzog-Kommission" 95 vor. Zur Leistung von Rentenausgaben, die mit den derzeitigen vergleichbar sind, müssten bei Zahlung aus Erträgen zwischen 5 und 6 Billionen Euro vorgehalten werden. ${ }^{96}$ Es ist kaum anzunehmen, dass die gegenwärtig erwerbstätige Generation zu einem derart gewaltigen Opfer zugunsten späterer Generationen bereit ist, welches mit dem Aufbau eines solch hohen Vermögens verbunden wäre. Wegen der relativ geringeren Finanzvolumina empfiehlt die „Herzog-Kommission“ speziell für die gesetzliche Krankenversicherung und die soziale Pflegeversicherung allerdings die Überführung jeweils in ein kapitalgedecktes System. ${ }^{97}$

Erweist sich der Übergang zur Kapitaldeckung als der zwar an sich richtige, aber zumindest derzeit sehr schwierige Weg, so bedarf es im Falle der Beibehaltung des Umlageverfahrens der Reduzierung der Sozialleistungen auf eine Grundsicherung.98 Mehr sollte auch über die Steuersolidarität nicht eingefordert werden. Der - allerdings zu späten Einsicht, dass sich mehr als eine solche Grundsicherung durch die gesetzliche Rentenversicherung auf absehbare Zeit nicht gewährleisten lässt, verdankt die „Riester-Rente“ ihre Entstehung, also der Aufbau einer zusätzlichen kapitalgedeckten privaten Altersvorsorge mit staatlicher Förderung in Form von Zulagen und Steuerfreibeträgen. ${ }^{99}$ Gleichfalls in diese Richtung zielte die im so genannten GKV-Modernisierungsgesetz (GMG) vom 14. November $2003^{100}$ für die Zeit ab 2005 vorgesehene Ausgliederung des Zahnersatzes aus dem Leistungskatalog der gesetzlichen Krankenversicherung. ${ }^{101}$ Am 1. Oktober 2004 beschloss jedoch der Deutsche Bundestag die Aufhebung der diesbezüglichen Regelungen noch vor ihrem Wirksamwerden. ${ }^{102}$ Der Sachverständigenrat für die Konzertierte Aktion im Gesundheitswesen hat bereits vor etwa zehn Jahren ein Modell

\footnotetext{
${ }^{94}$ Kommission (Fn. 22), $71 \mathrm{f}$.

95 Herzog-Kommission (Fn. 49), $39 \mathrm{f}$.

96 R. Waltermann (Fn. 8), Rn. 324.

${ }^{97}$ Herzog-Kommission (Fn. 49), $22 \mathrm{f} ., 31 \mathrm{f}$.

$98 \mathrm{Vgl}$. dazu für die gesetzliche Krankenversicherung H. Sodan (Fn. 42), $340 \mathrm{f}$.

${ }^{99} \mathrm{~S}$. dazu näher $W$. Blomeyer Die „Riester-Rente“ nach dem Altersvermögensgesetz (AVmG), NZA 2001, $913 \mathrm{ff}$. Einen Überblick über die bisherige Inanspruchnahme der „Riester-Förderung“" geben C. Rieckhoff/R. Thiede „Riester-Rente“: Umfang der bisherigen staatlichen Förderung und Perspektiven für ihre Weiterentwicklung, DAngVers 2004, $49 \mathrm{ff}$. 100 BGB1 I 2190.

101 Vgl. Art. 1 Nr. 17 und 36 iVm Art. 37 Abs. 8 GMG. S. dazu näher H. Sodan (Fn. 47), 393 ff.; ders. (Fn. 60), 308; zum „Gesundheitskompromiss“ als Grundlage der Regelungen H. Sodan „Gesundheitsreform“ ohne Systemwechsel - wie lange noch?, NJW 2003, 2581 (2583).

102 S. Art. 1 des Gesetzes zur Anpassung der Finanzierung von Zahnersatz vom 15. Dezember 2004 (BGB1 I 3445).
} 
zur Diskussion gestellt, durch welches „mit Hilfe von medizinischen und ökonomischen Kriterien ein harter Kern von Leistungen finanziert wird, der für alle Versicherungspflichtigen solidarisch abgesichert werden muß.... Zur Festlegung von Kernleistungen sind die medizinischen Kriterien von besonderer Bedeutung. So werden dringliche Behandlungen, also alle Notfallbehandlungen zu den Kernleistungen zählen müssen. Akute Erkrankungen hingegen müssen nicht generell Kernleistungen sein. So kann ein akuter Infekt durchaus auch privat finanziert werden. Hier wird das ökonomische Merkmal ,Großrisiko“ ergänzend hinzugezogen werden müssen“.103 „Vollkommene Sekurität gefährdet nach der Erfahrung die Moralität.“104

Der Gedanke der Grundsicherung ist mittlerweile bereits außerhalb der Sozialversicherung in einem anderen wesentlichen System der sozialen Sicherung umgesetzt. Das Vierte Gesetz für moderne Dienstleistungen am Arbeitsmarkt vom 24. Dezember 2003105, das unter dem Schlagwort „Hartz IV“ diskutiert wird, fügt in das Sozialgesetzbuch ein Zweites Buch ein, das den Titel trägt: „Grundsicherung für Arbeitsuchende“. Insoweit werden Arbeitslosenhilfe und Sozialhilfe für erwerbsfähige Hilfebedürftige mit Wirkung zum 1. Januar 2005 zusammengeführt. Schon nach noch geltendem Recht ist - was in der politischen Diskussion häufig übersehen wird - die Arbeitslosenhilfe keine Versicherungsleistung der Arbeitslosenversicherung. ${ }^{106}$ Sie wird vielmehr aus Mitteln des Bundes (steuer-)finanziert (§363 Abs. 1 SGB III). Seit dem Inkrafttreten des Bundessozialhilfegesetzes am 1. Juli 1962 ,bestehen mit der Arbeitslosenhilfe und der Sozialhilfe zwei steuerfinanzierte staatliche Fürsorgeleistungen nebeneinander". 107 Die Arbeitslosenhilfe weist deutliche Parallelen zur Sozialhilfe auf. Die künftige „Grundsicherung für Arbeitsuchende soll die Eigenverantwortung von erwerbsfähigen Hilfebedürftigen und Personen, die mit ihnen in einer Bedarfsgemeinschaft leben, stärken und dazu beitragen, dass sie ihren Lebensunterhalt unabhängig von der Grundsicherung aus eigenen Mitteln und Kräften bestreiten können“ (§ 1 Abs. 1 S. 1

\footnotetext{
103 Sachverständigenrat für die Konzertierte Aktion im Gesundheitswesen, Gesundheitsversorgung und Krankenversicherung 2000, Sachstandsbericht 1994, $182 \mathrm{f}$. (Nr. 430 und 433). Vgl. auch M. Arnold Die Krise im Gesundheitswesen - Optionen zur Lösung der Probleme, BKK 1993, 474 (480).

104 K. A. Schachtschneider Res publica res populi, 1994, 440.

105 BGB1 I 2954.

106 S. R. Waltermann (Fn. 8), Rn. 434.

107 So zutreffend die Begründung zu dem von den Fraktionen SPD und Bündnis 90/ Die Grünen eingebrachten Entwurf eines Vierten Gesetzes für moderne Dienstleistungen am Arbeitsmarkt, BT-Drucks. 15/1516, 42.
} 
SGB II). Damit kommt deutlich ein Subsidiaritätsprinzip ${ }^{108}$ zum Ausdruck, dessen Umsetzung generell für die Zukunft der sozialen Sicherungssysteme von großer Bedeutung ist. Zugleich wird an ein Bismarcksches Prinzip angeknüpft: zuerst Eigenverantwortung und dann erst Solidarität ${ }^{109}$. Nach einem Urteil des Bundessozialgerichts zum Bundeskindergeldgesetz ist ohne Verstoß gegen das Sozialstaatsprinzip ein „Abbau von Sozialleistungen mit der Folge einer Einkommensminderung ... bis zur Grenze des Existenzminimums des Berechtigten zulässig“.110

\section{Leistungserbringung für die Sozialversicherung}

Wesentlich für soziale Sicherungssysteme und ihre Finanzierung ist auch das Verhältnis zu den privaten Erbringern von Sozialleistungen. Dies gilt besonders für das Recht der gesetzlichen Krankenversicherung und insoweit vor allem für Ärzte und Zahnärzte, Apotheker, private Krankenhäuser, Leistungserbringer von Heilmitteln und Hilfsmitteln sowie pharmazeutische Unternehmen. ${ }^{111}$ Speziell im so genannten Vertragsarztrecht, das früher „Kassenarztrecht“ hieß, existiert ein mittlerweile hochkompliziertes Regelungsinstrumentarium, welches selbst Experten kaum noch überschauen. Veränderungen des Vertragsarztrechts sind seit langem wesentliche Bestandteile von Reformen der gesetzlichen Krankenversicherung. ${ }^{112}$ Allein seit 1977 hat der Gesetzgeber diese Sozialversicherung durch über 50 größere Gesetze mit deutlich über 7000 Einzelbestimmungen zu sanieren versucht ${ }^{113}$ - jedoch ohne dauerhaften Erfolg und mit erheblichen Belastungen der Leistungserbringer. Das GKV-Modernisierungsgesetz aus dem Jahre 2003 enthält Regelungen in Bezug auf insgesamt 34 Parlamentsgesetze und Rechtsverordnungen. Allein das für die gesetzliche Krankenversicherung zentrale Fünfte Buch Sozialgesetz-

108 Vgl. allgemein zum Subsidiaritätsprinzip H. Sodan (Fn. 42), 307 ff. mwN.

109 Vgl. W. Mommsen (Fn. 2), 133; A. P. F. Ehlers Kostendämpfung und ärztlicher Standard - Theorie und Praxis der Finanzierung der Ausgaben im Gesundheitswesen und Wirtschaftlichkeitsprüfungen, MedR 1993, 334 (337); H. Sodan (Fn. 42), 341.

110 BSG, NJW 1987, 463. S. näher H. Sodan/J. Ziekow (Fn. 25), § 10 Rn. 9.

111 S. speziell zur Einbindung „freier“ heilkundlicher Berufe in das Recht der gesetzlichen Krankenversicherung H. Sodan (Fn. 42), 91 ff., 94 ff., $196 \mathrm{ff} ., 208 \mathrm{ff}$.

112 S. zu einigen Gesetzen aus jüngerer Zeit H. Sodan Gesundheitsrecht, in: Achterberg/Püttner/Würtenberger (Hrsg.) Besonderes Verwaltungsrecht, Bd. II, 2. Aufl. 2000, $\S 25$ Rn. 1.

113 Vgl. zum Stand von 1996 die Begründung der Fraktionen der CDU/CSU und F.D.P. zu ihrem Entwurf eines Gesetzes zur Weiterentwicklung der Strukturreform in der gesetzlichen Krankenversicherung vom 30. Januar 1996, BT-Drucks. 13/3608, 13. 
buch wurde durch Änderungen, Aufhebungen und Einfügungen von über 200 Paragraphen reformiert. ${ }^{114}$ Der Aktionismus des Gesetzgebers, der besonders dem Ziel kurzfristiger Kosteneinsparungen dienen soll, führt zunehmend zu einem Verlust notwendiger Systematik. Denn ein System verlangt eine gedankliche Geschlossenheit, insbesondere Widerspruchsfreiheit. ${ }^{115}$

Die vielfältigen Inpflichtnahmen von Leistungserbringern, die an sich einen so genannten Freien Beruf ${ }^{116}$ ausüben, lassen sich an folgendem Beispiel verdeutlichen: In Verkennung nicht nur einer „einfachgesetzlichen" Vorschrift"117, sondern vor allem auch des in Art. 12 Abs. 1 GG gewährleisteten Grundrechts der Berufsfreiheit geht der 6. Senat des Bundessozialgerichts in ständiger Rechtsprechung 118 davon aus, ein Vertragsarzt habe (regelmäßig) keinen Rechtsanspruch auf eine angemessene Vergütung seiner Tätigkeit, sondern nur einen Anspruch auf eine angemessene Teilhabe an der Verteilung der Gesamtvergütung - mag diese auch zu einer unangemessenen Vergütung der einzelnen Leistungen führen. ${ }^{119}$ Das Bundesverfassungsgericht stellte aber in einem Fall, in dem es

114 Der österreichische Schriftsteller und Übersetzer K. Frieberger schrieb einmal: „Karl der Große erließ in der Zeit seiner Herrschaft hundertzwanzig Gesetze. Ein so armseliges Ergebnis kostet eine gesetzgeberische Versammlung unserer Tage nur ein Auflachen.“ Zitiert nach D. Zimmermann Zimmermanns Zitatenlexikon für Juristen, 1998, 93.

115 S. dazu näher H. Sodan Das Prinzip der Widerspruchsfreiheit der Rechtsordnung, JZ 1999, $864 \mathrm{ff}$.

116 S. zum Begriff etwa $\S 1$ Abs. 2 des Gesetzes über Partnerschaftsgesellschaften Angehöriger Freier Berufe; H. Sodan (Fn. 42), $26 \mathrm{ff}$., $36 \mathrm{ff}$., $63 \mathrm{ff}$.; zu den vielfältigen Gefährdungen der Freiberuflichkeit ebenda, $157 \mathrm{ff}$.

117 S. $§ 72$ Abs. 2 SGB V: „Die vertragsärztliche Versorgung ist im Rahmen der gesetzlichen Vorschriften und der Richtlinien des Gemeinsamen Bundesausschusses durch schriftliche Verträge der Kassenärztlichen Vereinigungen mit den Verbänden der Krankenkassen so zu regeln, daß ... die ärztlichen Leistungen angemessen vergütet werden.“ 118 S. etwa BSGE 75, 187 (189ff.); 77, 279 (288); BSG, SozR 3-2500, § 85 Nr. 12, S. 82; BSGE 83, 205 (217).

119 S. zur Kritik an dieser Rechtsprechung etwa J. Isensee Das Recht des Kassenarztes auf angemessene Vergütung, VSSR 1995, 321 (346f.); M. Heinze Die rechtlichen Rahmenbedingungen der ärztlichen Heilbehandlung, MedR 1996, 252 (255); R. Maaß Die Angemessenheit der Vergütung der vertragsärztlichen Leistung, NZS 1998, 13 (20); R. Wimmer Der Rechtsanspruch von Vertragsärzten auf angemessene Vergütung, MedR 1998, 533 ff.; ders. Der Grundsatz der Beitragssatzstabilität in der gesetzlichen Krankenversicherung, in: Sodan (Hrsg.) Finanzielle Stabilität der gesetzlichen Krankenversicherung und Grundrechte der Leistungserbringer - Vorträge im Rahmen der 1. Berliner Gespräche zum Gesundheitsrecht am 16. und 17. Juni 2003, 2004, 45 (48ff.); P. Axer Normsetzung der Exekutive in der Sozialversicherung, 2000, 265; H. Sodan (Fn. 36), 1763; G. Schneider Die Preisfindung für vertragszahnärztliche Leistungen - Ein Beitrag 
um Konkursverwalter ging, bereits 1993 allgemein fest, die grundrechtlich geschützte Freiheit, einen Beruf auszuüben, sei „untrennbar verbunden mit der Freiheit, eine angemessene Vergütung zu fordern“. ${ }^{120}$

Im Recht der gesetzlichen Krankenversicherung sollen aber offenbar andere Maßstäbe gelten. Das Bundesverfassungsgericht rechtfertigt bereits seit längerem selbst intensive Eingriffe in die Berufsfreiheit wie etwa die vom Gesetzgeber 1992 wieder eingeführten Zulassungsbeschränkungen für Vertragsärzte wegen vermeintlicher Überversorgung ${ }^{121} \mathrm{mit}$ der Formel von der „Sicherung der finanziellen Stabilität und damit der Funktionsfähigkeit der gesetzlichen Krankenversicherung“ als einem „Gemeinwohlbelang von hinreichendem Gewicht“.122 Die gesetzliche Krankenversicherung ist jedoch kein Institut mit Verfassungsrang, sondern „einfachgesetzlich“ begründet.123 Eine eingehende Analyse von Friedhelm Hufen kam unlängst zu dem Ergebnis: Würde das Bundesverfassungsgericht „,seine Rechtsprechung zu anderen Bereichen der Berufsfreiheit auf die gesetzliche Krankenversicherung anwenden, dann wären viele der ergriffenen Maßnahmen verfassungswidrig." ${ }^{24}$ In diesem Sinne stellte Eberhard Schmidt-Aßmann vor kurzem fest: „Von der kontinuierlichen Liberalisierung, die die Grundrechtsrechtsprechung in andere Teile der Wirtschafts- und Sozialordnung hineingetragen hat, ist das Gesundheitsrecht ausgespart geblieben. ... Nach wie vor ist das Gesundheitsrecht in seinem Kern ein um sich selbst kreisendes Sonderrecht."125 Bereits Wolfgang Rüfner formulierte in seinem Bericht auf der Staatsrechtslehrertagung 1969: „In der Sozialversicherung ist vieles anders.“126

zur „Angemessenheit“ der vertragszahnärztlichen Vergütung unter Berücksichtigung der aktuellen Rechtsprechung, SGb 2004, 143 (148).

120 BVerfGE 88, 145 (159); vgl. auch bereits BVerfGE 54, 251 (271); 68, 193 (218); 83, 1 (13).

121 S. dazu näher $H$. Sodan (Fn. 42), $221 \mathrm{ff}$.

122 S. BVerfGE 103, 172 (184); BVerfG, DVB1 2002, 400 (401). Vgl. ferner etwa BVerfGE 68, 193 (218); 70, 1 (29); 82, 209 (230); 103, 392 (404). S. dazu auch H. Sodan Verfassungsrechtsprechung im Wandel - am Beispiel der Berufsfreiheit, NJW 2003, 257 (259).

${ }^{123} R$. Jaeger Welches System der gesetzlichen Krankenversicherung wird durch das Grundgesetz geschützt?, in: Empter/Sodan (Hrsg.) Markt und Regulierung - Rechtliche Perspektiven für eine Reform der gesetzlichen Krankenversicherung, 2003, 15; H. Sodan (Fn. 60), 306.

124 F. Hufen Grundrechtsschutz der Leistungserbringer und privaten Versicherer in Zeiten der Gesundheitsreform, NJW 2004, 14 (18).

125 E. Schmidt-Aßmann Verfassungsfragen der Gesundheitsreform, NJW 2004, 1689 (1690).

126 W. Rüfner Die Rechtsformen der sozialen Sicherung und das Allgemeine Verwaltungsrecht, VVDStRL 28 (1970), 187 (192). 
Ein nennenswerter Zwang zur gebotenen Liberalisierung im Bereich der gesetzlichen Krankenversicherung geht bislang vom europäischen Gemeinschaftsrecht nicht aus. In seinem mit Spannung erwarteten Urteil vom 16. März 2004 antwortete der Europäische Gerichtshof auf eine Vorlagefrage des Bundesgerichtshofes, dass die deutschen Kassenverbände insoweit keine Unternehmen oder Unternehmensvereinigungen iSd Art. 81 EG sind, als sie Festbeträge festsetzen, bis zu deren Erreichen die Krankenkassen die Kosten für Arzneimittel übernehmen. ${ }^{127}$ Damit hält der Europäische Gerichtshof insoweit die Regelungen des europäischen Wettbewerbsrechts nicht für anwendbar. ${ }^{128}$ In den Rechtssachen Decker und Kohll stellte der Europäische Gerichtshof 1998 allerdings klar, dass die Mitgliedstaaten bei der Ausübung ihrer Befugnisse auf dem Gebiet der sozialen Sicherheit das Gemeinschaftsrecht einschließlich der einschlägigen Grundfreiheiten beachten müssen; die Verweigerung von Kostenerstattungen für in einem anderen Mitgliedstaat in Anspruch genommene Gesundheitsleistungen hielt der Gerichtshof für unvereinbar mit der Warenverkehrsfreiheit bzw. Dienstleistungsfreiheit. ${ }^{129}$ Der deutsche Gesetzgeber trug dieser Rechtsprechung jedoch erst mehr als fünf Jahre später im GKV-Modernisierungsgesetz von 2003 Rechnung. ${ }^{130}$

Nahezu unverändert hält der deutsche Gesetzgeber allerdings an dem so genannten Sachleistungs-, genauer: Naturalleistungsprinzip ${ }^{131}$ in der gesetzlichen Krankenversicherung fest, welches die Krankenkassen ihren Versicherten gegenüber zur Vermittlung geeigneter Leistungserbringer

127 EuGH, DVB1 2004, 555. Anders jedoch die Schlussanträge des Generalanwalts F. G. Jacobs, Verbundene Rechtssachen C-264/01, C-306/01, C-354/01 und C-355/01 AOK-Bundesverband u.a./Ichthyol-Gesellschaft Cordes u.a., Rz. $37 \mathrm{ff}$. S. dazu ausführlich H. Sodan Die gesetzlichen Krankenkassen als Unternehmen im Sinne des europäischen Gemeinschaftsrechts, in: Krause/Veelken/Vieweg (Hrsg.) Recht der Wirtschaft und der Arbeit in Europa, GS Blomeyer, 2004, 691 (696ff.).

128 S. dazu, dass dieses Urteil ausdrücklich nur das Verhältnis der deutschen gesetzlichen Krankenkassen zu den Leistungserbringern, nicht jedoch die Unternehmenseigenschaft der gesetzlichen Krankenkassen im Verhältnis zu den privaten Krankenversicherungsunternehmen betrifft, $H$. Sodan (Fn. 60), 308.

${ }^{129}$ EuGH, Slg. 1998, I-1871 - Decker; EuGH, Slg. 1998, I-1935 - Kohll, mit Anmerkung von $H$. Sodan JZ 1998, $1168 \mathrm{ff}$.

${ }^{130}$ S. $\S 13$ Abs. 4 S. 1 SGB V idF von Art. 1 Nr. 4 lit. b GMG: „Versicherte sind berechtigt, auch Leistungserbringer in anderen Staaten im Geltungsbereich des Vertrages zur Gründung der Europäischen Gemeinschaft und des Abkommens über den Europäischen Wirtschaftsraum anstelle der Sach- oder Dienstleistung im Wege der Kostenerstattung in Anspruch zu nehmen, es sei denn, Behandlungen für diesen Personenkreis im anderen Staat sind auf der Grundlage eines Pauschbetrages zu erstatten oder unterliegen auf Grund eines vereinbarten Erstattungsverzichts nicht der Erstattung.“

131 S. dazu näher H. Sodan (Fn. 42), 119ff., $310 \mathrm{ff} ., 319 \mathrm{ff}$. 
verpflichtet. Seit dem GKV-Modernisierungsgesetz gesteht er immerhin allen Versicherten zu, anstelle der Sach- oder Dienstleistungen Kostenerstattung zu wählen.132 Das überkommene Naturalleistungsprinzip hat zur Folge, dass die Versicherten an den Abrechnungsvorgängen betreffend die für sie erbrachten Leistungen nicht beteiligt sind, also noch nicht einmal eine diesbezügliche Kontrolle ausüben können. Die Einführung eines generellen Kostenerstattungsprinzips dürfte das Kostenbewusstsein und damit die Sparsamkeit der Versicherten fördern. Zur Kostensteuerung und wirtschaftlichen Leistungserbringung hat sich das Naturalleistungsprinzip ohnehin als ungeeignet erwiesen. ${ }^{133}$

\section{Resümee}

Nach allem bleibt festzuhalten: Verbindende Strukturelemente eines einheitlichen Systems sozialer Sicherung könnten künftig sein: einkommensunabhängige Versicherungsprämien mit einem steuersolidarisch finanzierten sozialen (Familienlasten-)Ausgleich bei gleichzeitiger Beschränkung des Versichertenkreises auf sozial Schutzbedürftige und Reduzierung der Sozialleistungen auf eine Grundsicherung. Speziell für die gesetzliche Krankenversicherung sollte das Naturalleistungsprinzip durch ein Kostenerstattungsprinzip ersetzt werden. Diese Strukturelemente würden sich sowohl auf die Einnahmen- als auch auf die Ausgabenseite auswirken.

Noch im Jahre 2000 konnte Bernd Rüthers zu Recht feststellen: „Die Republik lebt und handelt derzeit nach einem ungeschriebenen Art. 0 des Grundgesetzes: Erreichte soziale Besitzstände sind unantastbar."134 Nach der mit dem Schlagwort „Hartz IV“ verbundenen Entwicklung in der jüngsten Zeit trifft diese Bilanz nicht mehr uneingeschränkt zu. Gleichwohl sind für die sozialen Sicherungssysteme noch viele Probleme zu lösen. „Aber Generationen vor uns hätten sich gewünscht, unsere Probleme zu haben.“ Daher ist es „nicht die Zeit, sich durch Untergangsphantasien lähmen zu lassen. Es ist allerdings hohe Zeit, die Herausforderungen und die großen Chancen der Gegenwart anzunehmen und zu handeln.“135

$132 \mathrm{~S}$. die Regelungen in $\S 13$ Abs. 2 SGB V idF von Art. 1 Nr. 4 lit. a GMG.

133 S. näher H. Sodan (Fn. 42), 315 ff.; ders. Normsetzungsverträge im Sozialversicherungsrecht, NZS 1998, 305 (312).

${ }^{134}$ B. Rüthers Die Arbeitsgesellschaft im Umbruch - Krise auf Zeit oder Zerfall eines Leitbildes?, 2000, 58.

${ }^{135}$ B. Rüthers (Fn. 134), 58f. Zustimmend K. Adomeit Die Agenda 2010 und das Arbeitsrecht, 2004, 34f. 
Leitsätze des 2. Berichterstatters über:

\section{Die Zukunft der sozialen Sicherungssysteme}

\section{Entwicklung sozialer Sicherungssysteme}

(1) Die wesentlich durch Otto von Bismarck kreierte Sozialpolitik führte zu dem Gesetz betreffend die Krankenversicherung der Arbeiter (1883), dem Unfallversicherungsgesetz (1884) sowie dem Gesetz betreffend die Invaliditätsund Altersversicherung (1889).

(2) Diesen wegweisenden Gesetzgebungswerken liegen Prinzipien zugrunde, die noch heute die Sozialversicherung prägen: die Errichtung einer grundsätzlichen Pflichtversicherung mit öffentlich-rechtlicher Organisation und auf der Grundlage einer Selbstverwaltung mit staatlicher Aufsicht; die Finanzierung durch gemeinsam von Arbeitern und deren Arbeitgebern aufgebrachte Beiträge, wobei für die Rentenversicherung ein Staatszuschuss vorgesehen war; die Regelung eines für den Eintritt des Versicherungsfalls gegebenen öffentlich-rechtlichen Leistungsanspruchs.

(3) Die spätere Expansion der sozialen Sicherungssysteme hat zugleich zu einer Explosion der Kosten geführt. Im Jahre 2002 umfasste das Sozialbudget, in dem sämtliche Ausgaben für Zwecke der sozialen Sicherung enthalten sind, rund 685 Milliarden Euro - knapp ein Drittel des Bruttoinlandsprodukts in Deutschland. Noch 1960 betrug das Verhältnis des Sozialbudgets zum Bruttoinlandsprodukt desselben Jahres nur etwas über 20 Prozent, 197025 Prozent.

\section{Personeller Umfang der Sozialversicherung}

(4) Grundlage jeder Versicherung ist der Versichertenkreis. Basis einer sozialen Versicherung ist das Prinzip der Pflichtversicherung. Der gesetzlichen Krankenversicherung gehörten im 19. Jahrhundert zunächst nur etwa 10 Prozent der Bevölkerung als sozial Schutzbedürftige an, nämlich die Arbeiter mit den niedrigsten Löhnen. In der Bundesrepublik Deutschland sind unter Hinzurechnung der mitversicherten Familienangehörigen mittlerweile etwa 90 Prozent der Bevölkerung in den Schutz der gesetzlichen Krankenversicherung einbezogen. 
(5) Die aktuell beitragszahlenden Mitglieder einer Sozialversicherung sind für deren Funktionsfähigkeit von besonderer Bedeutung, weil die deutsche Sozialversicherung auf dem so genannten Umlageverfahren beruht: In dem die private Versicherung prägenden Kapitaldeckungsverfahren wird aus den Beiträgen Vermögen gebildet, das die Grundlage späterer Versicherungsleistungen darstellt; das Umlageverfahren, welches auch als „Generationenvertrag“ bezeichnet wird, kommt hingegen ohne Kapitalakkumulation aus. Aufgrund der demographischen Entwicklung müssen immer weniger junge Erwerbstätige die Sozialleistungen für immer mehr ältere Menschen finanzieren. Dieser Trend wird sich fortsetzen.

(6) In Bezug auf die gesetzliche Krankenversicherung sieht die von der Bundesministerin für Gesundheit und Soziale Sicherung eingesetzte „Rürup-Kommission“ eine mögliche Alternative in der Einführung einer „Bürgerversicherung“. Das vorgeschlagene Modell hebt die bisherige Versicherungsplichtgrenze auf und schafft eine umfassende „Einwohnerversicherung“, bezieht also auch Selbständige und Beamte ein; die private Krankenversicherung soll auf das Angebot von Zusatzversicherungen beschränkt werden.

(7) Dieses Konzept stößt jedoch auf schwerwiegende verfassungsrechtliche Einwände. Sehr zweifelhaft ist, ob der Bund für gesetzliche Festlegungen einer als umfassende Zwangsversicherung ausgestalteten gesetzlichen Krankenversicherung den Kompetenztitel „Sozialversicherung“ (Art. 74 Abs. 1 Nr. 12 GG) für sich in Anspruch nehmen könnte. Nach der Judikatur des Bundesverfassungsgerichts können neue Lebenssachverhalte in das Gesamtsystem „Sozialversicherung“ einbezogen werden, wenn zumindest eine Orientierung am klassischen Bild der Sozialversicherung erfolgt. Von diesem Bild würde sich jedoch eine umfassende „Bürgerversicherung“ - gerade durch die künftige Einbeziehung von Selbständigen und Beamten - vollends lösen.

(8) Auch in materieller Hinsicht bestehen Bedenken gegen eine als ,Volksversicherung" ausgestaltete Sozialversicherung. Zwar ist eine soziale Pflichtversicherung prinzipiell zulässig. Eine die gesamte Bevölkerung einbeziehende Bürgerzwangsversicherung würde aber für viele Pflichtmitglieder, die eindeutig nicht sozial schutzbedürftig sind, in keinem vernünftigen Verhältnis zu den diesen Personen aus der Pflichtzugehörigkeit erwachsenden Vorteilen stehen. Sie wäre daher wegen Verstoßes gegen das Recht auffreie Entfaltung der Persönlichkeit verfassungswidrig. Ebenso wenig ließe sich der zumindest mittelbare Eingriff in das den privaten Krankenversicherungsunternehmen gewährleistete Grundrecht der Berufsfreiheit rechtfertigen. Der Gesetzgeber hat die bipolare Versicherungsverfassung zu beachten.

(9) Eine abgeschwächte Variante einer „Bürgerversicherung“ sieht das Ende August 2004 vorgelegte „Modell einer solidarischen Bürgerversicherung" vor. Danach bleiben die bestehenden Altverträge in der privaten Krankenversicherung unangetastet. Für Neuverträge soll jedoch ausschließlich ein 
„Tarif Bürgerversicherung“ zur Verfügung stehen. Zum Angebot dieses Tarifs könnten sowohl die gesetzlichen Krankenkassen als auch die privaten Krankenversicherungsunternehmen zu gleichen Wettbewerbsbedingungen zugelassen werden; Beitragssatzunterschiede sind möglich. Der „Tarif Bürgerversicherung" ist u.a. durch einen einheitlichen gesetzlichen Leistungskatalog und einen Kontrahierungszwang auch für private Krankenversicherungsunternehmen gekennzeichnet.

(10) Erhebliche verfassungsrechtliche Bedenken gegen dieses Modell bestehen bereits im Hinblick auf die erforderliche Gesetzgebungskompetenz des Bundes. Diese lässt sich, soweit die private Krankenversicherung betroffen ist, aus dem in Art. 74 Abs. 1 Nr. 11 GG genannten Kompetenztitel „privatrechtliches Versicherungswesen “ nicht herleiten. Denn die gesetzliche Regelung eines von jedem individuellen Risiko gelösten, versicherungsintern einheitlichen „Tarifs Bürgerversicherung “ würde zu einer Nivellierung der Prämien führen. Für die Versicherten würde sich angesichts der Tatsache, dass ihre Wahlmöglichkeit nur auf die Organisationsform der gesetzlichen Krankenkasse bzw. des privaten Krankenversicherungsunternehmens beschränkt wäre, faktisch keine nennenswert geringere Belastung ergeben als im Falle der zwangsweisen Einbeziehung in eine Sozialversicherung. Die privaten Krankenversicherungsunternehmen könnten dem genannten Modell ihr Grundrecht der Berufsfreiheit entgegenhalten, welches die Wettbewerbsfreiheit einschließt.

(11) Das von der „Rürup-Kommission“ als zweite Alternative vorgeschlagene „System pauschaler Gesundheitsprämien “ orientiert sich am Äquivalenzprinzip und zielt auf eine völlige Entkoppelung der Beiträge zur gesetzlichen Krankenversicherung von den Arbeitskosten. Die bisherigen Arbeitgeberbeiträge sollen als Bruttolohnbestandteile ausgezahlt werden. Beitrags- bzw. Prämienerhöhungen zögen künftig keine Verteuerung des Faktors Arbeit mehr nach sich. Um den erforderlichen sozialen Ausgleich zu gewährleisten, sollen Versicherte mit geringen Haushaltseinkommen steuerfinanzierte Prämienzuschüsse erhalten.

(12) Durchgreifende verfassungsrechtliche Bedenken gegen ein einkommensunabhängiges Prämienmodell sind nicht ersichtlich. Für die angestrebten Neuregelungen hätte der Bund die Gesetzgebungszuständigkeit aus dem Kompetenztitel „Sozialversicherung“. Zwar baut das klassische Bild der Sozialversicherung auf dem Prinzip der versicherungsinternen Umverteilung und nicht auf einer Finanzierung über das Steuersystem auf. Das vom Bundesverfassungsgericht genannte Kriterium, wonach zur Sozialversicherung „jedenfalls die gemeinsame Deckung eines möglichen, in seiner Gesamtheit schätzbaren Bedarfs durch Verteilung auf eine organisierte Vielheit" gehört, wäre aber erfüllt.

(13) Zusätzlich zur Einführung eines Prämienmodells sollte auch der Versichertenkreis durch eine deutliche Senkung der Versicherungspflichtgrenze 
und eine Beseitigung der Möglichkeit zur freiwilligen Versicherung erheblich reduziert werden, und zwar auf die wirklich sozial Schutzbedürftigen. Mit einer Kombination von Prämiensystem und Beschränkung des Versichertenkreises auf sozial Schutzbedürftige ließe sich auch dem Einwand „sozialer Ungerechtigkeit" begegnen, der auf die gleiche Höhe der Beitragsleistungen von Menschen mit hohem und solchen mit niedrigem Einkommen gestützt wird. Die Unterschiede der in die gesetzliche Krankenversicherung Einbezogenen wären in materieller Hinsicht nämlich deutlich geringer; der Versichertenkreis erwiese sich insgesamt als homogener. Über ein Steuer-Transfer-System würden auch die finanziell Leistungsstärksten zur Unterstützung der sozial Schutzbedürftigen herangezogen, ohne - wie beim Modell einer umfassenden „Bürgerversicherung“ - zugleich selbst in eine Sozialversicherung gezwungen zu werden. Wer nicht sozial schutzbedürftig ist, vermag sein Krankheitsrisiko eigenverantwortlich abzusichern.

(14) Das Modell einkommensunabhängiger Prämien bei gleichzeitiger Reduzierung des Versichertenkreises auf sozial Schutzbedürftige ließe sich auch auf andere Zweige der Sozialversicherung übertragen. Es könnte zu einem verbindenden Strukturelement eines einheitlichen Systems sozialer Sicherung werden.

(15) Konsequent wäre es, den notwendigen Familienlastenausgleich künftig nicht innerhalb einer begrenzten Solidar-Versichertengemeinschaft, sondern als gesamtgesellschaftiche Aufgabe durch Steuern zu finanzieren.

\section{Sachlicher Umfang der Sozialversicherung}

(16) Die derzeit erheblichen Finanzierungsprobleme stellen auch den Umfang der Sozialleistungen auf den Prüfstand. Dies gilt zunächst für die gesetzliche Rentenversicherung. Auf deren Finanzierbarkeit wirken sich die demographische Entwicklung, die Massenarbeitslosigkeit und der anhaltende Trend zur Frühverrentung in besonderem Maße aus. Der Gesetzgeber versucht seit längerem, den veränderten Rahmenbedingungen durch Maßnahmen zu begegnen, die letztlich zu Rentenkürzungen führen.

(17) Das Bundesverfassungsgericht erstreckt seit seiner Entscheidung zum Versorgungsausgleich aus dem Jahre 1980 den Grundrechtsschutz der Eigentumsgarantie auch auf Ansprüche und Anwartschaften auf Versichertenrenten aus der gesetzlichen Rentenversicherung.

(18) Die Kürzung sowohl von Rentenansprüchen als auch von Rentenanwartschaften wird allgemein als Inhalts- und Schrankenbestimmung eingeordnet, die am Grundsatz der Verhältnismäßigkeit zu messen ist. Nach der Rechtsprechung des Bundesverfassungsgerichts verengt sich die Gestaltungsfreiheit des Gesetzgebers ,in dem Maße, in dem Rentenansprüche oder Ren- 
tenanwartschaften durch den personalen Bezug des Anteils eigener Leistung des Versicherten geprägt sind“. Daher steht dem Gesetzgeber bei der Regelung beitragsunabhängiger Rentenberechnungsfaktoren, wie etwa der Anrechnung von Ausbildungsausfallzeiten, ein weiter Gestaltungsspielraum zu; die Änderung beitragsabhängiger Faktoren, insbesondere der Entgeltpunkte in der gegenwärtigen Rentenformel, unterliegt hingegen engen verfassungsrechtlichen Beschränkungen.

(19) Die Gestaltungsfreiheit des Gesetzgebers im Hinblick auf die Änderung von Sozialleistungen wird nicht nur bei der gesetzlichen Rentenversicherung, sondern auch bei den anderen Sozialversicherungszweigen wesentlich durch das Umlageverfahren beeinflusst. Dieses beruht nicht auf der Bildung von Vermögen, sondern auf der Kontinuität der Versicherung. Ein auf dem Umlageverfahren beruhendes Sozialleistungssystem kann keine Sicherheit garantieren, weil sein Fortbestand von Leistungsbereitschaft und Leistungsvermögen künftiger Generationen abhängt.

(20) Der Übergang zur Kapitaldeckung erweist sich als der zwar an sich richtige, aber zumindest derzeit sehr schwierige Weg. Im Falle der Beibehaltung des Umlageverfahrens bedarf es der Reduzierung der Sozialleistungen auf eine Grundsicherung.

(21) Der Gedanke der Grundsicherung ist mittlerweile bereits außerhalb der Sozialversicherung in einem anderen wesentlichen System der sozialen Sicherung umgesetzt. Das Vierte Gesetz für moderne Dienstleistungen am Arbeitsmarkt vom 24. Dezember 2003, das unter dem Schlagwort „Hartz IV“ diskutiert wird, fügt in das Sozialgesetzbuch ein Zweites Buch ein, das den Titel trägt: „Grundsicherung für Arbeitsuchende“. Insoweit werden Arbeitslosenhilfe und Sozialhilfe für erwerbsfähige Hilfebedürftige mit Wirkung zum 1. Januar 2005 zusammengeführt.

\section{Leistungserbringung für die Sozialversicherung}

(22) Wesentlich für soziale Sicherungssysteme und ihre Finanzierung ist auch das Verhältnis zu den privaten Erbringern von Sozialleistungen. Dies gilt besonders für das Recht der gesetzlichen Krankenversicherung. Speziell im so genannten Vertragsarztrecht, das früher „Kassenarztrecht“ hieß, existiert ein mittlerweile hochkompliziertes Regelungsinstrumentarium, welches selbst Experten kaum noch überschauen.

(23) Das Bundesverfassungsgericht rechtfertigt bereits seit längerem selbst intensive Eingriffe in die Berufsfreiheit wie etwa die vom Gesetzgeber 1992 wieder eingeführten Zulassungsbeschränkungen für Vertragsärzte wegen vermeintlicher Überversorgung mit der Formel von der „Sicherung der finanziellen Stabilität und damit der Funktionsfähigkeit der gesetzlichen Krankenver- 
sicherung“ als einem „Gemeinwohlbelang von hinreichendem Gewicht“. Die gesetzliche Krankenversicherung ist jedoch kein Institut mit Verfassungsrang, sondern „einfachgesetzlich“ begründet. In der Literatur wird zu Recht kritisiert, das Gesundheitsrecht sei „ein um sich selbst kreisendes Sonderrecht“.

(24) Ein nennenswerter Zwang zur gebotenen Liberalisierung im Bereich der gesetzlichen Krankenversicherung geht bislang vom europäischen Gemeinschaftsrecht nicht aus.

\section{Resümee}

(25) Verbindende Strukturelemente eines einheitlichen Systems sozialer Sicherung könnten künftig sein: einkommensunabhängige Versicherungsprämien mit einem steuersolidarisch finanzierten sozialen (Familienlasten-)Ausgleich bei gleichzeitiger Beschränkung des Versichertenkreises auf sozial Schutzbedürftige und Reduzierung der Sozialleistungen auf eine Grundsicherung. Speziell für die gesetzliche Krankenversicherung sollte das Naturalleistungsprinzip durch ein Kostenerstattungsprinzip ersetzt werden. Diese Strukturelemente würden sich sowohl auf die Einnahmen-als auch auf die Ausgabenseite auswirken. 


\section{Aussprache und Schlussworte}

\section{Die Zukunft der sozialen Sicherungssysteme}

Vorsitzender (Huber): Verehrte Kolleginnen und Kollegen. Nachdem wir heute Vormittag die staatstheoretischen und grundrechtsdogmatischen Grundlagen des Sozialstaats diskutiert haben, wollen wir uns nach den beiden Referaten von Herrn Pitschas und Herrn Sodan der institutionellen Ausgestaltung der sozialen Sicherungssysteme zuwenden, nicht zuletzt in dem Bestreben, das Sozialrecht stärker als Referenzgebiet für das Öffentliche Recht zu erkennen und zu entfalten. Beide Referenten waren, auch wenn sie die Akzente unterschiedlich gesetzt haben, und Herr Pitschas eher die Gestaltungsfreiheit des Gesetzgebers betont hat, während es Herrn Sodan mehr um deren grundrechtliche Grenzen ging, im Ergebnis dabei wohl gar nicht so weit voneinander entfernt.

Die Diskussion sollten wir wie folgt strukturieren: in einem ersten Abschnitt allgemeine Fragen zu den Grundlagen der sozialen Sicherungssysteme, ihrer Entwicklung, den ökonomischen Rahmenbedingungen und ihrer Ausgestaltung im Einzelnen. Im zweiten Teil sollte es dann um die verfassungsrechtlichen Anforderungen der akutellen und zukünftigen Reformen gehen, während zum Schluss die Zukunftsperspektiven zur Sprache kommen sollen.

Im Rahmen unseres ersten Abschnitts, den Grundlagen, habe ich als Erstes Herrn Gröschner, nach Herrn Gröschner Herrn Ruland und dann Herrn Breuer. Herr Gröschner bitte.

Gröschner: Eine Frage an Herrn Pitschas und eine Antwort auf Herrn Wiederin. Beides lässt sich besser miteinander verbinden, wenn ich mit dem Schlusssatz des Schlusswortes von Herrn Wiederin beginne. Dort war die Rede davon, dass der Sozialstaat die Voraussetzungen für ein glückendes Leben aller - eine glückliche Formulierung - zu gewährleisten habe. Der so verstandene Sozialstaat darf die Freiheit dann aber nicht nur grundrechtlich, also in liberal-rechtsstaatlicher Tradition schützen, sondern er muss als freiheitlicher Sozialstaat tätig werden, das heißt: durch Gewährleistung der allgemeinen Voraussetzungen zum Gebrauch der Freiheitsgrundrechte. Das ist eine Formel, die heutzutage ja durchaus üblich geworden ist. Wenn man aber dieser üblichen und, wie ich finde, richtigen Formel folgt, dann ist der freiheitliche Sozialstaat essentieller 
Bestandteil der freiheitlichen demokratischen Grundordnung im Sinne des Grundgesetzes und damit im Rahmen der Grundsätze des Art. 20 GG änderungsfest im Sinne des Art. 79 Abs. 3 GG. Insofern war das Schlusswort von Herrn Wiederin, wenn auch unbeabsichtigt, ein Zugeständnis an die Kritiker der unhaltbaren These 13! Meine Frage an Herrn Pitschas betrifft die These 3, zunftgemäß zitiert: These 3 Abs. 1 S. 3. Dort heißt es: In objektiv-rechtlicher Wendung entspreche dem - nämlich dem Freiheitsprinzip der Sätze 1 und 2 - „,bis zu einem gewissen Ausmaß die Verpflichtung zu individueller Vorsorge durch Versicherung und Vermögensbildung“. Das ist sehr schön alliterierend formuliert, aber was bedeutet „Verpflichtung“ dogmatisch? Wenn es eine verfassungsunmittelbare Rechtspflicht - dann wohl aufgrund Sozialstaatsprinzips in Verbindung mit Menschenwürde - sein soll, fragt sich, wem gegenüber diese Pflicht besteht. Konsequenterweise wäre es dann eine Obliegenheit, also eine Rechtspflicht gegen sich selbst, oder, und das ist die Frage an Herrn Pitschas, handelt es sich doch um eine Verfassungserwartung und damit gerade nicht um eine Rechtspflicht, sondern um eine moralische Pflicht?

Ruland: Ich habe einige Anmerkungen zu den Vorträgen, wobei ich vorweg einräume, dass ich als jemand, der nicht mehr an der Hochschule lehrt, sondern für die Rentenversicherung eine besondere Verantwortung trägt, vielleicht eine eigene Sicht der Dinge habe. Herr Sodan hat differenziert: Eigenverantwortung, und dann erst Solidarität. Das kann ich nicht nachvollziehen. Als ob solidarisches Handeln nicht auch eigenverantwortlich wäre. Der Abschluss einer Versicherung ist eigenverantwortlich, trotzdem solidarisch. Zumeist ist Eigenverantwortung nur in Solidarität erreichbar.

Eigenverantwortung setzt in hohem Maße voraus, dass der Einzelne die Chance hat, auf dem Markt entsprechend richtige Entscheidungen zu treffen. Da gibt es gerade bei der sogenannten Riesterrente Probleme. Bei ihr ist Eigenverantwortung gesetzlich eingefordert worden. Der Markt bietet aber nicht die notwendige Transparenz. Deshalb halten sich die Leute zurück, entscheiden sich lieber für eine betriebliche Altersversorgung, wo sie sicher sind, nicht „über den Tisch gezogen“ zu werden. Daher: Wer Eigenverantwortung in stärkerem Maße fordert, muss auch Markttransparenz und Regelungen einfordern, die diejenigen, die auf den Markt und die dort geschlossenen Verträge angewiesen sind, entsprechend sozial schützen. Die meisten Sozialversicherten können mit Banken und Versicherungen nur schwer umgehen. Das darf man nicht vergessen. Solidarität ist nicht nur eine Verpflichtung für Arme. Solidarität ist eine Verpflichtung zwischen Reich und Arm. Deshalb ist die Begrenzung der Sozialversicherung nur auf die Bedürftigen ein völlig falscher Ansatz. 
Es ist generell schwer, Erkenntnisse anderer Disziplinen zu übernehmen. Die These, dass das Umlageverfahren von der Demographie abhängig ist, ist zwar richtig. Dass aber auch kapitalgedeckte Systeme von der Demographie abhängig sind, ist bei den Volkswirten inzwischen unbestritten. Dies ist bei den Juristen leider noch nicht angekommen. Insofern betrifft das Demographieproblem alle sozialen Sicherungssysteme, nicht nur die umlagefinanzierten. Wem wollen Sie Häuser vermieten, wenn es nicht mehr genug Mieter gibt? Wem wollen Sie Aktien verkaufen, wenn die Zahl der Käufer niedriger wird? Insofern - die Volkswirte haben das längst eingesehen - ist die Begrenzung der ganzen Problematik auf die umlagefinanzierte Rentenversicherung nur bedingt richtig. Sie erfasst die anderen Systeme der Altersvorsorge auch. Deshalb ist die Flucht oder der Ausweg in die Eigenverantwortung keine Chance, der Demographie und den daraus resultierenden Problemen zu entgehen. Da das so ist, ist die Sicht der beiden Referate, die - viel zu eng - nur die Sozialversicherung im Auge hatten, problematisch. Es wird nicht zur Kenntnis genommen, dass auch die Privatversicherung, vor allem die private Rentenversicherung, entsprechende Probleme hat, und dass die betriebliche Altersversorgung nicht weiß, wie sie ihre Leistungszusagen finanzieren soll. Denken Sie nur an die gravierenden Änderungen bei der VBL.

Was mich wundert - ich provoziere jetzt ein wenig - ist, dass das Stichwort „Beamtenversorgung“ mit den hohen Lasten, die auf die öffentliche Hand zukommen, überhaupt nicht angesprochen worden ist. Vielleicht ist das im Kreise so vieler Beamter nicht atypisch. Gerade im Vergleich zur Beamtenversorgung nervt mich aber das unzutreffende Schlagwort von Herrn Pitschas: „Komfortsicherung“. Da die beschlossenen Reformen dazu führen, dass im Bereich der Rentenversicherung das Sicherungsniveau vor Steuern auf etwa $45 \%$ abgesenkt wird, ist der Ausdruck „Komfortsicherung“ unzutreffend. Außerdem wüsste ich keinen Bereich der sozialen Sicherung, wo dieses Klischee noch zutreffen würde.

Bei der Sicht der aktuellen Probleme würde ich gerne auch ein paar andere Akzente setzen. Es klang so, als wenn die Zukunft erst mit der Agenda 2010 begonnen hätte. Für den wichtigen Bereich Rentenversicherung - der ja den größten Teil der sozialen Umverteilung ausmacht - darf ich Sie daran erinnern, dass wir schon jetzt den Beitragssatz für 2030, der 1989 mit 36-41 \% hochgerechnet wurde, trotz gestiegener Lebenserwartung und verschlechterten wirtschaftlichen Annahmen auf rund 22\% abgesenkt haben. Es gibt Bereiche, die ihre Zukunftsaufgaben weitgehend schon erledigt haben. Man muss es nur zur Kenntnis nehmen.

Es sind natürlich auch schon die Altersgrenzen angehoben worden. Zwar noch nicht die Regelaltersgrenze von 65 Jahren, wohl aber der 
wichtige Bereich der vorgezogenen Altersgrenzen, der ja sehr viel Geld gekostet hat.

Bei der Krankenversicherung ist ein ganz entscheidendes Problem bei der Bewertung von Gesundheitsprämie auf der einen Seite und Bürgerversicherung auf der anderen Seite nicht angesprochen worden. Soll der soziale Ausgleich über Steuern oder über Sozialversicherungsbeiträge finanziert werden? Es ist richtig - insofern unterstütze ich Ihre These, Herr Sodan -, dass es sinnvoll nur sein kann, den sozialen Ausgleich über Steuern zu finanzieren. Die Steuerfinanzierung ist die wesentlich gerechtere Finanzierungsweise, da sie alle entsprechend ihrer Leistungsfähigkeit trifft. Die Steuerfinanzierung erfasst auch Beamte, Richter und Einkommen oberhalb der Beitragsbemessungsgrenzen. Allerdings, ein Problem besteht noch: Werden die Milliardenbeträge, die zur sozialen Flankierung der Gesundheitsprämie notwendig sind, in den Bundeshaushalt hineingenommen, erhält in ihm das Soziale ein noch viel größeres Gewicht und gefährdet damit möglicherweise das Soziale. Das ist für mich das entscheidende Problem der Bürgerversicherung.

Vorsitzender: Vielen Dank, Herr Ruland. Wegen der besonderen Betroffenheit haben wir diese Abweichung von der Vier-Minuten-Regel ausnahmsweise gemacht. Ich darf nun Herrn Breuer das Wort erteilen.

Breuer: Gestatten Sie drei Bemerkungen. Zum Ersten möchte ich im Hinblick auf die historischen Grundlagen eine Korrektur anbringen. So richtig es ist, dass in Deutschland der Sozialstaat und das System der Sozialversicherung auf die Bismarckschen Reformen zurückgehen, muss man doch darauf hinweisen, dass Bismarck eigentlich etatistisch gedacht hat und von Staats wegen paternalistisch ein soziales Sicherungssystem einführen wollte. Es ist dann das Verdienst der christlichen Soziallehre gewesen, dass in Wahrheit ein anderes sozialversicherungsrechtliches System entstanden ist. Hier kann man aus dem Bereich der katholischen Soziallehre hinweisen auf Namen wie Ritter von Buß, Freiherr von Hertling, Franz Hitze, Bischof von Ketteler. Auf protestantischer Seite war es der Ministerialbeamte Theodor Lohmann, der unter Bismarck gearbeitet hat, sich dann mit Bismarck überworfen hat, gerade weil Bismarck etatistisch dachte und weil Theodor Lohmann der Meinung war, dass die Eigenverantwortlichkeit gestärkt werden sollte, wie auch die Subsidiarität und die Solidarität. Damit treffen sich also die katholische und die protestantische Lehre. Das sollte man der historischen Wahrheit wegen hervorheben, und insoweit wäre ich den Referenten für ein klärendes Wort dankbar.

Zweiter Punkt: Man wird wohl sehen müssen, dass, wie Herr Pitschas es ausgedrückt hat, das deutsche System des Sozialstaates und der So- 
zialversicherung im nationalen Kontext verstanden werden muss. Es war eine Aufgabe der nationalen Integration, und es war die Phase, in der der Sozialismus und der Kommunismus als Gefahr erkannt wurden. Die Integration des neu gebildeten Deutschen Reiches stand auf dem Spiel. Es war aber zugleich eine Phase, in der sich dann die verschiedenen Strömungen der Gesellschaft zusammengefunden haben. Staat und Gesellschaft sind in dieser Phase miteinander verschweißt worden, das sollte man erkennen. Und hier müssen wir uns heute kritisch die Frage stellen, ob der Widerpart des Staates, also die Gesellschaft, nicht intern einer Erosion ausgesetzt ist. Ich glaube, um die Dinge zuzuspitzen, dass es nicht damit getan ist, in ökonomischer und juristischer Hinsicht irgendetwas zu reparieren. Wir müssen das Problem des demographischen Wandels sehen, wir müssen die Phänomene der sozialen Desintegration sehen. Ich kann und will das im Moment nicht vertiefen. Hier wäre in der Tat im gesellschaftlichen Innenbereich mehr zu fordern.

Dritte Frage: Wenn man, was ich im Prinzip für richtig halte, die alten Prinzipien der Subsidiarität, der Solidarität und des Gemeinwohls beschwört, dann muss man sich fragen, ob hier, in der sozialen Demokratie, wie Lorenz von Stein gesagt hat, diese Prinzipien reaktiviert werden können. Das bedeutet dann allerdings Versicherungspflicht, staatlicher Rahmen, ordnungsrechtlicher Rahmen des Staates. Oder zwingt uns möglicherweise das Europarecht, einen europäischen Sozialstaat aufzubauen? Ich halte das für eine Utopie. Aber gerade wenn es im gegenwärtigen Moment eine Utopie ist, dann müsste doch klargestellt werden, was an Verantwortung dem demokratischen Gesetzgeber in den Mitgliedstaaten aufgebürdet ist und aufgebürdet bleibt. Insofern meine ich, dass mehr strukturelle Klarheit erforderlich ist. Es reicht nicht aus, mit einigen Stichworten die Probleme anzutippen, dann muss man sozialstaatlich schon Farbe bekennen. Ich würde mich hier im Prinzip zur Tradition des deutschen Sozialstaats bekennen und die alten Prinzipien der Subsidiarität, Solidarität und des Gemeinwohls noch einmal in Erinnerung bringen wollen.

Vorsitzender: Vielen Dank, Herr Breuer. Ich habe jetzt als Letzten zu Punkt eins Herrn Höfling, und dann zu Punkt zwei Herrn Ebsen, Herrn Schachtschneider und Frau Iliopoulos-Strangas. Herr Höfling, bitte.

Höfling: Wem auch immer das Lob gebührt, dieses Thema auf die Tagesordnung gesetzt zu haben, in der Tat: Sozialrecht als Referenzgebiet, insbesondere für die Verfassungsrechtler, das war dringend notwendig. Nur glaube ich, fruchtbare Befassung mit solchen Referenzgebieten ist nur möglich, wenn man auch die soziale Wirklichkeit 
einbezieht. Und insofern habe ich ein bisschen mehr an Empirie vermisst, wenn ich das so sagen darf. Ich will nur ganz wenige Punkte benennen. Ein ganz wichtiger Referenzbereich innerhalb unseres Referenzgebiets wird die soziale Pflegeversicherung sein. 2030 werden wir etwa fünf Millionen pflegebedürftige alte Menschen haben. Ich frage mich: Wie soll das finanziert werden? Vor allen Dingen, um die Verknüpfung zu heute Morgen zu finden: Wie soll das finanziert werden unter Bedingungen, die auch der Menschenwürde - und die Menschenwürde dirigiert das Sozialstaatsprinzip - gerecht werden? Auch da nur ganz wenige Blicke auf die heutige soziale Wirklichkeit. Da wird man sehen müssen, dass aus Kostengründen jede vierte, wenn nicht jede dritte Magensonde, die gelegt wird, medizinisch nicht indiziert ist, sondern gelegt wird, weil die Pflegekassen die Kosten nur übernehmen, wenn nicht gefüttert werden muss, was viel Zeit kostet, und keine Bettwäsche gewaschen werden muss, weil auch das Geld kostet. Wenn tausendfach Dekubitusgeschwüre unzureichend behandelt werden, also Körperverletzungen stattfinden und die (Heim-)Aufsicht unzulänglich funktioniert, dann frage ich mich: Wie machen wir das in 25 Jahren mit fünf Millionen Betroffenen? Und ein Letztes: Diese Zustände sind nicht Schicksal, sondern Folge von Allokationsentscheidungen; und deshalb sollte man auch sagen, wo nehmen wir etwas weg, damit wir wenigstens die Mindestbedingungen für ein menschenwürdiges Leben garantieren können für diejenigen - sie sind heute Morgen schon mit Adolf Muschg zitiert worden -, die wirklich die Schwachen sind, und die wir im Moment eigentlich nur mit einer Strategie der Institutionalisierung weitgehend „wegsperren“, auch aus unserer Wahrnehmung. Das scheint mir ein zentrales Problem zu sein.

Vorsitzender: Vielen Dank, Herr Höfling. Jetzt zu Teil zwei, zu den verfassungsrechtlichen Grenzen für den Umbau der Sozialversicherung. Herr Ebsen.

Ebsen: Ich möchte noch einmal auf etwas zurückkommen, was besonders deutlich in den Thesen von Herrn Sodan angesprochen wurde, aber natürlich auch anknüpft an die vorherige Debatte zum Spannungsfeld von Eigenvorsorge und Fürsorge, nämlich auf die Frage nach den verfassungsrechtlichen Grenzen für den Umfang von Sozialversicherung. Das betrifft sowohl den Gegenstand, also die abzusichernden Risiken, als auch den personellen Umfang. Als Erstes möchte ich mich kritisch mit dem Phantom der Schutzbedürftigkeit als Voraussetzung für Sozialversicherung auseinandersetzen. Wenn Sie unter dem Stichwort „alle in einem Boot“" umverteilende Zwangsversicherungssysteme haben wollen, dann 
ist es nun einmal so, dass in diesem Boot Ruderer benötigt werden. Und deswegen ist es geradezu erforderlich, dass nicht allein die Schutzbedürftigkeit, sondern auch die Leistungsfähigkeit ein Kriterium ist für die Einbeziehung in Sozialversicherungsgemeinschaften. Hierzu hat Herr $R u$ land in der Diskussion auf das Steuersystem als alle Leistungsfähigen einbeziehendes System verwiesen. Jedoch ist das Steuersystem, weil es unmittelbar vom parlamentarischen Gesetzgeber abhängt, entsprechend auch abhängig von kurzfristigen Strömungen und Stimmungen, und insofern spricht viel für eine parafiskalische Finanzierung von sozialer Sicherung, bei der auch Vertrauen in langfristige Verlässlichkeit wichtig ist. Wenn man eine parafiskalische Finanzierung haben will, dann ist allerdings gerade auch der Gleichheitssatz ein Argument dafür, diese personell möglichst umfassend unter Einbeziehung aller Leistungsfähigen $\mathrm{zu}$ gestalten. Denn bei einer parafiskalischen Finanzierung in voller personeller Breite greifen die Gerechtigkeitseinwände gegen soziale Umverteilung innerhalb des jeweiligen Systems nicht durch. Insofern ist also eine unfassende Bürger- bzw. Einwohnerversicherung geradezu die optimale Vollendung von Sozialversicherung.

Nun noch ein Wort zu gegenständlichen Grenzen von Sozialversicherung. Gegenständliche Grenzen können verfassungsrechtlich vor allem hergeleitet werden aus der allgemeinen Handlungsfreiheit (Art. 2 Abs. 1 GG). Der Gesetzgeber muss sich natürlich fragen lassen, für welche Zwecke er welche Personen in Zwangssystemen zusammenschließt. Das ironische Beispiel von Herrn Schnapp im Begleitaufsatz im DVB1. einer Existenzversicherung, die für genügend Essen und Trinken und für gesunde Nahrung sorgt, zeigt, dass es in der Tat inhaltliche Grenzen geben muss. Allerdings müssen wir uns klar machen, dass insoweit die Berufung auf Art. 2 Abs. 1 GG die Verweisung auf etwas Prozedurales ist, nämlich auf die Anwendung des Verhältnismäßigkeitsprinzips durch das Bundesverfassungsgericht, das kaum inhaltliche Vorgaben auf diesem Gebiet hat. Das ist meines Erachtens erträglich, denn es gibt zunehmend einen anderen prozeduralen Aspekt, der politisch wirkt. Es ist oft die Rede vom Kapital, welches flüchtig sei wie ein Reh. Nun kann nicht nur der Kapitalanleger unter den Bedingungen von Globalisierung die „Abstimmung mit den Konten“ machen. Zunehmend können auch Menschen die „Abstimmung mit den Füßen“ machen, und insofern wird die Politik zunehmend die Grenzen der Belastungsbereitschaft der Leistungsfähigen ins Kalkül zu ziehen und gegebenenfalls aus Fehlern zu lernen haben. Dieser prozedurale Mechanismus dürfte vernünftiger sein als irgendwelche gegriffenen inhaltlichen Grenzen für Sozialversicherung. 
Schachtschneider: Herr Vorsitzender, liebe Kolleginnen und Kollegen, zunächst herzlichen Dank für die beachtlichen Referate heute Nachmittag. Ich möchte dennoch ein wenig opponieren. Das Solidarprinzip scheint mir die Lebenslüge der Krankenversicherung zu sein. Das Solidarprinzip ist fraglos Bestandteil des Sozialprinzips und verbindet das Gemeinwesen unter dem Prinzip der Einheitlichkeit der Lebensverhältnisse. Aber eine spezifische Solidarität der 90\% der Bevölkerung, die in die gesetzliche Krankenversicherung gezwungen sind, die oktroyierte Solidarität, scheint mir mehr als fragwürdig zu sein. Die GKV ist kein System der Solidarität, sondern eher eines der gegenseitigen, ja allseitigen Ausnutzung. Die Fiktion der Solidarität scheint notwendig, um die Familienversicherung, insbesondere die beitrags-, also kostenlose Versicherung der Kinder, zu rechtfertigen, die aber nach dem Versicherungsprinzip, das auch die Krankenversicherung bestimmen sollte, nicht zu rechtfertigen ist. Jeder hat ein Krankheitsrisiko und muss das damit verbundene Kostenrisiko tragen. Wenn Familien das nicht leisten können, muss das Gemeinwesen, der Staat, nicht die Versichertenzwangsgemeinschaft für sie einstehen. Das ist in einem freiheitlichen Gemeinwesen sozial. Der Sozialstaat setzt allerdings den Nationalstaat voraus, d.h. eine Volkswirtschaft, welche die Leistungen erbringt, die die sozialen Systeme zu tragen vermag. Wir haben die Grenzen vor allem für die Wirtschaft, zumal für das Kapital, weit, ja allzuweit geöffnet. Das schafft die wirtschaftlichen Schwierigkeiten, die sozialen Systeme zu finanzieren. Bedenken möchte ich auch gegen das Großargument „demographische Entwicklung“ äuBern, deren Konsequenzen gerade eben wieder für die Pflegeversicherung angesprochen wurden. Die Volkswirtschaft muss und kann auch die Kosten für die alten Menschen erwirtschaften. Die Produktivität kann fast grenzenlos gesteigert werden. Es sind die volkswirtschaftlichen Rahmenbedingungen, welche die Produktivität gerade in unserem Lande erheblich behindern. Ich habe heute Vormittag auf die Kapitalverkehrsfreiheit hingewiesen. Dass die Sozialversicherungssysteme nicht mehr mit den Arbeitsverhältnissen verbunden werden können, versteht sich. Aber wir sollten wegen der Alterung der Gesellschaft keine Ängste schüren. Diese lässt sich wirtschaftlich bewältigen, wenn wir die nötigen wirtschaftsverfassungsrechtlichen Bedingungen schaffen, genauer, wieder herstellen.

Eine Bemerkung noch zu dem schönen Referat von Herrn Sodan: Die Kapitaldeckung der Rentenversicherung ist 1957 abgelehnt worden, weil sie das gesamte wirtschaftliche System strukturell vermachten würde. Sie würde die Wirtschaft völlig den Versicherungen überantworten. Für die Wettbewerbswirtschaft wäre die Kapitalmacht der Versicherungen untragbar. Die Gefahr der Vermachtung der Wirtschaft muss man berücksichtigen, wenn man für die Kapitalversicherung streitet. 
Erlauben Sie als Letztes noch ein Plädoyer für das Privatheitsprinzip oder, wie meist gesagt wird, das Subsidiaritätsprinzip. Das Privatheitsprinzip hat auch europarechtlichen Rang, nämlich in den Grundfreiheiten des Binnenmarktes. Vor diesem Privatheitsprinzip lassen sich die deutschen Sozialversicherungssysteme, jedenfalls die gesetzliche Krankenversicherung, ohnehin längerfristig nicht verteidigen.

Vorsitzender: Vielen Dank, Herr Schachtschneider. Ich habe jetzt als Nächstes Frau Iliopoulos-Strangas, dann Herrn Lorz und dann Herrn Zacher. Frau Iliopoulos-Strangas zum Vorrang der Systemkontinuität als Verfassungsfrage.

Iliopoulos-Strangas: Vielen Dank, Herr Vorsitzender. Was das Prinzip der Systemkontinuität angeht, so frage ich mich aus verfassungsrechtsvergleichender Sicht, ob dieses Prinzip uneingeschränkt gelten kann und ob ihm Verfassungsrang zuzuerkennen ist. Zwar sind in einigen europäischen Rechtsordnungen entsprechende Vorstellungen entwickelt worden, die trotz unterschiedlicher methodologischer Ansätze auf ähnliche Ergebnisse hinauslaufen. Erwähnt seien hier nur zwei Beispiele, nämlich einerseits die Rechtsprechung des französischen Conseil d'État zum so genannten „effet cliquet“ („Sperreffekt“), wonach - grob gesagt - ein Rückschritt hinter bereits geltende Grundrechte ausgeschlossen ist, und andererseits die Rechtsprechung des griechischen Staatsrates zum so genannten sozialen Besitzstand, insbesondere im Bereich des Umweltschutzes, die von vergleichbaren Überlegungen getragen ist. Auch wenn in beiden Fällen diese Rechtsprechung, politisch gesehen, zu begrüßen sein mag, sind solche Rechtsvorstellungen doch in ihrer Absolutheit unvereinbar mit dem Demokratieprinzip, das grundsätzlich die Sofortwirkung von Gesetzen verlangt. Deshalb ist einerseits davon auszugehen, dass Erfordernisse der Systemkontinuität und des Vertrauensschutzes dem Demokratieprinzip grundsätzlich keine Schranken zu ziehen vermögen. Andererseits folgt aus der notwendigen Sofortwirkung von Gesetzen nicht, dass Systemkontinuität und Vertrauensschutz völlig unberücksichtigt bleiben müssten. Vielmehr kann und muss ihnen bei Änderungen des geltenden Rechts gegebenenfalls durch Übergangsregelungen Rechnung getragen werden. Dies ist etwa bei Änderungen der Sozialversicherungssysteme von besonderer Bedeutung. Freilich ist in diesem Zusammenhang daran zu erinnern, dass der Vertrauensschutzgedanke nicht in allen Mitgliedstaaten zum Verfassungsprinzip erhoben worden ist. In einigen Mitgliedstaaten wird er als bloßer Rechts- oder Verwaltungsgrundsatz anerkannt. Darüber hinaus und unabhängig davon sollte neu überlegt werden, inwieweit der Vertrauensschutzgedanke oder die Systemkonti- 
nuität letztlich imstande sein sollen, den demokratisch legitimierten und verantwortlichen Gesetzgeber zu „fesseln“, wenn er eine Gesetzesänderung für notwendig hält. Ich stelle das hier nur zur Diskussion.

Vorsitzender: Vielen Dank, Frau Iliopoulos-Strangas. Als Nächstes Herr Lorz, der weitere rechtliche Kriterien wie Systemgerechtigkeit und Systemtransparenz thematisieren möchte.

Lorz: Herr Vorsitzender, meine sehr verehrten Damen und Herren, ich darf in der Tat nahtlos daran anschließen: Wir haben über systemimmanente Begrenzungen der Leistungsfähigkeit oder der Leistungsansprüche in den sozialen Sicherungssystemen gesprochen, wir haben Systemkontinuität und Sachgerechtigkeit von Systemänderungen angesprochen, und ich möchte jetzt fragen, ob wir nicht eine Rechtsfigur wiederbeleben sollten, die in meinen Augen zu Unrecht ein Schattendasein führt, nämlich die Systemgerechtigkeit oder die Gewährleistung der inneren Logik von Systemen. Das hatte vor einigen Jahren Konjunktur und ist dann sehr schnell wieder verabschiedet worden, weil man allgemein gesagt hat, es sei eigentlich nicht fassbar. Das hat mir auch immer eingeleuchtet. Nur muss ich gestehen, Systemkontinuität oder gar Sachgerechtigkeit sind für mich letztlich genauso schwer fassbar oder konkretisierbar. Und wenn ich mir die stetig schlechter werdende Qualität unserer Gesetzgebung anschaue, was nicht an der Fachkompetenz der Ministerialverwaltung liegt, die Hektik, mit der nicht nur, aber auch und gerade im Sozialrecht Gesetze verabschiedet werden, wo die ersten Änderungen schon das Inkrafttreten überholen, die Inkonsistenzen, die viele der beteiligten Entscheider dadurch hineinbringen, dass sie die Systeme in ihrer komplexen Gesamtschau gar nicht mehr überblicken, dann glaube ich, dass wir wirklich ein Gebot der Systemkonsistenz neu etablieren müssen. Das Bundesverfassungsgericht hat das einmal in einem ganz anderen Kontext angedeutet, als es vor einigen Jahren das Gebot der Widerspruchsfreiheit der Rechtsordnung postuliert hat. Dabei handelt es sich eigentlich um eine bare Selbstverständlichkeit: dass nämlich die Bürger in der Lage sein müssen, zu erkennen, was der Staat rechtlich von ihnen fordert. Aber es scheint heutzutage nötig zu sein, das auszusprechen. Und damit bin ich bei dem anderen Punkt, den ich ansprechen wollte, nämlich der Systemtransparenz. Die Frage, die sich daraus für uns als Juristen ergibt, ist die: Müssen wir nicht auch solche rechtlichen Maßstäbe wie Systemgerechtigkeit und Systemtransparenz etablieren, einfach um die innere Logik und die Durchschaubarkeit der Systeme zu erhalten oder wiederherzustellen? Das muss ja nicht gleich mit dem Verdikt der Verfassungswidrigkeit gekoppelt werden. Aber man könnte zumindest denjenigen, die neue 
Systembrüche oder eine Erhöhung der Komplexität einführen, eine Art Begründungslast auferlegen. Und zu Ende gedacht: Muss nicht der Grundsatz der Systemkontinuität - das hat Frau Iliopoulos-Strangas eben schon angesprochen - auch irgendwann zurücktreten, nämlich dann, wenn die Systembrüche und die Komplexität so überhand nehmen, dass ein offener Systemwechsel ehrlicher, in sich logischer und transparenter wäre? Vielleicht in einem Satz zusammengefasst: Es ist vollkommen klar, dass der Sozialgesetzgeber bei der Ausgestaltung der sozialen Sicherungssysteme einen weiten Spielraum haben muss und dass es sehr schwierig sein wird, hier materielle Grenzen zu ziehen. Aber müssen wir nicht vom Juristischen her wenigstens darauf achten, dass er dabei in sich konsequent und nachvollziehbar bleibt?

Vorsitzender: Vielen Dank, Herr Lorz. Ich habe jetzt als letzten Punkt zu Abschnitt zwei Herrn Zacher, und dann kommen Herr Häberle, Herr Hase und Herr Baumeister. Herr Zacher, bitteschön!

Zacher: Zunächst vielen Dank, Herr Huber. Eine Anmerkung möchte ich Herrn Sodan ans Herz legen, ohne dass ich das als Beitrag zu seinem Vortrag werten möchte: Sie haben ja auf die Christlichkeit des Motivs Bismarcks hingewiesen. Ich möchte das nicht in Frage stellen. Aber das hat doch noch eine feine Nuance. Es gab nämlich damals einen ,innerchristlichen“ Streit. Das katholische Zentrum war gegen die Bismarcksche Sozialpolitik und -gesetzgebung, weil es eine christliche Pflicht sei, den Armen zu helfen. Wenn jetzt die Sozialversicherung käme, wie erfüllte man dann die christliche Pflicht?

Und nun zu den Vorträgen. Zu Herrn Pitschas: meine volle Zustimmung zu Ihrem Referat. Ganz besonders meine Zustimmung zu dem, was Sie zur aktuell anstehenden Revision des normativen Konzepts und der Wirklichkeit des deutschen Sozialstaats gesagt haben. Wenn ich Sie akustisch richtig verstanden habe, haben Sie von repetitiver Revision gesprochen. Was Sie dabei zur Sache gesagt haben, ist eine ganz zentrale Erkenntnis. Ich habe das an mir selbst auf eine ganz einzigartige Weise erlebt, als ich die neue Auflage vom „Sozialen Staatsziel“ für das Handbuch des Staatsrechts geschrieben habe. Ich musste sehen, dass jedenfalls ich es nicht fertig bringe, das in einem methodischen Zug zu beschreiben: was sich in der geschichtlichen und Aufbauphase an Inhalt des Sozialstaatsprinzips angelandet hat und jetzt sicher in Harmonie damit ist; und das, was jetzt notwendig ist, um den Sozialstaat weiterführen zu können unter den Erkenntnissen, die wir jetzt haben. Das ist eine sehr wichtige Einsicht: dass die Verwirklichung des Sozialstaatsprinzips immer wieder einer Revision bedarf; und dass das Sozialstaatsprinzip dafür ebenso of- 
fen sein muss, wie es neu interpretiert werden muss, um auch unter den neuen Umständen wegleitend sein zu können. Wo ich eher Bedenken habe, das ist der „Vorrang der Systemkontinuität“. Ich glaube, das haben Sie besser formuliert, als Sie gesagt haben, dass es ein Abwägungsgerüst gibt. Da würde ich den Sozialstaat besser aufgehoben sehen. Systemkontinuität scheint mir ein zu sehr besitzstandswahrendes Stichwort zu sein.

Damit käme ich, wenn ich noch Zeit hätte, zu Herrn Sodan. Herr Sodan, bei Ihrem Referat habe ich folgende Bedenken: Wie es nicht geht, wissen wir doch immer alle, und Sie haben uns sehr nachhaltig gezeigt, was nicht geht; aber was wir wissen müssen, ist ja doch bei dem Vielen, was der Sozialstaat heute lernen muss, wie es geht. Und diese elementaren Aufgaben, die sind von Ihnen beiden noch nicht dramatisch genug beschrieben worden.

Vorsitzender: Vielen Dank, Herr Zacher. Wir bekommen jetzt etwas Provokatives zu Hartz IV von Herrn Häberle.

Häberle: Verehrte Kolleginnen und Kollegen, ich habe mich präzise zu Hartz IV gemeldet und richte eine doppelte Frage an beide Referenten. Herr Sodan hat in These 29 von Hartz IV gesprochen, und Sie, Herr Pitschas, sind im Text auch auf Hartz IV eingegangen. Meine Frage lautet: Was für ein Menschenbild steckt hinter Hartz IV? Nach dem einstmals Jenenser Hegel findet sich in der öffentlichen Meinung „alles Wahre und Falsche zugleich“. Dies gilt meines Erachtens auch für Hartz IV. Das Positive daran sind die gemeinnützigen Ein-Euro-Jobs, weil dort das Gemeinwohl mit Freiheit und Eigenverantwortung, mit sozialer Sicherheit und Gerechtigkeit und mit Arbeit verknüpft ist. Vielleicht sehe ich all dies ein wenig zu idealistisch, und Sie belehren mich empirisch, wobei auch an die an Art. 6 GG zu messenden harten Kontrollmechanismen zu denken ist. Das besonders Problematische an Hartz IV ist - hier wende ich mich ein wenig gegen Herrn Sodans These 29 -, dass die Arbeitslosenversicherung und die Sozialhilfesicherung in einen Topf zusammengelegt werden. Dagegen habe ich große philosophische, idealistische Bedenken. Die Arbeitslosenversicherung knüpft an (geleistete) Arbeit an; damit haben wir und denken wir den großen, schon klassischen Zusammenhang von John Locke über Günter Dürig bis zum Sondervotum von Frau Rupp von Brünneck und schließlich dem Bundesverfassungsgericht in Sachen Eigentum, Arbeit, Schutz öffentlich-rechtlicher Positionen. Dies war der große Gedanke der sozialen Sicherung der Arbeitnehmer. Demgegenüber knüpft die Sozialhilfe geistig an anderes an: an Art. 1 (Menschenwürde) und Art. 20 (Demokratie und Sozialstaat). Ich bezweifle, dass der parlamentarische Gesetzgeber, dem wir in der Tat viel Gestaltungsspiel- 
raum lassen sollten, gut beraten war, diese zwei philosophisch und verfassungsjuristisch ganz unterschiedlichen Tatbestände in ein und dasselbe Gesetz zusammenfassen - das merkwürdigerweise immer noch Hartz IV heißt, obwohl es mit Hartz ja gar nichts mehr zu tun hat, weder mit I, II, III noch mit IV. Vielen Dank.

Vorsitzender: Vielen Dank, Herr Häberle. Ich habe als Nächstes Herrn Hase, der zur sozialen Sicherheit durch Umlagefinanzierung und Steuerfinanzierung des sozialen Ausgleichs sprechen wird.

Hase: Ich möchte zwei kurze Bemerkungen zu dem Referat von Herrn Sodan vortragen, die erste zum Leitsatz Nr. 19. Dort wird ausgeführt, ein auf dem Umlagefinanzierungsverfahren beruhendes Sozialleistungssystem könne letztlich keine Sicherheit gewährleisten, daraus werden dann Folgerungen für die Gestaltungsfreiheit der Gesetzgebung abgeleitet. Träfe diese Aussage zu, so hätte die Sozialversicherung im Grunde keinerlei Existenzberechtigung. Die Versicherungs- und Beitragspflichten, auf denen die soziale Vorsorge beruht, wären verfassungsrechtlich überhaupt nicht zu legitimieren. Tatsächlich ist es aber die einzige Aufgabe der Sozialversicherung, für die Versicherten und deren Angehörige Sicherheit zu erzeugen, aber eben eine privatrechtstranszendente Sicherheit: eine Absicherung, auf die der Einzelne angewiesen ist, die er aber mit seinen Mitteln im Rahmen des Privatrechts nicht erreichen kann. Man kann diese Privatrechtstranszendenz als Vorteil, man kann sie aber auch als Nachteil betrachten, sie ist, gleichsam ihrer Natur nach, ambivalent. Einerseits hat die Sozialversicherung, das zeigen gerade die Erfahrungen Deutschlands im vergangenen Jahrhundert mit seinen großen Umbrüchen und Katastrophen, für breite Bevölkerungskreise eine Sicherheit erschlossen, die auf privatwirtschaftlichen Grundlagen nicht $\mathrm{zu}$ erreichen gewesen wäre. Insoweit hat die soziale Sicherung, wenn Sie so wollen, überlegene Sicherungsqualitäten unter Beweis gestellt. Andererseits fehlen ihr natürlich alle Mittel, mit denen die Privatversicherung Sicherheit erzeugt. Es gibt keinen Vertrag, der für das einzelne Versicherungsverhältnis ein für alle Mal die Bedingungen und insbesondere die nach dem Eintritt des Versicherungsfalls zu erbringenden Leistungen fixiert, es fehlt die Kapitaldeckung, und so weiter und so fort. Insoweit ist, wenn Sie so wollen, im direkten Vergleich ein Minus an Sicherheit gegeben. Aber all dies bedeutet ja nur, dass die Sozialversicherung aus ganz anderen Quellen als die Privatversicherung schöpft, eine ganz andere Aufgabenstellung als diese hat, dass sie eine eigenständige Schöpfung des öffentlichen Rechts ist, die mit ihren spezifischen Möglichkeiten Sicherheit vermitteln soll und dazu jedenfalls im Grundsatz auch durchaus im Stande ist. Das 
zentrale Problem liegt meines Erachtens darin - und da bin ich wieder bei der Diskussion, die wir heute Morgen geführt haben -, dass diese Sicherheit, die als ein knappes Gut gesehen werden muss, im Zuge der sozialstaatlichen Expansion der Nachkriegszeit auf Belange ausgedehnt worden ist, denen der Einzelne ebenso gut oder sogar besser mit seinen Mitteln gerecht werden kann.

Meine zweite Bemerkung bezieht sich auf die Leitsätze 13, 14 und 25. Dort wird ein neues, einheitliches System sozialer Sicherung umrissen, das aus drei Elementen bestehen soll. Erstens wird der Kreis der Versicherten auf die Schutzbedürftigen beschränkt, womit ich im Grundsatz vollständig einverstanden bin. Zweitens sollen die Versicherungsprämien einkommensunabhängig erhoben werden. Und drittens soll der soziale Ausgleich über die Steuern zu finanzieren sein. Ein solcher Ansatz ist meines Erachtens insofern nicht tragfähig, als auf seiner Grundlage eine nicht zu ertragende Spannung zwischen selektiver leistungsrechtlicher Begünstigung auf der einen Seite und universeller Abgabenbelastung auf der anderen Seite entstünde. Bezahlen sollen für den sozialen Ausgleich letztlich alle über die Steuern, die Vorteile des Systems kommen aber nur dem schutzbedürftigen Teil der Bevölkerung zugute! Ein solches System hielte ich nicht für legitimierbar, weil es aus zu heterogenen und letzten Endes inkompatiblen Bauelementen zusammengesetzt ist.

Vorsitzender: Vielen Dank, Herr Hase. Jetzt Herr Baumeister, der mit der These 19 von Herrn Sodan, „Umlagefinanzierung schafft keine Sicherheit", Probleme hat. Bitteschön.

Baumeister: Ich komme, wie Herr Hase, noch mal auf die These 19 zurück, nur eine ganz kurze, kleine Bemerkung. Dort heißt es: Die Gestaltungsfreiheit des Gesetzgebers im Hinblick auf die Änderung von Sozialleistungen wird nicht nur in der Rentenversicherung wesentlich durch das Umlageverfahren beeinflusst. Das heißt mit anderen Worten, so verstehe ich das, dass mit einem Kapitaldeckungssystem eine wesentlich stärkere Begrenzung des Gesetzgebers verbunden wäre. Das ist meines Erachtens nicht ganz einleuchtend, obwohl ich davon ausgehe, dass eine Vielzahl von anderen auch dieser Meinung ist. Bei einem Kapitaldeckungssystem wäre die eigentumsrechtliche Sicherung dieses Anspruchs auf jeden Fall gegeben, aber das wäre meines Erachtens auch bei einem Umlageverfahren so. Auch dort besteht eine eigentumsrechtliche Sicherung dieses Rentenanspruchs. Das hängt damit zusammen, dass der Bürger nicht das Risiko trägt, wie der Staat jetzt mit seinem Geld umgeht, das er ihm nur deshalb abverlangen darf, weil er gleichzeitig einen Anspruch gewährt, ein Versprechen gibt, dass er später für die Altersvorsorge in einem ge- 
wissen Umfang aufkommt. Und aus diesem Grund kann es auch keine Bedeutung, keine eigentumsrechtliche Bedeutung haben, wie der Staat mit dem Geld, das er vom Bürger verlangt, umgeht. Also, ob er etwa das Geld anspart oder sofort ausgibt und eben darauf hofft, dass er zu einem späteren Zeitpunkt wieder ausreichend Geld zur Verfügung hat, um auch diese Ansprüche noch erfüllen zu können.

Vorsitzender: Vielen Dank, Herr Baumeister. Wir haben jetzt zum Schluss Herrn Wieland, der über die Bürgerversicherung und das Verfassungsrecht etwas sagen möchte.

Wieland: Ich habe mich gemeldet, weil Herr Huber zum Abschluss der beiden Referate gesagt hat, beide seien sich doch eigentlich recht ähnlich und nahe beieinander. Den Eindruck teile ich nicht. Ich hatte bei Herrn Pitschas deutlich mehr das Gefühl, dass er zwar gewisse Ansätze in der Verfassung sieht für die Zukunft des sozialen Sicherungssystems, aber doch eine große Offenheit auch für Gestaltung, während Herrn Sodans Referat sich ja dadurch auszeichnet, dass er eigentlich aus der Verfassung gewissermaßen zwingend die Zukunft der Sozialversicherung abgeleitet hat. Vielleicht nicht zwingend, Herr Sodan, ich wollte daran auch Fragen knüpfen. Sie haben gesagt, der Gesetzgeber muss die bipolare Versicherungsverfassung beachten. Jetzt würde ich einfach mal ganz vorsichtig fragen: Wo finde ich diese bipolare Versicherungsverfassung, im Grundgesetz, neben der Finanzverfassung oder der Notstandsverfassung? Ich hatte manchmal etwas den Eindruck, dass für Sie ungeschrieben steht: Wir leben in einem sozialen Rechtsstaat, nach Maßgabe einer dynamischen Bestandsgarantie für private Krankenversicherungen. Das habe ich im Grundgesetz noch nicht gelesen und ich fände es begründungsbedürftig. Also, wenn man eine solche neue Subverfassung entwickelt, denke ich, muss man auch ein bisschen dazu sagen, wo man sie denn eigentlich findet. Wenn man sie nur aus den Grundrechten ableitet, würde ich zumindest zu erwägen geben, ob nicht der Hinweis, den Sie ja auch aufgenommen haben in Ihr Referat, dass in der europäischen Rechtsordnung, die sehr liberal und wettbewerbsorientiert ausgerichtet ist, der EuGH ja im Frühjahr gerade diesen Weg nicht gegangen ist. Das, was Sie in Art. 12 GG zugunsten der privaten Versicherung hineingelesen haben, scheint auf europäischer Ebene, jedenfalls wenn man Luxemburg folgt, so eindeutig nicht zu sein. Spricht das nicht doch dafür, dass wir möglicherweise einen größeren gesetzgeberischen Gestaltungsspielraum haben, als das in Ihrem Referat zum Ausdruck kam? Herr Steiner hat ja heute Morgen schon die Entscheidung zur Einbeziehung der Ehegatten von Landwirten in die Altersversorgung der Landwirte genannt, wo das Verfas- 
sungsgericht das sehr großzügig gerechtfertigt hat. Ich habe das bedauert, weil ich Prozessvertreter war, aber man muss das hinnehmen. Aber ist das nicht doch ein Zeichen dafür, dass auch in Karlsruhe gesehen wird: Hier tauchen Probleme auf, über die muss ein Stück weit abwägend entschieden werden, und die kann man nicht einfach durch Verfassungsvollzug praktisch zu einem richtigen Ergebnis bringen. Und es ist ja schon mehrfach gefragt worden heute: Wenn man Sozialversicherung nur auf die Bedürftigen beschränkt, für mich ist das nicht gut erklärbar, wie soll es sein? Sollen die Kranken sich selber gegenseitig unterstützen, die Arbeitslosen alle zusammengefasst werden? Man braucht doch irgendwo die, die auch ein bisschen leistungsfähiger sind, damit etwas ins System hereinkommt und damit tatsächlich dieser soziale Gedanke verwirklicht werden kann. Und wenn Sie dann einfach sagen, das macht das Steuersystem, da kann ich Ihnen als Steuerrechtler nur sagen: Das Steueraufkommen bricht weg, der abschöpfende Steuerstaat war ein Erzeugnis praktisch geschlossener Staatlichkeit, das hinter uns liegt. Wer heute keine Steuern zahlen will, kann sich dem relativ leicht entziehen, als Unternehmen sowieso, auch als vermögender Privatmensch. Und es scheint mir etwas zu leicht gedacht, zu sagen, die Probleme der Sozialversicherung verlagern wir ins Steuersystem, da werden wir die 20 Milliarden schon finden. Die CSU bezweifelt das am CDU-Modell meines Erachtens nicht ohne Grund. Und eine Kopfsteuer - und das ist ja das, was Ihnen vorschwebt mit dem Kopf-Modell, mit dem pauschalen Modell -, das wäre jedenfalls im Steuerrecht eindeutig verfassungswidrig. Ob es im Sozialrecht verfassungsgeboten ist, wage ich zu bezweifeln.

Vorsitzender: Danke, Herr Wieland. Herr Steiner bitte.

Steiner: Ich will noch ein ganz vorsichtiges Wort zu den verfassungsrechtlichen Fragen sagen. Die beiden Referenten haben der Rechtsprechung des Bundesverfassungsgerichts in Sozialrechtsfragen hohe Referenz erwiesen, und das ist artig und immer seriös. Die Prämisse Ihrer beiden Referate ist allerdings, dass die Rechtsprechung in diesen Fragen so bleibt, wie Sie sie zitiert haben. Das muss nicht so sein. Es gibt, das füge ich gleich hinzu, überhaupt keine Tendenz in irgendeiner Frage, dass der Erste Senat also zu bestimmten Problemkomplexen in Zukunft anders entscheidet als bisher. Aber wir haben eines vor, und das, glaube ich, darf ich sagen: Vor dem Hintergrund offensichtlich sehr weitreichender Umgestaltungen des Sozialsystems bemühen wir uns im Augenblick, nicht einfach Formeln fortzuschreiben, wenn dies im Einzelfall zu verneinen ist. Das gilt zum Beispiel für den Begriff der Sozialversicherung. Sie haben ja heute die Künstlersozialversicherungsentscheidung des BVerfG 
sehr exzessiv zitiert. Es kann sein, dass das nur ein Zwischenruf war, und wir in diesen Fragen möglicherweise noch zu anderen Antworten kommen. Das wollte ich nur noch kurz anmerken.

Vorsitzender: Vielen Dank, Herr Steiner. Herr Meyer, eine kurze Intervention dazu.

Meyer: Ich habe nur zwei Fragen an Herrn Sodan. Herr Sodan, zu Ihrer These 19. Wo haben Sie eigentlich die Sicherheit her, dass ein Rentensystem sicherer ist, wenn Sie es auf das Vermögen statt auf eine Umlage stützen? Es sind im Laufe der Zeit viele Vermögen zu Schanden gegangen. Zweite Frage: Wo ist eigentlich der verfassungsrechtliche Unterschied, wenn Sie die Finanzierung über die Steuer bewerkstelligen oder wenn Sie alle einbeziehen? Ich meine, es gibt gute Gründe, es nicht über die Steuer zu machen. Darauf haben Herr Wieland und auch Herr Ebsen hingewiesen. Wo aber der verfassungsrechtlich relevante Unterschied sein soll, vermag ich nicht zu sehen. Es zahlen immer alle, die zahlen können, bei der Steuer sowohl wie bei der Umlage.

Vorsitzender: Dankeschön. Dann kommen wir zu den Schlussworten in umgekehrter Reihenfolge. Herr Sodan.

Sodan: Vielen Dank. Zunächst einmal darf ich mich bei allen Kollegen bedanken, die mit ihren Diskussionsbeiträgen wichtige Hinweise gegeben haben. Zugleich bitte ich um Verständnis dafür, dass ich mich angesichts der knappen Zeit, die jetzt zur Verfügung steht, auf einige Aspekte beschränken muss und nicht auf alle Beiträge im Einzelnen eingehen kann. Zunächst möchte ich auf die Einwände von Herrn Ruland erwidern. Sie haben in Zweifel gezogen, dass das Bismarcksche Prinzip zutrifft, welches ich mit der Formel beschrieben habe: zunächst Eigenverantwortung, dann erst Solidarität. Für mich ist dieses Prinzip deshalb wichtig, weil wir teilweise beispielsweise im Bereich der gesetzlichen Krankenversicherung - schon geradezu eine Nulltarif-Mentalität der Versicherten beobachten konnten. Das heißt, dass die Mitnahmeeffekte sehr deutlich ausgeprägt sind: Erwartet werden Gegenleistungen für die erbrachten Versicherungsbeiträge. Insoweit scheint es mir wichtig, an Folgendes zu erinnern: Es muss nicht alles abgesichert werden über die so genannte Solidarität; die bereits ergriffenen Maßnahmen zur Stärkung der Eigenbeteiligung halte ich prinzipiell für sinnvoll. Das - man kann es wohl nicht anders nennen - Geschrei, welches die Regelung einer Praxisgebühr in Höhe von zehn Euro ausgelöst hat, konnte ich nie recht nachvollziehen, zumal es hier auch soziale Abfederungen gibt. Was die Beamtenversorgung betrifft, die Sie angesprochen haben, 
Herr Ruland: Selbstverständlich ist es ein großes Problem, dass hier von staatlicher Seite aus offenbar nicht hinreichend Rücklagen gebildet worden sind, möglicherweise gar keine, und dann stets das aktuelle Steueraufkommen herangezogen wird. Wir haben gestern gehört, zu welcher dramatischen Neuverschuldung der Bund wieder greifen muss bzw. die Bundesregierung meint greifen zu sollen. Das betrifft im Übrigen auch den Einwand von Ihnen, Herr Ruland, der sich auf den sozialen Ausgleich über Steuern und die diesbezügliche Finanzierung bezieht. Weil dieses Problem auch in anderen Beiträgen angesprochen wurde, möchte ich jetzt insgesamt darauf antworten. Die Zahlen differieren ganz erheblich. Bert Rürup beispielsweise hat im Juli 2004 von 22,5 Milliarden Euro gesprochen, die ein pauschales Gesundheitsprämiensystem kosten würde; teilweise hört man jetzt von 30, 35 oder 40 Milliarden Euro. Die Kosten dürften also noch nicht hinreichend geklärt sein. Folgender, dem Prämienmodell zugrunde liegender Gedanke ist jedenfalls richtig: Dass man eben über die Steuern die gesamte Gemeinschaft des Volkes und damit auch die Leistungsstärksten heranzieht, ohne diese aber, und insoweit darf ich auf die zweite Frage von Herrn Meyer antworten, in eine Sozialversicherung zu zwingen, sondern ihnen die eigenverantwortliche Absicherung des Krankheitsrisikos überlässt. Wegen dieses fundamentalen verfassungsrechtlichen Unterschiedes ist es wichtig, dass einerseits das Steueraufkommen herangezogen und andererseits eine nur begrenzte Solidargemeinschaft in die Sozialversicherung einbezogen wird.

Auf Herrn Breuers Bemerkungen hinsichtlich des Europarechts und eines europäischen Sozialstaates möchte ich erwidern: Insoweit ist noch viel zu tun. Es existiert eben im Moment eine eher begrenzte Kompetenzlage. Ich denke, dass wir hier durchaus noch etwas Hoffnung in die Rechtsprechung des Europäischen Gerichtshofs setzen sollten. Diese sprach Herr Wieland in seinem Diskussionsbeitrag an; er wies insoweit auf das Urteil des Europäischen Gerichtshofs vom 16. März 2004 hin, welches sich auf die Regelungen der Festbeträge für Arzneimittel bezieht. Hier ist der Redlichkeit halber allerdings hinzuzufügen, dass das Urteil des Europäischen Gerichtshofs insoweit nur das Verhältnis der deutschen gesetzlichen Krankenkassen zu den Leistungserbringern betrifft, allerdings nichts darüber aussagt, wie das Verhältnis der privaten zur gesetzlichen Krankenversicherung zu beurteilen ist. Daran sollte erinnert werden, damit wir hier nicht vorschnell jede Hoffnung auf den Europäischen Gerichtshof aufgeben.

Was die von Herrn Höfling genannte dramatische Situation der sozialen Pflegeversicherung betrifft: Wenn wir 2030 fünf Millionen Pflegebedürftige haben sollten, würde der Druck, durch Steuermittel diese Sozialversicherung am Leben zu erhalten, noch größer werden. Daraus lässt sich 
ein weiteres Argument dafür herleiten, dass wir insgesamt die Gemeinschaft in die Verantwortung nehmen müssen.

Herrn Ebsens Bemerkung zur „Bürgerversicherung als optimaler Vollendung von Sozialversicherung“ kann ich nun überhaupt nicht folgen. Ich meine, dass sein Beitrag - er sprach von einem „Phantom von der Schutzbedürftigkeit“" - an meinem Grundanliegen vorbeigeht: Die Reduzierung des personellen Umfangs der Sozialversicherung kann nicht verkehrt sein, wenn wir sie eben mit einem steuerfinanzierten Prämiensystem kombinieren. Dies habe ich ja als Ergänzung vorgeschlagen, damit sozusagen aus verschiedenen Elementen als Summe etwas Sinnvolles entsteht. Denn gegenüber dem jetzigen Vorschlag, ein Prämiensystem zu installieren, wird vor allem die soziale Schieflage gerügt, die darin gesehen wird, dass im Ausgangspunkt der Höchstverdiener den gleichen Beitrag bezahlen soll wie der Geringverdiener. Dabei handelt es sich um ein Argument, das sicherlich im nächsten Bundestagswahlkampf noch eine wesentliche Rolle spielen wird. Insoweit wären diejenigen, die diese - ja nicht von mir erfundenen - Gesundheitsprämien vorschlagen, gut beraten, wenn sie ihr Modell mit einer Reduzierung des personellen Umfangs der Sozialversicherung flankieren würden, damit klar wird: Eine Sozialversicherung ist für die sozial Schutzbedürftigen gedacht und nicht für Menschen, die auf eine solche Absicherung nicht angewiesen sind und teilweise sogar die Leistungen missbrauchen. In aller Deutlichkeit ist festzustellen: Es gibt teilweise sehr gut verdienende Mitglieder der gesetzlichen Krankenversicherung, insbesondere freiwillig Versicherte mit mehreren Kindern, die sich von ihrer Zugehörigkeit zu dieser Sozialversicherung etwa über die beitragsfreie Mitversicherung von Familienangehörigen Vorteile versprechen. Die Gesundheitsleistungen für diese Menschen müssen aber nicht unbedingt aus der Solidargemeinschaft finanziert werden.

Auf den Hinweis von Herrn Schachtschneider zum Kapitaldeckungsverfahren, das für die gesetzliche Rentenversicherung bis zur Reform von 1957 galt, darf ich erwidern: Nach meiner Erinnerung war vor allem die Entwertung der Geldvermögen durch die beiden Weltkriege ein wesentlicher Grund für die Umstellung auf das Umlageverfahren. Es geht mir im Übrigen nicht darum - das möchte ich auch gegenüber anderen Beiträgen klarstellen -, die Kapitaldeckung als die optimale Lösung zu präsentieren. Selbstverständlich haben die privaten Systeme ebenfalls große Schwierigkeiten, auch als Folge des demographischen Faktors; aber letztlich ist eine Kapitaldeckung der solidere Weg. Nur bezweifele ich, wie ich in meinem Vortrag deutlich zu machen versucht habe, dass wir hier in nächster Zeit zu einer Umstellung werden kommen können, so bedauerlich dies vielleicht auch sein mag. 
Herr Lorz hat vom Gebot der Widerspruchsfreiheit der Rechtsordnung gesprochen. Dem kann ich nur uneingeschränkt zustimmen. Es wäre schön, wenn dieses Postulat des Bundesverfassungsgerichts aus mehreren Entscheidungen des Jahres 1998 wieder stärker in das Bewusstsein des Gesetzgebers käme.

Herrn Zachers Vorhalt, ich hätte vor allem die Probleme geschildert und es an Lösungsvorschlägen fehlen lassen, muss ich widersprechen. Denn ich habe versucht aufzuzeigen - insoweit darf ich nochmals besonders auf mein Resümee in Leitsatz Nr. 25 verweisen -, dass ein künftig einheitliches System sozialer Sicherung durch mehrere, näher bezeichnete Merkmale geprägt sein sollte; in dieser Kombination liegt jedenfalls eine deutliche Alternative zu den bestehenden sozialen Sicherungssystemen.

Herr Häberle stellte die künftige Zusammenführung von Arbeitslosenhilfe und Sozialhilfe infrage und bezweifelte deren Sinn. Ich meine aber nach wie vor, dass es wegen der schon jetzt gegebenen Nähe der Arbeitslosenhilfe zur Sozialhilfe durchaus Sinn macht, den Weg zu gehen, welchen die unter dem Schlagwort „Hartz IV“ diskutierte Reform vorsieht. Allerdings ist nochmals darauf hinzuweisen: Die Arbeitslosenhilfe ist auch nach noch geltendem Recht keine Versicherungsleistung der Arbeitslosenversicherung; daher lassen sich insoweit keine verfassungsrechtlichen Ansprüche herleiten, außer dem Anspruch auf die Sicherung des Existenzminimums.

Trotz der fortgeschrittenen Zeit möchte ich noch auf den Diskussionsbeitrag von Herrn Wieland eingehen, der die so genannte Bürgerversicherung thematisiert und mich gefragt hat, woraus ich die These ableite, dass eine bipolare Versicherungsverfassung zu beachten ist. Dieses Gebot ergibt sich zum einen aus Grundrechtsgewährleistungen. Mit dem Modell einer umfassenden „Bürgerversicherung“ würde der Staat weitestgehend die Existenzgrundlagen der privaten Krankenversicherungsunternehmen vernichten und damit massiv in deren Grundrechte eingreifen. Dies bedürfte nach klassischer liberaler Grundrechtssicht der Rechtfertigung, die ich aber eben nicht sehe. Ein solches Sozialversicherungsmonopol lässt sich auch in Zeiten großer Schwierigkeiten der finanziellen Sicherung der Grundlagen der Sozialversicherung nicht begründen. Ferner ergibt sich die bipolare Versicherungsverfassung aus den verschiedenen, von mir in meinem Vortrag dargelegten Gesetzgebungskompetenzen. $\mathrm{Zu}$ beachten ist überdies europäisches Gemeinschaftsrecht: Ich halte es für sehr zweifelhaft, dass der Europäische Gerichtshof die Verdrängung eines privaten Krankenversicherungsunternehmens aus einem anderen EU-Mitgliedstaat vom deutschen Markt der Krankenversicherung als mit der Dienstleistungsfreiheit vereinbar ansehen würde. 
Zur Frage der künftigen Finanzierbarkeit der sozialen Sicherungssysteme darf ich im Übrigen noch auf folgenden Aspekt aufmerksam machen: Vor einigen Tagen hat der Bund der Steuerzahler wieder seine aktuellen Zahlen präsentiert, wonach etwa 30 Milliarden Euro aus öffentlichen Haushalten jährlich verschwendet werden. Jetzt stellen wir uns einmal den schönen Traum vor, dass diese 30 Milliarden Euro wenigstens zum größten Teil eingespart werden könnten: Dann dürfte für die gesetzliche Krankenversicherung bereits die gesamte Prämienfinanzierung abgesichert sein. Schon deshalb kann ich den Einwand angeblicher Unfinanzierbarkeit nicht teilen. Im Übrigen müssen natürlich insbesondere die Ökonomen für seriöse Zahlen sorgen. Es wäre gewiss auch hilfreich, einmal vom Verband der privaten Krankenversicherung weiterführende Lösungsvorschläge zu hören. Ich habe das schon mehrfach angeregt, bislang leider ohne Erfolg. Woran es liegt, vermag ich nicht zu sagen.

Abschließend bedanke ich mich nochmals sehr herzlich bei allen Kollegen, die zu dieser Diskussion beigetragen haben. Dass wir künftig weiter über die Lösungen der Probleme nachdenken müssen, scheint mir zwangsläufig. Letztlich gelten auch hier die berühmten Worte, die Heraklit zugeschrieben werden: panta rhei, alles fließt. Die tagespolitische Aktualität überschattet im Grunde genommen auch diese Veranstaltung. Ich bin aber um der Sache willen dafür dankbar, dass der Sozialstaat überhaupt wieder zum Thema der Tagung der Vereinigung der Deutschen Staatsrechtslehrer geworden ist.

Pitschas: Liebe Kolleginnen und Kollegen, für die knappe Restzeit der heutigen Diskussion bitte ich sehr herzlich um Ihr Verständnis, wenn ich nicht alle Beiträge namentlich aufrufe, sondern nur einzelne. Der Ausgangspunkt meines Schlusswortes ist die Bemerkung von Herrn Steiner, dass man im zuständigen Senat des Bundesverfassungsgerichts nach neuen Formeln für die verfassungsrechtliche Bewältigung der Modernitätskrise und von Modernisierungsprozessen in der Sozialversicherung sucht. Wenn wir solche neuen Formeln selbst entdecken und kreieren bzw. alte Formeln fortschreiben wollen, dann müssen zunächst die empirischen Grundlagen stimmen. Empirisch gesehen besteht derzeit kein Anlass, den Untergang der Privatversicherung im Gesundheitssystem zu beklagen, sondern ganz im Gegenteil ist die im Fluss befindliche Diskussion gegenwärtig darauf angelegt, so etwas wie eine europäischen Maßstäben und Rechtsentwicklungen entsprechende Konkurrenz von gesetzlichen und privaten Krankenversicherungen zu entwickeln. Dies ist ein sehr komplexer Prozess, bei dem es Irrungen und Wirrungen gibt, und in dem das Bundesverfassungsgericht als Kontrollinstanz selbstverständlich die richtigen Kontrollinstrumente vorhalten muss. Wenn man von dieser ver- 
fassungsrechtlichen Grundsituation einer „offenen“ Modernisierungsfähigkeit gegebener Systeme sowohl der Kranken-, der Renten- und der Pflege- sowie anderer Sozialversicherungen ausgeht, dann muss man in der Analyse der bisherigen Rechtsprechung wohl zu dem Ergebnis kommen, dass die Grundrechte - namentlich Art. 12 und Art. 14 GG - nicht so sehr effektiv sind. Sie mögen in Einzelfällen Schutz gewähren, aber das sind dann individuelle Bedarfserwartungen und Enttäuschungen, die von Verfassungs wegen reguliert bzw. ausgeglichen werden können. Konzeptionell, also im Großen und Ganzen, setzt die Neumodellierung der Sozialversicherung bzw. der Versuch, eine Systemveränderung verfassungsrechtlich kontrollierend zu begleiten, doch mehr voraus. Das war der eigentliche Ansatzpunkt meiner Überlegungen. Die zentrale Frage ist, was müssten wir verfassungsdogmatisch entwickeln? Da bietet sich an, schon bisherige Überlegungen einzuspeisen in einen neuen, verfassungsgrundsätzlich gesicherten konzeptionellen Rahmen.

Ich habe hierfür einerseits das Verfassungsprinzip der sozialen Sicherheit angeboten. Wenn man entsprechende Überlegungen zu entwickeln versucht, kommt die private Investition in soziale Sicherheit in den Blick. Dabei stößt man auf eine der Fragen, die Herr Häberle angeschnitten hat, nämlich die zu dem Menschenbild in „Hartz IV“. Eine eindeutige Antwort hierauf fällt schwer. Ihr Ausgangspunkt ist sicher nicht die Grundverschiedenheit von Arbeitslosenversicherung und Sozialhilfe, weil lange Jahre mit einer gewissen Berechtigung, weil die Arbeitslosenhilfe an das Arbeitslosengeld als Versicherungsleistung angeknüpft hat - verdeckt worden ist, dass Arbeitslosenhilfe steuerfinanziert wurde und insofern zur Sozialhilfe eine gewisse Verwandtschaft aufwies. Man sah das besonders schön am alten BSHG in den $\S \S 18$ und 25, in denen es um zumutbare Arbeit ging, also um die Bewältigung einer Krise, in der jemand arbeitslos geworden ist und Sozialhilfe braucht. Heute stellt sich in der Tat die Frage, wie gestaltet man die Zusammenführung beider Leistungsbereiche für die Zukunft menschenwürdig aus. Richtigerweise hat sich insoweit die Bundesregierung zu Verbesserungen der Rechtslage bereit erklärt. Das hängt damit zusammen, dass private Vorsorgeinvestitionen von Verfassungs wegen geschützt werden. Aber man braucht ein geschärftes verfassungsexegetisches Verständnis, um die zukunftsweisenden Ansätze eines „Förderns und Forderns" verfassungsrechtlich im Sinne der Verhältnismäßigkeit besser ausleuchten zu können.

Das ist der erste Punkt, und der zweite Punkt ist: Wenn man sich auf den angedeuteten Weg eines schonenden Ausgleichs begibt, dann darf es nicht dazu kommen, die Systeme, die man geschaffen hat, oder die Wege, die man gefunden hat, kurzfristig umzustoßen. Selbstverständlich darf man dem parlamentarisch-demokratischen Gesetzgeber keine Ketten an- 
legen, aber wenn man sich für den Weg in die Eigenverantwortung der Vorsorge entscheidet - deswegen war letztlich die Änderung des Hartz IVGesetzes zu deren Schutz richtig -, dann muss man diesen Weg konsequent gehen. Das aber könnte einer der neuen Formelsplitter sein: Kontinuität. Es gilt das Konsistenzgebot. Herr Papier hat an anderer Stelle von einem „Systemwahrungsgebot“ gesprochen. Ich meine, Kontinuität drückt noch besser aus, was ich meine: Wir brauchen eine Verlässlichkeit, die den eingeschlagenen Weg der Modernisierung dann auch beharrlich fortsetzt. Das sind die verfassungsrechtlichen Kosten der Modernisierung, die den Gesetzgeber treffen.

In diesem Zusammenhang bin ich ferner der Ansicht, lieber Herr Gröschner, dass für den Einzelnen ebenso eine Rechtspflicht, und zwar eine Pflicht gegen sich selbst, besteht. Wenn wir Eigenverantwortung für soziale Sicherung einfordern, dann entspricht es dem wohlverstandenen freiheitlichen Sozialstaat, dass diese Freiheitsverantwortung auch konsequent gegen sich selbst wahrgenommen wird. Man muss dann auch das Recht des Einzelnen akzeptieren, um den Preis verminderter Solidarität für sich selbst eben nicht vorzusorgen. Auch das entspricht dann dem Menschenbild im Hartz IV-Gesetz; verminderte Solidarität sieht sich in eine Verpflichtung zu zumutbarer Arbeit ausgemünzt. Zwei Punkte sind dazu aber anzumerken: Ein-Euro-Jobs sind nicht an sich zumutbar, weil es fern der Berufsfreiheit eine „Massenware“ ist, die da angeboten wird. Zweitens führt diese Vorgehensweise zu einer Verdrängung im doppelten Sinne: Einmal gegenüber den örtlichen oder regionalen Handwerkern und sonstigen formalen Arbeitsanbietern, zum anderen folgt daraus, dass die Zahl der nicht produktiven Arbeitsmarktbeschaffungsmaßnahmen steigen wird. Mir macht deshalb in der Tat Sorge, ob man hierbei wirklich noch von „Komfortsicherung“ sprechen kann. Aber ich neige nach mehr als 30-jähriger Beschäftigung - ich komme ja beruflich aus der Sozialhilfe - dazu, zu sagen: Es gibt auch viele Mitnahmeeffekte, Herr Sodan hat das ausgeführt, und solche Effekte, die würde ich schon versuchen auszuschließen. Ein schönes Beispiel ist immer in der Krankenversicherung der Ministerialrat, der seine beschäftigungslose Ehefrau in irgendeiner Form mitversichern lässt. Es gibt tatsächlich so etwas wie das Ausnutzen des Sozialstaats. Hinsichtlich der Altersgrenzen in der sozialen Rentenversicherung - darin, lieber Herr Ruland, stimmen wir überhaupt nicht überein - haben wir einen ersten Schritt zur Neuregulierung gemacht, aber mehrere weitere Schritte liegen noch vor uns. Wir sollten bei ihnen nicht darauf warten, dass die nächsten Jahre ins Land gehen. Gegen die Lösung, den sozialen Ausgleich in Steuern zu verlegen, habe ich nur einen oder zwei Sätze in meinem Vortrag gesagt. Aber die Diskussion hierum ist bekannt: Nehmen wir etwas aus der Beitragsfinanzierung he- 
raus, dann müssen wir uns dem steuerstaatlich-parlamentarischen System bei der Steuerfinanzierung und Mittelzuweisung stellen; wir zerreißen dadurch das System. Im Übrigen müssen wir darauf achten, dass wir die Beitrags-Leistungs-Beziehung aufrechterhalten. Denn wenn alles in das Steuersystem abdriftet, beachtet keiner mehr diese Beziehung, und damit gehen die individuellen Verantwortlichkeiten verloren.

Ich will zum Schluss einen vierten Punkt anschneiden, lieber Herr Höfling, der mich sehr bewegt. Das Grundgesetz gibt auf, die Familie zu schützen. In der Pflegeversicherung hat dies gleichwohl dazu geführt, die Pflegeverhältnisse zu „ökonomisieren“; jetzt kriegen wir die Quittung dafür. Ich weiß auch keinen Ausweg, Herr Höfling, aus dieser Situation, die mir wie Ihnen bekannt ist. Aber eines ist gewiss: Über ausschließlich privatwirtschaftliche Finanzierung im Wege der Kapitaldeckung werden wir es nicht schaffen. Dann haben wir nämlich genau das, was wir nicht erreichen wollen, nämlich das Abschieben vieler einkommensarmer Älterer und Pflegebedürftiger in Heimeinrichtungen. Das wollen wir vermeiden. Also müssen wir eine solidarische Lösung, umlagefinanziert und kombiniert mit einem partiellen Anwartschaftsdeckungsverfahren, erreichen. Daran müssen wir arbeiten.

Meine Damen und Herren, ich bedanke mich für Ihre sehr liebenswürdige Kritik. Die Suche nach der Zukunft der sozialen Sicherungssysteme ist ein Prozess, der im Flusse ist. Wir werden hierfür Lösungen entwickeln und das Bundesverfassungsgericht wird uns wie bisher dabei helfen.

Vorsitzender: Verehrte Kolleginnen und Kollegen, wir sind am Ende unserer heutigen Beratungen. Ich darf den beiden Referenten des Nachmittags noch mal sehr herzlich für ihre Referate danken. Sie haben in vielfältiger Weise zur Diskussion und zum Nachdenken angeregt. 